NATIONAL LABORATORY

\title{
An Experimental and Analytical Evaluation of Wall and Window Retrofit Configurations: Supporting the Residential Retrofit Best Practices Guide
}

\section{December 2006}

\author{
Prepared by \\ Therese Stovall \\ Thomas Petrie \\ Jan Kosny \\ Phillip Childs \\ Jerald Atchley
} Kimberly Hulvey Sissom

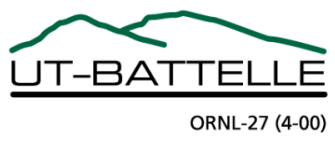




\section{DOCUMENT AVAILABILITY}

Reports produced after January 1, 1996, are generally available free via the U.S. Department of Energy (DOE) Information Bridge.

Web site http://www.osti.gov/bridge

Reports are available to DOE employees, DOE contractors, Energy Technology Data Exchange (ETDE) representatives, and International Nuclear Information System (INIS) representatives from the following source.

Office of Scientific and Technical Information

P.O. Box 62

Oak Ridge, TN 37831

Telephone 865-576-8401

Fax 865-576-5728

E-mail reports@osti.gov

Web site http://www.osti.gov/contact.html

This report was prepared as an account of work sponsored by an agency of the United States Government. Neither the United States Government nor any agency thereof, nor any of their employees, makes any warranty, express or implied, or assumes any legal liability or responsibility for the accuracy, completeness, or usefulness of any information, apparatus, product, or process disclosed, or represents that its use would not infringe privately owned rights. Reference herein to any specific commercial product, process, or service by trade name, trademark, manufacturer, or otherwise, does not necessarily constitute or imply its endorsement, recommendation, or favoring by the United States Government or any agency thereof. The views and opinions of authors expressed herein do not necessarily state or reflect those of the United States Government or any agency thereof. 
ORNL/TM-2007/006

Engineering Science and Technology Division

\title{
AN EXPERIMENTAL AND ANALYTICAL EVALUATION OF WALL AND WINDOW RETROFIT CONFIGURATIONS: SUPPORTING THE RESIDENTIAL RETROFIT BEST PRACTICES GUIDE
}

\author{
Therese Stovall \\ Thomas Petrie \\ Jan Kosny \\ Phillip Childs \\ Jerald Atchley \\ Kimberly Hulvey Sissom
}

Date Published: December, 2006

Prepared by

OAK RIDGE NATIONAL LABORATORY

Oak Ridge, Tennessee 37831-6283

managed by

UT-BATTELLE, LLC

for the

U.S. DEPARTMENT OF ENERGY

under contract DE-AC05-00OR22725 


\begin{abstract}
A Retrofit Best Practices Guide was developed to encourage homeowners to consider energy conservation issues whenever they modify their siding or windows. In support of this guide, an experimental program was implemented to measure the performance of a number of possible wall siding and window retrofit configurations. Both thermal and air-leakage measurements were made for a $2.4 \times 2.4 \mathrm{~m}(8 \times 8 \mathrm{ft})$ wall section with and without a $0.9 \times 1.2 \mathrm{~m}(3 \times 4 \mathrm{ft})$ window. A computer model was also used to provide information for the Best Practices Guide. The experimental data for walls and windows were used in conjunction with this model to estimate the total annual energy savings for several typical houses in a number of different locations
\end{abstract}


Contents

LIST OF FIGURES N VII

LIST OF TABLES

1. INTRODUCTION

2. LITERATURE REVIEW 2

3. THERMAL PERFORMANCE TESTS IN THE ROTATABLE GUARDED HOT BOX (RGHB) $\quad 2$

$\begin{array}{ll}\text { 3.1 Test Apparatus } & 2\end{array}$

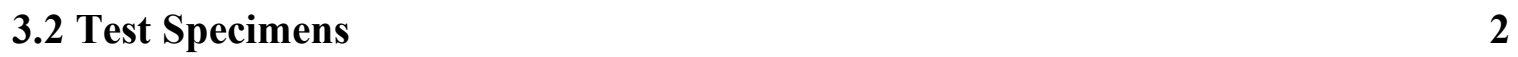

$\begin{array}{ll}3.3 \text { Results } & 7\end{array}$

4. AIR LEAKAGE TESTS $\quad 13$

$\begin{array}{ll}\text { 4.1 Test Apparatus and Procedures } & 13\end{array}$

4.2 Uncertainty Analysis For The Modified Apparatus 15

$\begin{array}{ll}4.3 \text { Specimen Configurations } & 18\end{array}$

4.4 Air Leakage Test Results $\quad 18$

5. WORKSHOP 24

$\begin{array}{ll}5.1 \text { Workshop Objective } & 24\end{array}$

$\begin{array}{ll}5.2 \text { General Discussion } & 25\end{array}$

$\begin{array}{ll}5.3 \text { Construction Practices } & 25\end{array}$

5.4 Recommendations for Presentation Approaches in the Best Practices Guide 26

5.5 Advice for Future Research

Real world issues $\quad 26$

$\begin{array}{ll}\text { Laboratory measurements and analysis } & 27\end{array}$

6. MODELING: WALL AND WINDOW RETROFITS 28 
7. SUMMARY

REFERENCES

APPENDIX A LITERATURE RESOURCES

APPENDIX B: DETAILED MODEL RESULTS

APPENDIX C: RETROFIT BEST PRACTICES GUIDE 


\section{List of Figures}

Figure 1. Home improvement expenditures (Source: Joint Center for Housing Studies of Harvard University)...............................................................................................

Figure 2. General configuration when new siding is applied on top of existing wooden siding. ...3

Figure 3. Wall framed to accept window, mounted in RGHB test frame....................................

Figure 4. Wall frame after insulation placed in cavity and RGHB guard insulation added ...........4

Figure 5. Thermocouple locations for the wall with a window................................................

Figure 6. Photographs showing thermocouple placement on clear wall front and back and on

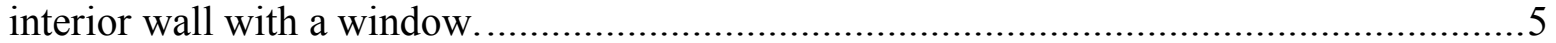

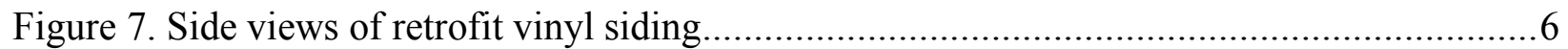

Figure 8. Corner details for the flanged vinyl replacement window ........................................6

Figure 9. Insulation R-values compared to wall air to air R-values ...........................................10

Figure 10. Heat flow measured through wall sections in the RGHB .........................................11

Figure 12. Panel to Adapt Blower Door Fan to Enclosure over Retrofit Base Wall ..................... 14

Figure 13. Example of the scatter about the average of 200 measurements at each building pressure that are made by the Automatic Performance Testing System (y-axis units of $\mathrm{cfm}$ )

Figure 14. Raw test data for three replicate low leakage rate tests...........................................17

Figure 15. Equivalent Leakage Area for open and fiberglass-stuffed window/wall joints for

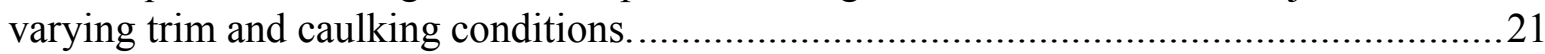

Figure 16. Equivalent Leakage Area for a number of window/wall joint sealing products. ........22

Figure 17. Air leakage flow at a pressure difference of $50 \mathrm{~Pa}$ for a number of window/wall joint

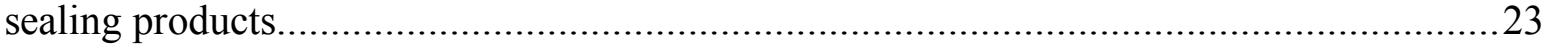

Figure 18. Locations and house designs used for savings estimates .......................................28 


\section{List of Tables}

Table 1. Experimental clear wall configurations.

Table 2. Thermal test results for insulation specimens used in retrofit wall (using ASTM C518).7

Table 3. Thermal test results for retrofit wall and window configurations.................................. 8

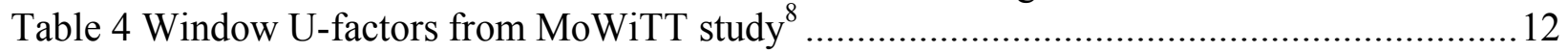

Table 5. Calculation of uncertainties for three data sets (nomenclature as shown in Eqs. 7, 8, and

9) 17

Table 6. Air leakage results for the gap between the window frame and the rough wall opening.

Table 7. Workshop participants.

Table 8. Equation 9 parameters for heating and cooling energy consumption ...........................22

Table 9. Total house heating and cooling load savings (\%) due to wall retrofits for three

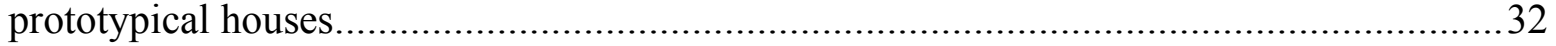

Table 11. Gas and electricity prices used to calculate annual savings......................................34

Table 11. Range of annual energy cost savings for multiple house types and wall retrofit options ……

Table 13. Total house heating and cooling loads with differences in the window/wall gap treatment for three different prototypical houses............................................................. 38 


\section{Introduction}

Approximately $\$ 260$ billion was spent on residential remodeling in $2000-01$, and almost $\$ 30$ billion of that amount was spent on retrofitting siding, windows and doors, and insulation, as shown in Figure 1. ${ }^{1}$ Although these retrofits are typically done for aesthetic or maintenance reasons, they also offer the opportunity to improve the efficiency of the home. The Retrofit Best Practices Guide was produced with the goal of gathering useful retrofit information into a single resource for consumers. ${ }^{2}$ This may prove especially useful for homeowners who wish to take advantage of the retrofit energy tax credit. ${ }^{3}$ Consumers may also be more interested in conserving energy because of recent energy price increases and uncertain future prices.

Much information was already available for energy-saving retrofits to attics, windows, and foundations. But estimating energy savings for wall retrofits has typically been more complex. New products for walls and windows have also entered the market in the last few years. To address these factors, an experimental program was implemented, covering wall siding retrofit methods, air leakage between windows and walls, and the combined effect of a window/wall retrofit. Complementing these experimental results, another experimental program at Lawrence Berkeley National Laboratory (LBNL) has produced real-world performance data for a number of window retrofit options. ${ }^{4}$

A computer model was also used to provide information for the Best Practices Guide. The experimental data for walls and windows were used in conjunction with this model to estimate the total annual energy savings for several typical houses in a number of different locations.

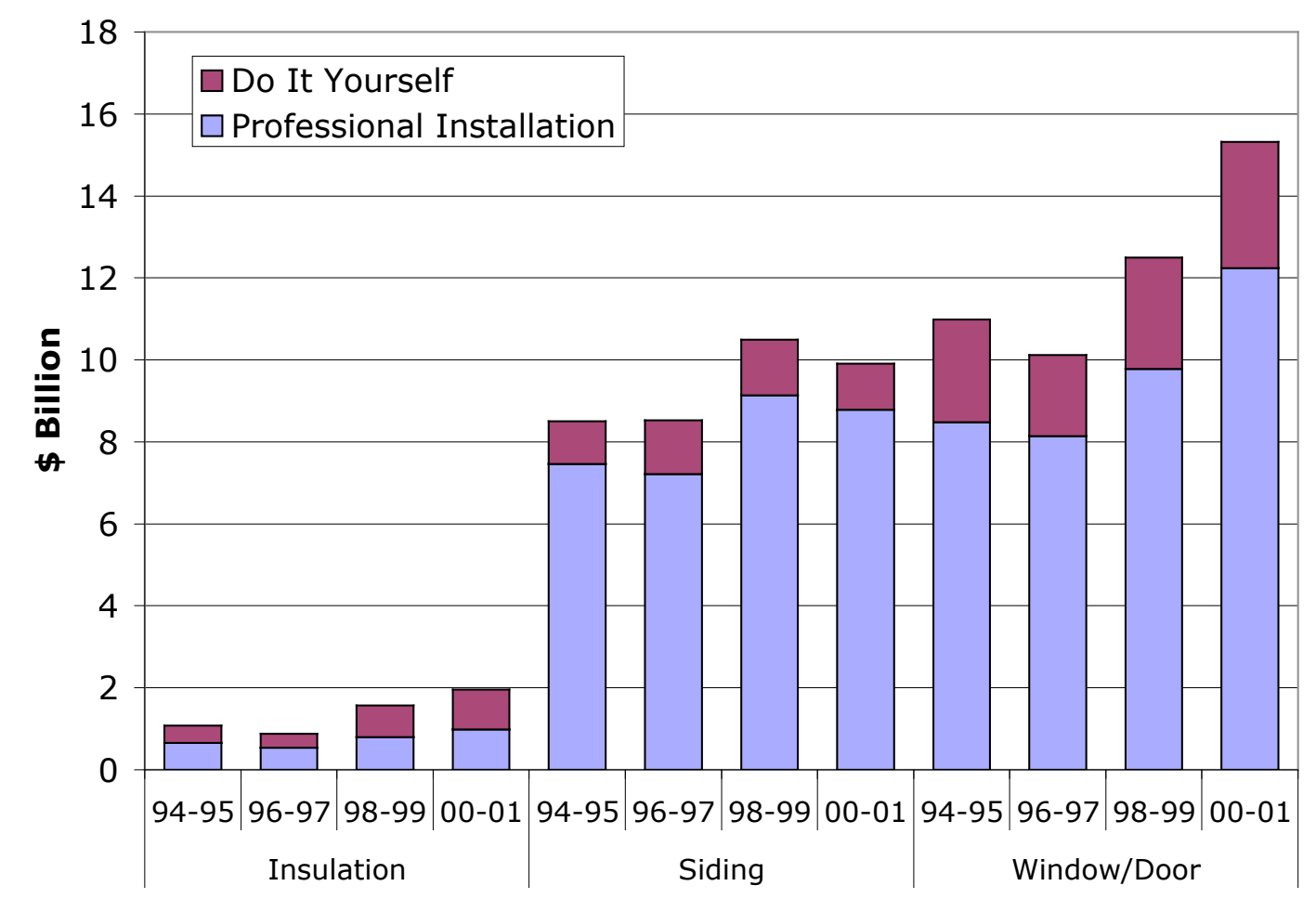

Figure 1. Home improvement expenditures (Source: Joint Center for Housing Studies of Harvard University) 


\section{Literature Review}

A host of resources are available for homeowners faced with a remodeling project. Some of these sources provide excellent advice, others are dated, and some are designed to promote a particular product. The resources listed in Appendix A were all reviewed in the preparation of the Retrofit Best Practices Guide. Many of these on-line materials have been provided as links within that guide.

\section{Thermal Performance Tests in the Rotatable Guarded Hot Box (RGHB)}

Standard guidance is available to calculate the thermal resistance of a wood- or metal-framed wall. ${ }^{5}$ However, previous work has shown that these calculations are approximate at best when used for more complex wall structures. ${ }^{6}$ Given the complexities introduced by a typical siding retrofit, where the new materials are laid upon the old as shown in Figure 2, experimental measurements offer a better indication of the heat transfer changes due to such a retrofit.

\subsection{Test Apparatus}

The wall thermal measurements were made using a guarded hot box constructed and operated according to ASTM C 1363, Standard Test Method for the Thermal Performance of Building Assemblies by Means of a Hot Box. ${ }^{7}$ The metered section was 2.4 x $2.4 \mathrm{~m}(8 \mathrm{x} 8 \mathrm{ft})$. The precision of this test method is reported to be approximately $\pm 8 \%{ }^{7}$ All test results reported here have been corrected for guard energy losses, which ranged from $2.4 \%$ of the total measured heat flow for the best insulated clear wall test to $0.7 \%$ for the least insulated window/wall test.

Each test ran from five to 11 days, as required to reach steady state conditions, and the data results included in this report are average values taken over a time period ranging from 30 to 100 hours of steady-state operation. All tests were run with a mean climate-side temperature of 10C $\left(50^{\circ} \mathrm{F}\right)$ and a mean meter-side temperature of $38 \mathrm{C}\left(100^{\circ} \mathrm{F}\right)$.

\subsection{Test Specimens}

The test specimens were constructed to represent typical building practices, with $4 \times 9 \mathrm{~cm}$ (nominal $2 \times 4$ in.) framing members placed on $40 \mathrm{~cm}$ (16 in.) centers, $1.3 \mathrm{~cm}$ (1/2 in.) gypsum wallboard screwed and taped on the metering side of the wall, and the cavity space between studs filled carefully with R-11 fiberglass batts. The wall's exterior sheathing was constructed of $1.3 \mathrm{~cm}(1 / 2$ in.) plywood rather than the more common particleboard because this surface was subject to repeated fastenings as the siding was modified between tests. With this typical construction, $85.8 \%$ of the area is covered by insulated wall cavities, $10.5 \%$ by vertical studs, and $3.7 \%$ by horizontal framing.

For the tests that included a window, the $0.9 \times 1.2 \mathrm{~m}(3 \times 4 \mathrm{ft})$ window was placed $86 \mathrm{~cm}(34 \mathrm{in}$. from the bottom of the wall and along a stud $88 \mathrm{~cm}$ (35 in.) from one side wall. The window header was made of a sandwich of two 4 × $30 \mathrm{~cm}$ (nominal 2 x 12 in.) framing members with 1.3 $\mathrm{cm}(0.5$ in.) plywood between them. The support below the window consisted of additional $4 \times 9$ $\mathrm{cm}$ (nominal 2x4 in.) framing members arranged as shown in Figure 3, which shows the wall frame installed in the RGHB test frame. Figure 4 shows this same wall after the cavity insulation and RGHB guard insulation have been added. 


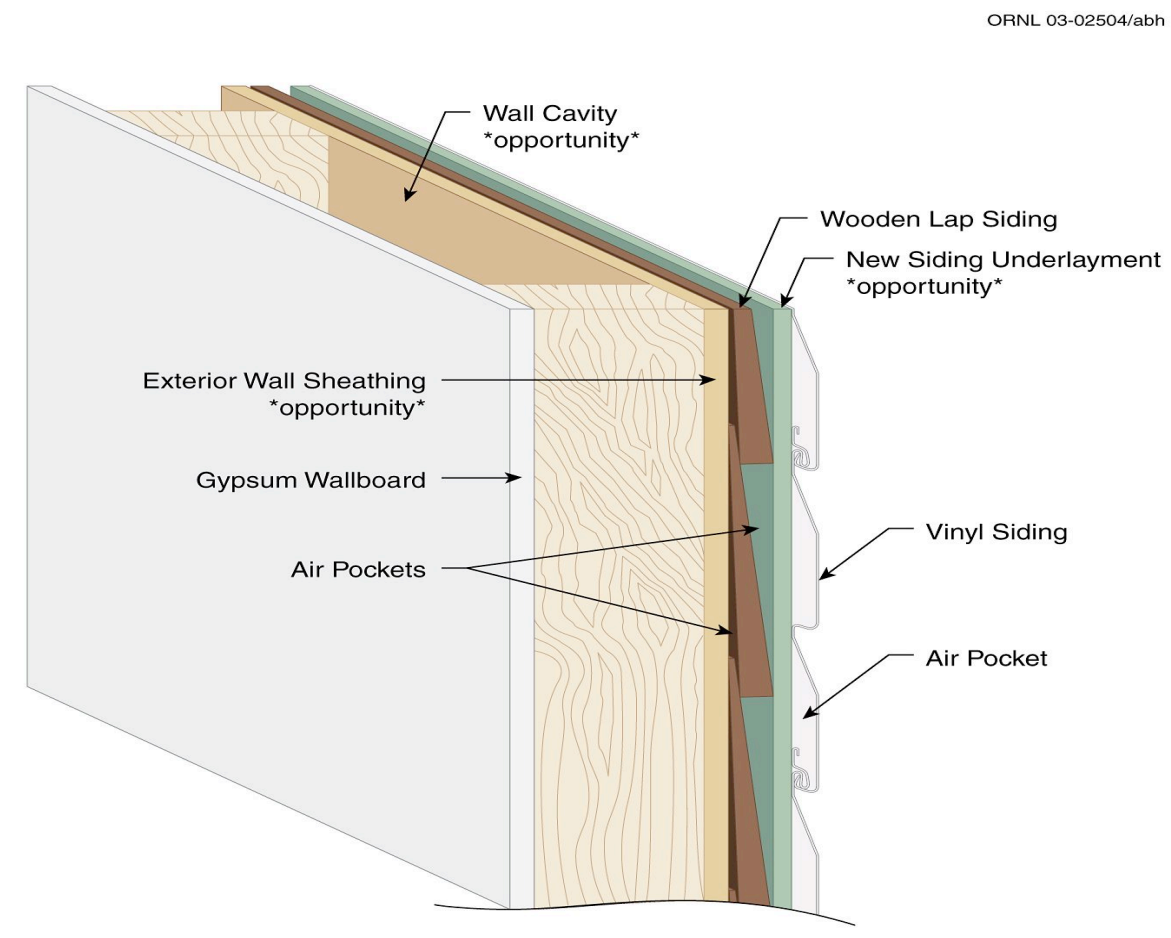

Figure 2. General configuration when new siding is applied on top of existing wooden siding.

Thermocouple positions on the clear wall were maintained in the same location for each successive test configuration. The thermocouple positions were adjusted to provide more information around the window area for the window/wall combinations; see Figure 5 and Figure 6.

Specimens, $60 \times 60 \mathrm{~cm}(24 \times 24$ in.), taken from the insulation materials used in these tests were characterized independently using a heat flux meter apparatus in accordance with ASTM C518. These tests were conducted at a mean temperature of $24 \mathrm{C}\left(75^{\circ} \mathrm{F}\right)$ with a $22 \mathrm{C}\left(40^{\circ} \mathrm{F}\right)$ temperature difference.

Six clear wall configurations were tested, as shown in Table 1. All of these configurations were based on the same gypsum, frame, cavity insulation, and exterior plywood sheathing layers. The left drawing in Figure 7 is representative of modifications 1-4 and the right drawing shows modification 5 (referred to throughout the rest of this report as Mods 1-5).

The windows used for this experimental program were previously tested at the Mobile Window Thermal Test Facility (MoWiTT) and are described fully by Klems and Kelly. ${ }^{8}$ These earlier tests provided an excellent characterization of the windows' seasonal performance. A flanged double-paned vinyl replacement window was tested with all six of the wall configurations listed in Table 1. A close-up look at the corner details on this window frame are shown In Figure 8. An unflanged (or insert) wood-framed, single paned window was tested in the Base Case wall, the Mod 2 wall, and the Mod 5 wall. This same single paned window was re-tested in these same three configurations after the addition of an exterior low-e storm window. 


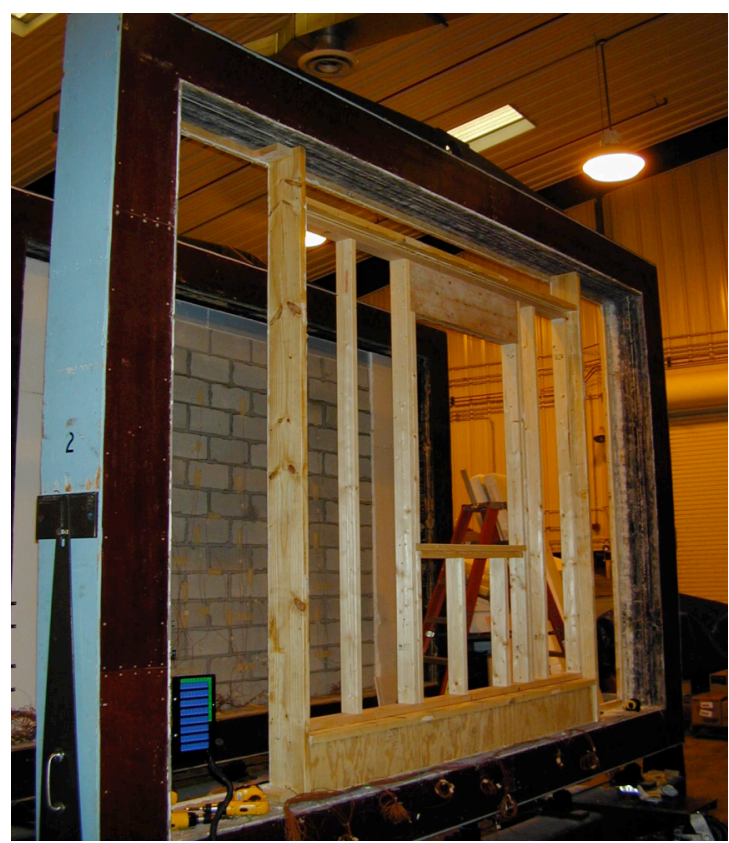

Figure 3. Wall framed to accept window, mounted in RGHB test frame

Retrofit Base Test Wall Meter Side
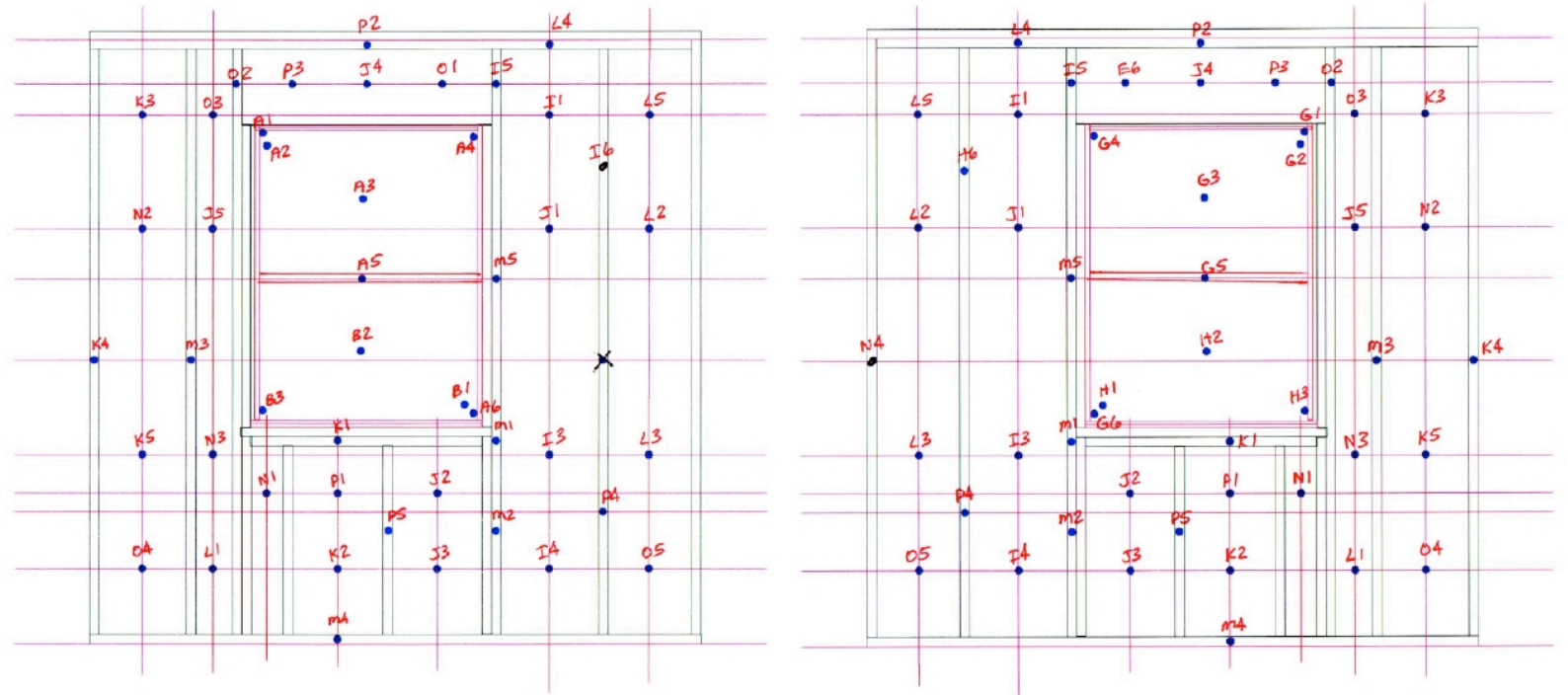

\section{East East}

Figure 5. Thermocouple locations for the wall with a window 


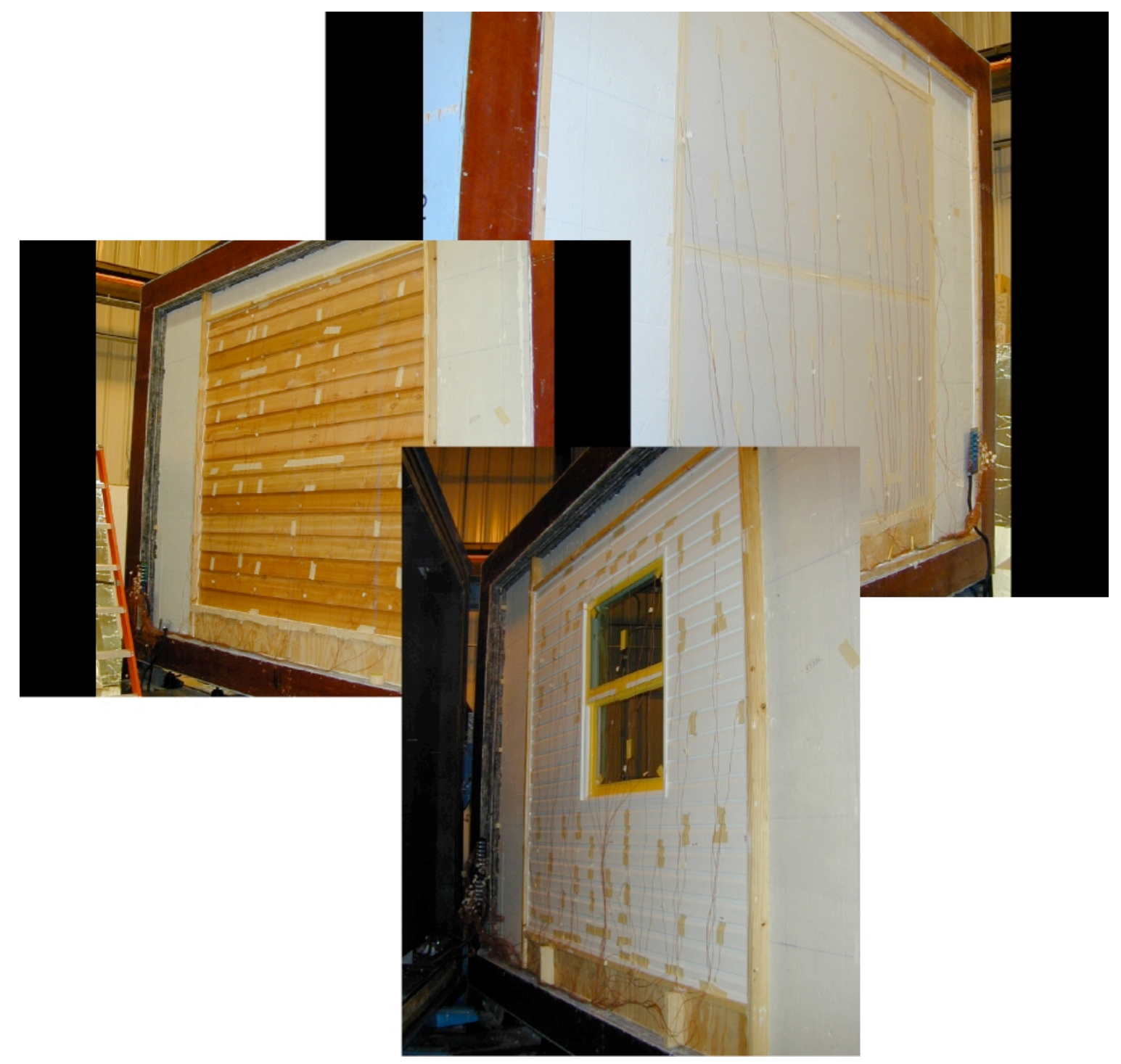

Figure 6. Photographs showing thermocouple placement on clear wall front and back and on interior wall with a window.

\begin{tabular}{|ll|}
\hline Table 1. Experimental clear wall configurations \\
\hline Base Case & Cedar lap siding \\
\hline Mod 1 & Cedar lap siding, 3/8 in. fan-fold extruded polystyrene (XPS), vinyl siding \\
\hline Mod 2 & Cedar lap siding, 3/8in. foil-faced fan-fold XPS, vinyl siding \\
\hline Mod 3 & Cedar lap siding, 1/2in. unfaced XPS sheet, vinyl siding \\
\hline Mod 4 & Cedar lap siding, two layers of 1/2in. foil-faced polyisocyanurate, vinyl siding \\
\hline Mod 5 & $\begin{array}{l}\text { Cedar lap siding, expanded polystyrene (EPS) contoured foam-backed vinyl } \\
\text { siding. }\end{array}$ \\
\hline
\end{tabular}



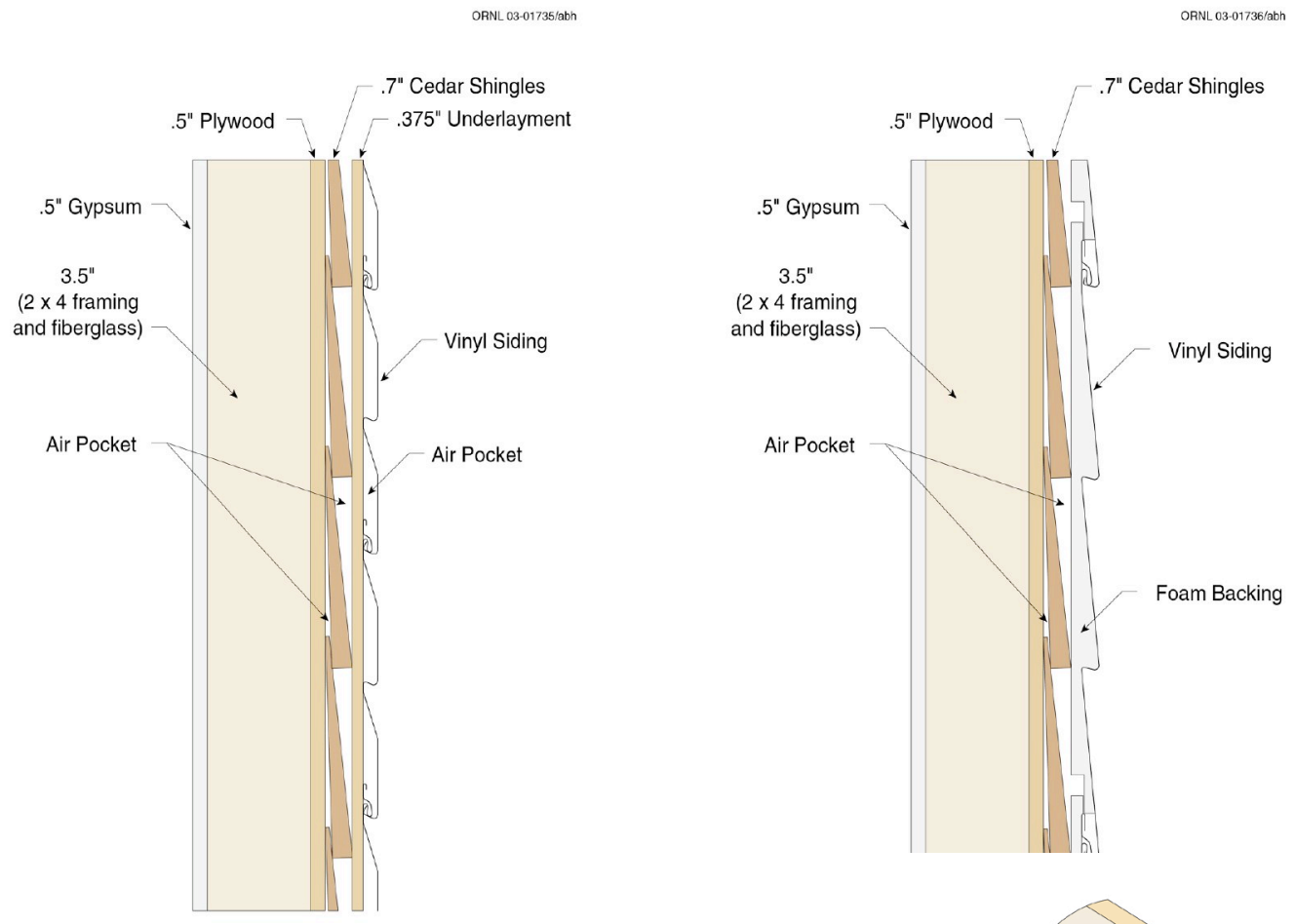

Figure 7. Side views of retrofit vinyl siding configurations



Figure 8. Corner details for the flanged vinyl replacement window 


\subsection{Results}

The thermal conductivity of each insulation product used in the retrofit wall experiments, as measured using a heat flux measurement apparatus according to ASTM C518, is shown in Table 2. The EPS material was contoured so that a C518 test, which requires a flat specimen, could not be made for that option.

The thermal resistance of most wall systems tested in the RGHB can be determined by using weighted average surface temperatures that take into account the location and surface area of each component. This weighted surface temperature is then used to calculate the surface-tosurface thermal resistance and the average surface heat transfer coefficients. That method applies for the six clear wall tests in this program and the results are shown in Table 3. However, for the window/wall test specimens, it would not be meaningful to use a weighted surface temperature because the heat transfer mechanisms are much more complex, encompassing not only a wide difference in material properties, but also radiation heat transfer through the glass and non-uniform surface heat transfer coefficients. Therefore, only the air to air thermal resistance is shown in Table 3 for these specimens. All values reported here have been corrected for the heat flow through the RGHB guard area.

Table 2. Thermal test results for insulation specimens used in retrofit wall (using ASTM C518)

\begin{tabular}{|l|l|l|l|l|l|l|l|}
\hline & \multicolumn{2}{l}{ Thickness } & \multicolumn{2}{l}{ Thermal Conductivity } & \multicolumn{2}{l|}{ Thermal Resistance } \\
\hline & $\mathrm{cm}$ & in. & $\mathrm{W} /(\mathrm{m} \bullet \mathrm{K})$ & $\mathrm{Btu} \bullet \mathrm{in} /\left(\mathrm{h} \bullet \mathrm{ft}^{2} \bullet{ }^{\circ} \mathrm{F}\right)$ & $\mathrm{m}^{2} \bullet \mathrm{K} / \mathrm{W}$ & $\mathrm{h} \bullet \mathrm{ft}^{2} \bullet{ }^{\circ} \mathrm{F} / \mathrm{Btu}$ \\
\hline Extruded polystyrene (XPS) & 1.529 & 0.602 & 0.03014 & 0.2090 & 0.51 & 2.88 \\
\hline Foil-faced Isocyanurate & 2.413 & 0.95 & 0.01977 & 0.1371 & 1.22 & 6.93 \\
\hline Foil-faced Isocyanurate & 1.207 & 0.475 & 0.01977 & 0.1371 & 0.61 & 3.46 \\
\hline $\begin{array}{l}\text { Fan-fold extruded } \\
\text { polystyrene }\end{array}$ & 0.884 & 0.348 & 0.03522 & 0.2442 & 0.25 & 1.43 \\
\hline $\begin{array}{l}\text { Fan-fold Extruded } \\
\text { polystyrene with foil }\end{array}$ & 0.833 & 0.328 & 0.03273 & 0.2269 & 0.25 & 1.45 \\
\hline Fiberglass batt & 8.89 & 3.5 & 0.04588 & 0.3181 & 1.94 & 11.00 \\
\hline
\end{tabular}


Table 3. Thermal test results for retrofit wall and window configurations

\begin{tabular}{|c|c|c|c|c|c|c|c|c|c|c|c|}
\hline \multirow{3}{*}{$\begin{array}{l}\text { Wall } \\
\text { Mod }\end{array}$} & \multirow[t]{3}{*}{ Window } & \multicolumn{7}{|c|}{ Temperature Differences } & \multirow{3}{*}{$\begin{array}{l}\text { Heat } \\
\text { Flow }\end{array}$} & \multirow{2}{*}{\multicolumn{2}{|c|}{ Thermal Resistance }} \\
\hline & & \multicolumn{4}{|c|}{ Wall } & \multicolumn{2}{|c|}{ Window } & \multirow[t]{2}{*}{ Air } & & & \\
\hline & & Cavity & Stud & Track & $\begin{array}{l}\text { Wtd. } \\
\text { Avg. }\end{array}$ & Frame & Glass & & & $\begin{array}{c}\text { Surface } \\
\text { to } \\
\text { Surface } \\
\end{array}$ & $\begin{array}{c}\text { Air } \\
\text { to } \\
\text { Air } \\
\end{array}$ \\
\hline \multicolumn{12}{|c|}{ English units } \\
\hline & & \multicolumn{7}{|c|}{${ }^{\circ} \mathbf{F}$} & Btu/h & \multicolumn{2}{|c|}{$\mathrm{h} \cdot \mathrm{ft}^{2} \bullet^{\circ} \mathrm{F} / \mathrm{Btu}$} \\
\hline Base & none & 45.8 & 43.0 & 42.9 & 45.4 & & & 50.0 & 278 & 10.5 & 11.5 \\
\hline 1 & none & 46.5 & 44.7 & 44.7 & 46.3 & & & 50.1 & 230 & 12.9 & 13.9 \\
\hline 2 & none & 46.6 & 44.8 & 44.6 & 46.3 & & & 49.9 & 221 & 13.4 & 14.4 \\
\hline 3 & none & 46.8 & 45.0 & 44.8 & 46.5 & & & 50.0 & 212 & 14.0 & 15.1 \\
\hline 4 & none & 47.4 & 45.8 & 45.8 & 47.1 & & & 49.9 & 179 & 16.9 & 17.9 \\
\hline 5 & none & 46.7 & 44.6 & 44.7 & 46.4 & & & 50.0 & 231 & 12.9 & 13.8 \\
\hline Base & Vinyl & 45.7 & 43.7 & 42.6 & & 31.6 & 29.0 & 50.1 & 434 & & 7.39 \\
\hline 1 & Vinyl & 46.7 & 45.1 & 44.5 & & 31.1 & 29.6 & 50.2 & 379 & & 8.47 \\
\hline 2 & Vinyl & 46.6 & 45.0 & 44.7 & & 30.8 & 29.6 & 50.0 & 369 & & 8.68 \\
\hline 3 & Vinyl & 46.9 & 45.6 & 44.7 & & 31.1 & 29.7 & 50.1 & 363 & & 8.83 \\
\hline 4 & Vinyl & 47.5 & 46.1 & 44.9 & & 30.8 & 29.7 & 50.1 & 337 & & 9.50 \\
\hline 5 & Vinyl & 46.8 & 45.4 & 44.2 & & 31.0 & 29.6 & 50.1 & 381 & & 8.41 \\
\hline Base & Wood & 45.3 & 43.7 & 43.2 & & 22.0 & 8.11 & 49.9 & 691 & & 4.62 \\
\hline 2 & Wood & 46.7 & 45.4 & 44.8 & & 22.1 & 7.99 & 50.1 & 642 & & 4.99 \\
\hline 5 & Wood & 46.6 & 45.3 & 44.1 & & 25.7 & 7.96 & 50.0 & 655 & & 4.88 \\
\hline Base & Storm & 45.5 & 43.4 & 43.0 & & 31.3 & 25.7 & 50.0 & 461 & & 6.94 \\
\hline 2 & Storm & 46.6 & 45.3 & 44.4 & & 33.5 & 29.3 & 49.9 & 395 & & 8.08 \\
\hline 5 & Storm & 46.7 & 45.1 & 44.3 & & 32.4 & 26.4 & 50.0 & 408 & & 7.83 \\
\hline
\end{tabular}


Table 3. Thermal test results for retrofit wall and window configurations (cont.)

\begin{tabular}{|c|c|c|c|c|c|c|c|c|c|c|c|}
\hline \multirow{3}{*}{$\begin{array}{l}\text { Wall } \\
\text { Mod }\end{array}$} & \multirow{3}{*}{$\begin{array}{l}\text { Win- } \\
\text { dow }\end{array}$} & \multicolumn{7}{|c|}{ Temperature Differences } & \multirow{3}{*}{$\begin{array}{l}\text { Heat } \\
\text { Flow }\end{array}$} & \multicolumn{2}{|c|}{ Thermal Resistance } \\
\hline & & \multicolumn{4}{|c|}{ Wall } & \multicolumn{2}{|c|}{ Window } & \multirow[t]{2}{*}{ Air } & & \multirow{2}{*}{$\begin{array}{c}\text { Surface } \\
\text { to } \\
\text { Surface }\end{array}$} & \multirow{2}{*}{$\begin{array}{l}\text { Air } \\
\text { to } \\
\text { Air }\end{array}$} \\
\hline & & Cavity & Stud & Track & $\begin{array}{l}\text { Wtd. } \\
\text { Avg. }\end{array}$ & Frame & Glass & & & & \\
\hline \multicolumn{12}{|c|}{ Metric units } \\
\hline & & \multicolumn{7}{|c|}{${ }^{\circ} \mathrm{C}$} & $\mathbf{W}$ & \multicolumn{2}{|c|}{$\mathbf{m}^{2} \cdot \mathbf{K} / \mathbf{W}$} \\
\hline Base & none & 25.4 & 23.9 & 23.8 & 25.2 & & & 27.8 & 81.4 & 1.84 & 2.03 \\
\hline 1 & none & 25.9 & 24.8 & 24.8 & 25.7 & & & 27.8 & 67.5 & 2.26 & 2.45 \\
\hline 2 & none & 25.9 & 24.9 & 24.8 & 25.7 & & & 27.7 & 64.9 & 2.36 & 2.54 \\
\hline 3 & none & 26.0 & 25.0 & 24.9 & 25.8 & & & 27.8 & 62.2 & 2.47 & 2.65 \\
\hline 4 & none & 26.3 & 25.5 & 25.4 & 26.2 & & & 27.7 & 52.4 & 2.97 & 3.15 \\
\hline 5 & none & 25.9 & 24.8 & 24.8 & 25.8 & & & 27.8 & 67.7 & 2.27 & 2.44 \\
\hline Base & Vinyl & 25.4 & 24.3 & 23.7 & & 17.5 & 16.1 & 27.8 & 127 & & 1.30 \\
\hline 1 & Vinyl & 25.9 & 25.0 & 24.7 & & 17.3 & 16.5 & 27.9 & 111 & & 1.49 \\
\hline 2 & Vinyl & 25.9 & 25.0 & 24.8 & & 17.1 & 16.4 & 27.8 & 108 & & 1.53 \\
\hline 3 & Vinyl & 26.0 & 25.3 & 24.8 & & 17.3 & 16.5 & 27.8 & 106 & & 1.56 \\
\hline 4 & Vinyl & 26.4 & 25.6 & 24.9 & & 17.1 & 16.5 & 27.8 & 98.9 & & 1.67 \\
\hline 5 & Vinyl & 26.0 & 25.2 & 24.6 & & 17.2 & 16.5 & 27.8 & 112 & & 1.48 \\
\hline Base & Wood & 25.2 & 24.3 & 24.0 & & 12.2 & 4.50 & 27.7 & 202 & & 0.81 \\
\hline 2 & Wood & 25.9 & 25.2 & 24.9 & & 12.3 & 4.44 & 27.8 & 188 & & 0.88 \\
\hline 5 & Wood & 25.9 & 25.1 & 24.5 & & 14.3 & 4.42 & 27.8 & 192 & & 0.86 \\
\hline Base & Storm & 25.3 & 24.1 & 23.9 & & 17.4 & 14.3 & 27.8 & 135 & & 1.22 \\
\hline 2 & Storm & 25.9 & 25.1 & 24.7 & & 18.6 & 16.3 & 27.7 & 116 & & 1.42 \\
\hline 5 & Storm & 26.0 & 25.1 & 24.6 & & 18.0 & 14.7 & 27.8 & 120 & & 1.38 \\
\hline
\end{tabular}




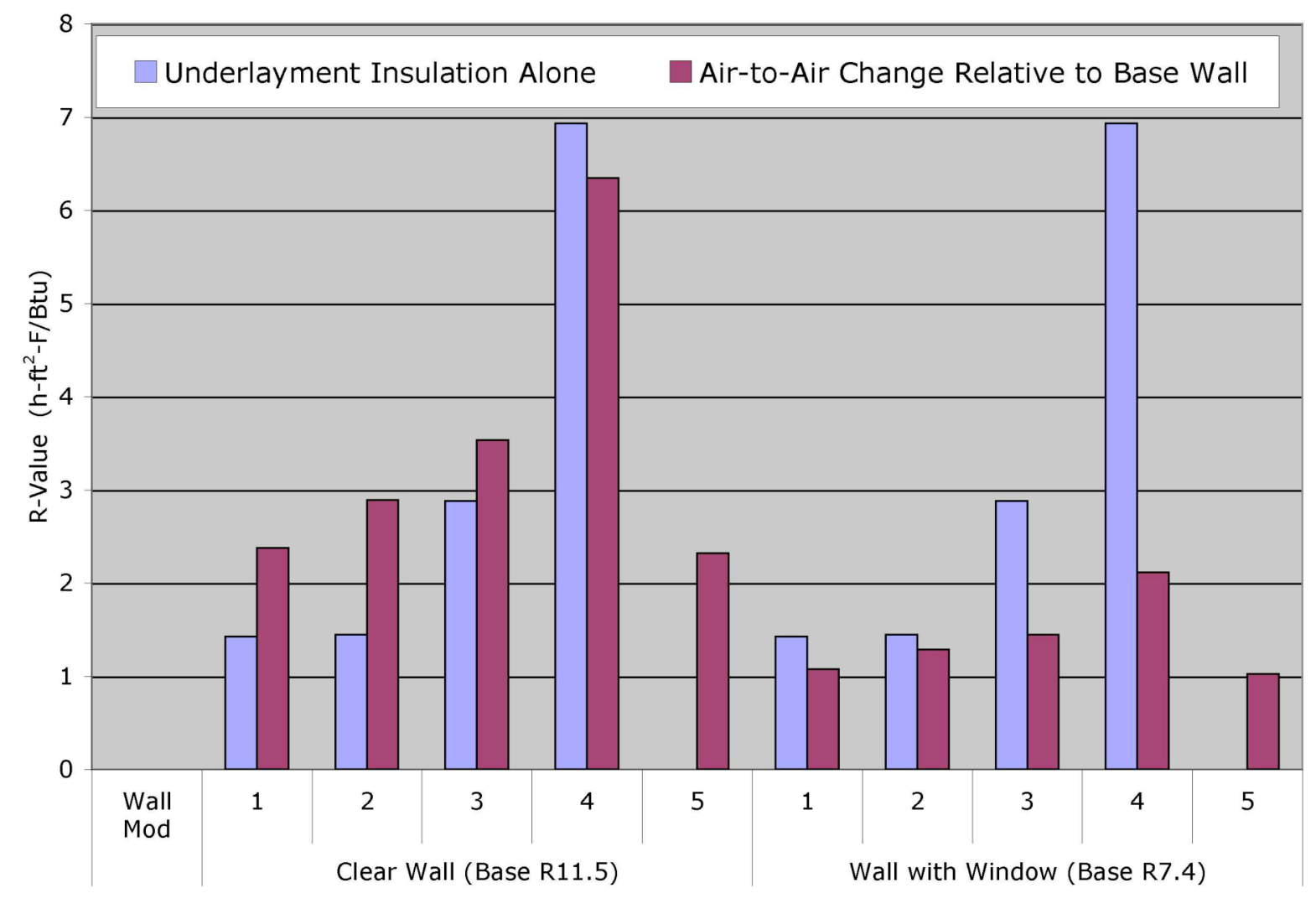

Figure 9. Insulation R-values compared to wall air to air R-values

Figure 9 compares the increase in thermal resistance of the wall retrofits to the thermal resistance of the products used to support the new vinyl siding. For the clear wall, the wall's R-value increases slightly more than the insulation itself for most cases. The difference for Mod 1 should reflect the additional thermal resistance of the air space on each side of the underlayment, as well as that of the vinyl itself. This incremental resistance from the air spaces and vinyl should be approximately the same for Mods 1-4. The thermal resistance effect of the foil facing on the insulative underlayment can be determined by comparing the change in the clear wall R-value for Mods 1 and 2. The value of this reflective surface will, of course, vary according to the temperature difference across the space, but it is clearly effective at the conditions tested here. As you go to the thicker insulation, Mods 3 and 4, the relative importance of the vinyl and trapped air space becomes less. For Mod 4, the greater thermal resistance of the underlayment material causes an increase in the temperature difference across the underlayment, thus increasing the average temperature within the fiberglass and within the underlayment itself. This will cause a very small decrease in the thermal resistance of both those materials. The insulation in Mod 5 is form-fitted to the vinyl siding, so no direct comparison with the material itself can be made. The insulation thickness in Mod 5 varies from 1 to $2.5 \mathrm{~cm}(3 / 8 \mathrm{in}$. to $1 \mathrm{in}$.) as it follows the contour of the vinyl. There are no trapped air spaces behind the vinyl with this product, but there would still be small air pockets between the cedar siding and the back of the insulation.

The change in overall wall R-value for the walls with a window is less than that of the clear walls because the major heat transfer path in this wall is the window itself. Although the overall 
change in R-value for the wall with a window is less, the more important comparison here is in the total heat flow through the wall. As shown in Figure 10, the energy savings in the wall with a window are about the same magnitude as those measured in the clear wall, even though the insulation now covers $19 \%$ less area. This is most likely attributable to the greater proportion of wall framing present in the wall with a window construction. External insulative sheathing is most effective in reducing heat transfer through walls with greater amounts of framing heat transfer paths, sometimes called thermal short circuits.

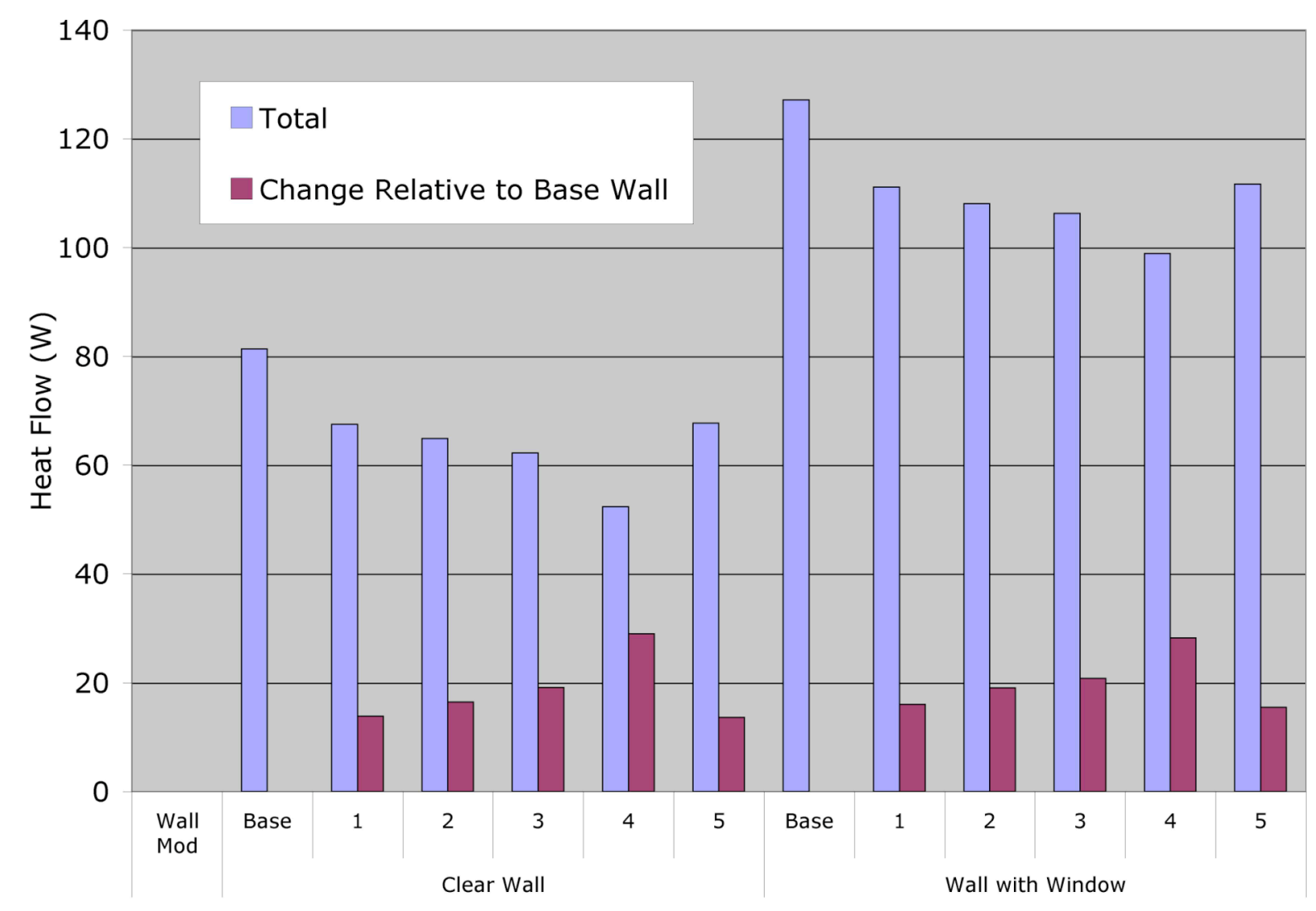

Figure 10. Heat flow measured through wall sections in the RGHB

The windows used for these tests were previously characterized in long-term tests at the MoWiTT facility. ${ }^{8}$ The winter heat transfer characteristics of the windows are shown in Eq. 1.

$$
\mathrm{W}=\mathrm{A} \bullet\left[\mathrm{U} \bullet\left(\mathrm{T}_{\text {out }}-\mathrm{T}_{\text {in }}\right)+\mathrm{g} \bullet \mathrm{S}\right]
$$

where:

$\mathrm{W}$ is a time series of measurements for heat flow,

$\mathrm{A}$ is the window area,

$\mathrm{U}$ is the $\mathrm{U}$-factor,

$\mathrm{T}_{\text {out }}$ is the outdoor temperature,

$\mathrm{T}_{\text {in }}$ is the indoor temperature, 
$\mathrm{g}$ is the solar heat gain coefficient, and

$\mathrm{S}$ is the incident diffuse solar flux.

The measured values for $\mathrm{W}, \mathrm{A}, \mathrm{T}_{\text {out }}, \mathrm{T}_{\mathrm{in}}$, and $\mathrm{S}$ were used to solve for the constant $\mathrm{U}$ factor, $\mathrm{U}$, and the constant solar heat gain coefficient, g. The U-factor is relevant to the tests reported here because it characterizes the window heat transfer in the absence of solar energy. The measured U-factors are shown in Table 4.

Table 4 Window U-factors from MoWiTT study ${ }^{8}$

\begin{tabular}{|l|c|c|}
\hline Window & $\begin{array}{c}\mathrm{U} \text { factor } \\
{\left[\mathrm{W} /\left(\mathrm{m}^{2} \mathrm{~K}\right)\right]}\end{array}$ & $\begin{array}{c}\text { Uncertainty } \\
{\left[\mathrm{W} /\left(\mathrm{m}^{2} \mathrm{~K}\right)\right]}\end{array}$ \\
\hline Vinyl Double-Paned & 2.33 & 0.03 \\
\hline Single-Paned Wood-Framed & 4.41 & 0.07 \\
\hline Single-Paned Wood-Framed + Low-e Exterior Storm Window & 2.84 & 0.04 \\
\hline
\end{tabular}

These window U-factors indicate that the performance of the single-paned window with a low-e storm is almost as good as that of a replacement vinyl-framed double-paned window. In the RGHB window-wall tests, the energy consumption for these two options matched within $4 \%$, and both showed about $40 \%$ less overall heat transfer than the wall containing the single-paned window, as shown in Figure 11. This relationship held true for all the wall treatments tested.

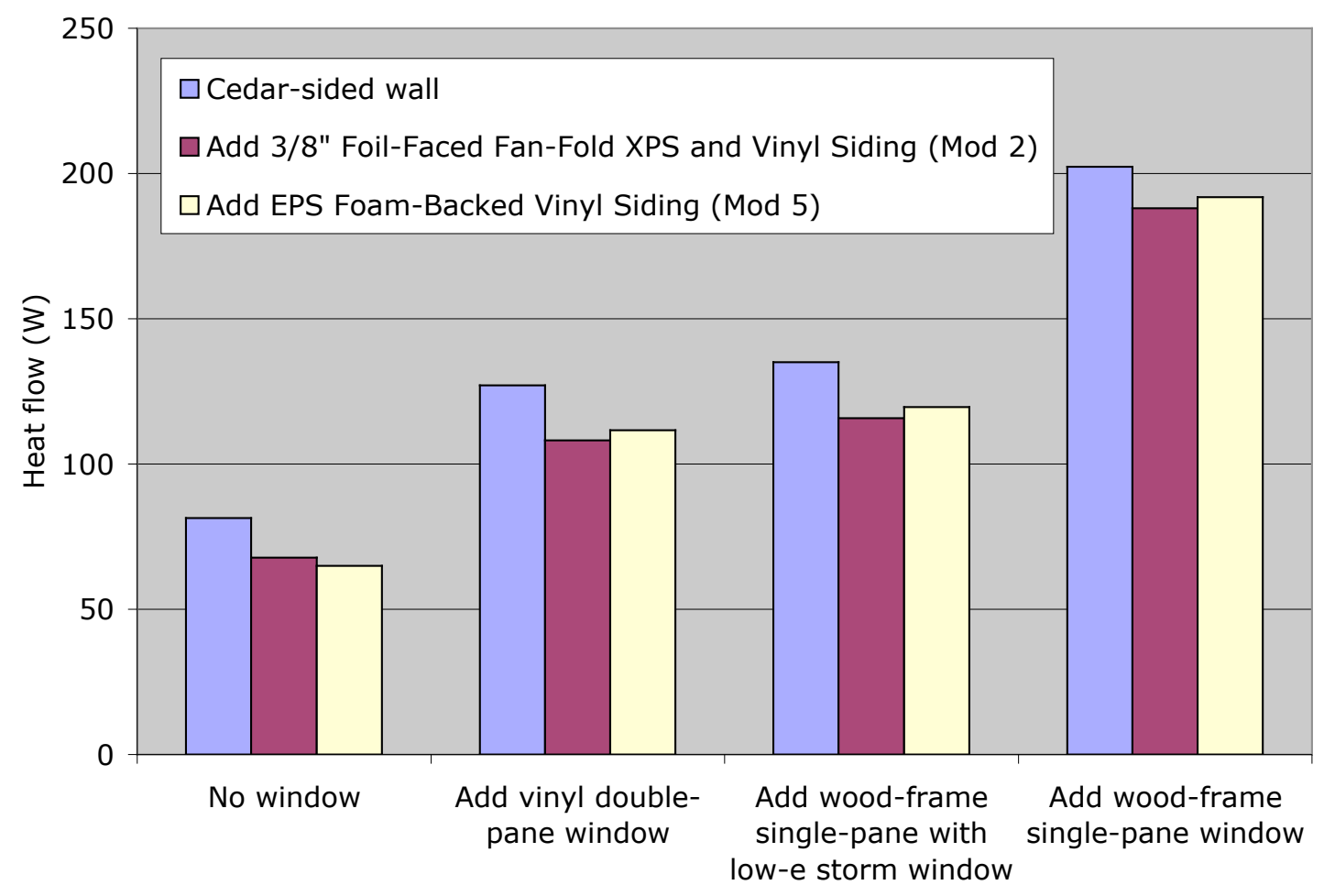

Figure 11. Heat flow measured through window-wall sections in the RGHB 


\section{Air Leakage Tests}

It is difficult to characterize the air leakage qualities that may be affected during a window retrofit job because there is such a wide variation in window size, relative to rough opening size, and workmanship. Nevertheless, a new test apparatus was designed to take measurements in a geometry representative of a typical retrofit window. The air leakage tests were not directed toward measuring the air leakage of the window units, but rather that of the wall and of the wall/window interface. These tests were made using the approach described in ASTM E283-91. ${ }^{9}$

A variety of metrics are used to quantify air leakage, all based upon approximate relationships between air leakage and pressure difference. In buildings, air leakage is typically measured by using a blower door apparatus to pressurize the building and measure the air flow rate as a function of the pressure difference between the inside and outside of the house. That data are typically fit to a power law curve of the form shown in Eq. 2.

$$
\mathrm{Q}=\mathrm{C} \times \Delta \mathrm{P}^{\mathrm{n}}
$$

where:

$\mathrm{Q}$ is the air flow rate,

$\mathrm{C}$ is a coefficient resulting from the curve fit,

$\Delta \mathrm{P}$ is the applied pressure differential, and

$\mathrm{n}$ is the exponent resulting from the curve fit.

Using this equation, it is common to quote the air leakage rates at pressure differentials of 50 and $75 \mathrm{~Pa}$. Air flow through a sharp-edged orifice can be calculated using Eq. 3. Based upon this relationship, an Estimated Leakage Area (ELA), has been defined to be the area of a sharp-edged orifice that would have the same air leakage as the total of all leakage in the house, as shown in Eq. 4. The ELA is traditionally based upon an extrapolation of the data used for the curve fit in Eq. 2 to calculate the leakage flow rate at a pressure differential of either $10 \mathrm{~Pa}$ (Canadian "EqLA") or $4 \mathrm{~Pa}$ ("LBNL ELA"). ${ }^{10,11}$

$$
\begin{aligned}
& Q=A \sqrt{\frac{2}{\rho} \Delta P} \\
& \text { ELA }=\frac{C \times \Delta P^{n}}{\sqrt{\frac{2}{\rho} \Delta P}}
\end{aligned}
$$

For Eq. 4, $\Delta \mathrm{P}$ is either $10 \mathrm{~Pa}$ or $4 \mathrm{~Pa}$ and $\rho$, the density of air, is $1.2 \mathrm{~kg} / \mathrm{m}^{3}$.

These air leakage values may be given on a per window basis, on an area basis, or on a linear basis (where area here refers to the window opening area and the linear basis refers to the length of the window perimeter).

\subsection{Test Apparatus and Procedures}

A well-sealed box was affixed to the face of the same retrofit wall assembly used for the thermal tests. This box was leak-tested before each series of experiments. In order to remove window 
assembly leakage from the measurements, all internal window joints were covered with tape. For some of the tests, the window unit was also covered with a plastic sheet.

A Model 3 Minneapolis Blower Door Fan manufactured by the Energy Conservatory was mounted in a $1.3 \mathrm{~cm}$ (0.5 in) plywood panel constructed to adapt the blower door to the leaktight enclosure, as shown in Figure 12. This plywood panel included a gasket and clamps to seal the fan to the surface of the wood and two small diameter holes, drilled about $61 \mathrm{~cm}(2 \mathrm{ft}$.) from the fan opening, to accommodate static pressure probes used to measure the pressure inside the enclosure.

The Automated Performance Testing System provided by the blower door manufacturer was used to gather a large number of data points for each measurement, reducing the measurement uncertainty as described in the next section. ${ }^{12}$ However, the leakage through the retrofit wall proved to be below the measurable range of the system. Therefore, two holes were drilled in the plywood panel above the fan opening to increase the total air flow into the equipment's measurable range, as shown in Figure 12. One hole was $2.697 \mathrm{~cm}$ (1.062 in.) and the other was $2.703 \mathrm{~cm}$ (1.064 in.) in diameter. The holes were chamfered from the outside to leave about 0.6 $\mathrm{cm}(0.25$ in.) of the plywood thickness at the measured diameters. The chamfering was to approximate the configuration of sharp-edged orifice meters. It also facilitated plugging the holes with rubber stoppers. Each hole increased the air flow rate from 2 to 5 1/s (4 to $10 \mathrm{cfm}$ ) over a range of pressures from 15 to $95 \mathrm{~Pa}$.

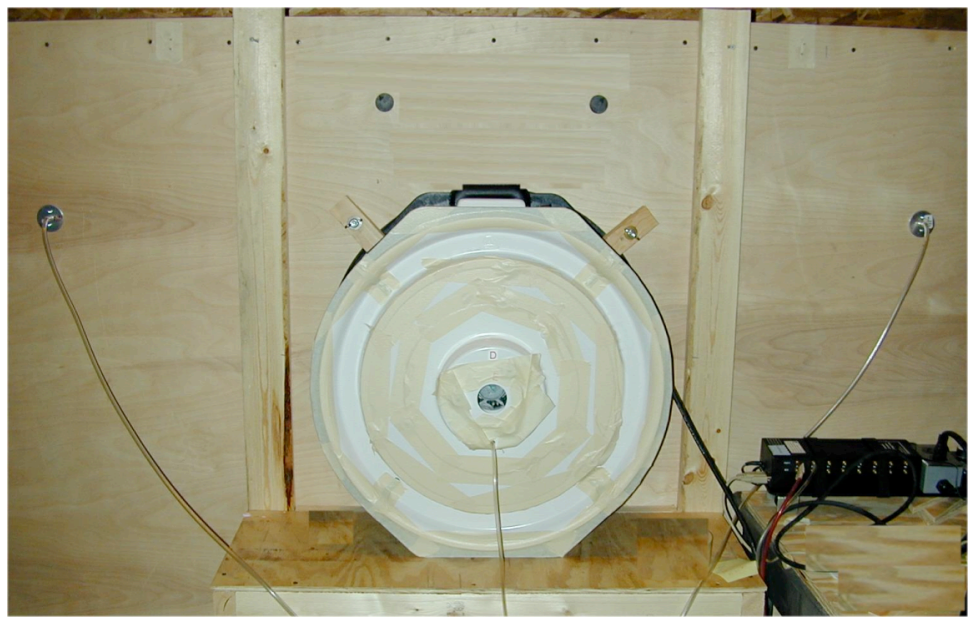

Figure 12. Panel to Adapt Blower Door Fan to Enclosure over Retrofit Base Wall

This modified apparatus, including the chamfered holes, was calibrated by using a separate wall specimen known to have a leakage rate in the equipment's usual measurable range, from 10 to 33 $1 / \mathrm{s}(20$ to $70 \mathrm{cfm})$ at 15 to $95 \mathrm{~Pa}$. During the calibration, a sequence of five tests was repeated four times. The sequence included (1) both holes plugged, (2) both holes open, (3) left hole open, (4) right hole open, and (5) both holes plugged. Based on this replicate series of measurements, the flow through both holes open was characterized as

$$
\mathrm{Q}=2.016 \Delta \mathrm{P}^{0.530} \quad \text { (where } \mathrm{Q} \text { is in } \mathrm{ft}^{3} / \mathrm{min} \text {. and } \Delta \mathrm{P} \text { is in } \mathrm{Pa} \text { ) Eq. } 5
$$


(or an LBNL Estimated Leakage Area of $7.69 \mathrm{~cm}^{2}\left(1.19 \mathrm{in}^{2}\right)$ ).

The flow through each test specimen was then calculated as the difference between the measured result for that specimen and the known flow through the chamfered holes in the apparatus.

\subsection{Uncertainty Analysis For The Modified Apparatus}

The Automated Performance Testing System takes about 200 readings at each pressure point, reports the average of these readings, and claims precisions from $\pm 0.1 \%$ to $\pm 0.4 \%$ (average of $\pm 0.25 \%$ ) for air flow rates between 4.7 and $14.21 / \mathrm{s}(10$ and $30 \mathrm{cfm})$ at $50 \mathrm{~Pa}$. It is assumed that these are measurement standard deviations, so that $95 \%$ uncertainties are twice these values, or $\pm 0.2 \%$ to $\pm 0.8 \%$ :

$$
U_{95}= \pm 2 S_{\bar{x}} \quad \text { Eq. } 6
$$

where:

$\mathrm{U}_{95}$ is the uncertainty at the $95 \%$ confidence level (for infinite degrees of freedom), and $S_{\bar{x}}$ is the measurement standard deviation (or standard deviation of the mean).

To check this interpretation of the reported precision, we observed low and high values during the evolution of the average of 200 readings at each building pressure. A digital image was taken of one such plot (see Figure 13). The low and high values at the nine pressures were fit to straight lines. These lines were used to predict the range (or standard deviation) at $50 \mathrm{~Pa}$. The range was then divided by the square root of the number of measurements $(\mathrm{N}=200)$ :

$$
S_{\bar{x}}=\frac{S_{x}}{\sqrt{N}}
$$

where:

$$
\begin{aligned}
& \mathrm{S}_{\mathrm{x}} \text { is the standard deviation, and } \\
& \mathrm{N} \text { is the number of measurements. }
\end{aligned}
$$

The mean of 200 readings from a single run would have an uncertainty of $\pm 0.75 \%$ by this crude estimate. This value is very close to $\pm 0.8 \%$ and justifies the estimation of uncertainty for leakage flow rates at $50 \mathrm{~Pa}$ by twice the average of the reported precision values divided by the square root of the number of replicated tests. Similarly, the data collection and analysis software calculates the precision of the LBNL and Canadian leakage areas. These values are 10 to 6 times larger than the reported precisions for the leakage flow rates at $50 \mathrm{~Pa}$, which makes sense because they are extrapolated to $4 \mathrm{~Pa}$ and $10 \mathrm{~Pa}$, respectively, from the measured leakage curve.

Moreover, the leakage rates for the specimen walls were determined by taking the difference between the measured values and those measured separately for the auxiliary holes in the apparatus. Uncertainty for a difference is the square root of the sum of the squares of the uncertainties of each component of the difference, as shown in Eqs. 8 and 9.

$$
\left(A \pm U_{95, A}\right)-\left(B \pm U_{95, B}\right)=C \pm U_{95, C} \quad \text { Eq. } 8
$$




$$
U_{95, C}=\sqrt{U_{95, A}^{2}+U_{95, B}^{2}}
$$

where
A is the measured leakage rate for the combined wall and holes,
$\mathrm{B}$ is the measured leakage rate for the holes only, and
$\mathrm{C}$ is the measured leakage rate for the wall only.

For example, for one wall with a window specimen, the total leakage through both the specimen and the auxiliary holes was measured ten times, yielding an uncertainty of $\pm 0.16 \%$. For this specimen's flow rate of $11.4 \mathrm{l} / \mathrm{s}(24.2 \mathrm{cfm})$ at $50 \mathrm{~Pa}$, the uncertainty is $\pm 0.018 \mathrm{l} / \mathrm{s}(0.038 \mathrm{cfm})$. The average precision reported at $50 \mathrm{~Pa}$ for the twelve replicated runs for the auxiliary holes alone is $\pm 0.375 \%$. Using Eqs. 6 and 7, with $\mathrm{N}=12$, yields an uncertainty of $\pm 0.22 \%$. For the flow rate of $7.6 \mathrm{l} / \mathrm{s}(16.1 \mathrm{cfm})$ at $50 \mathrm{~Pa}$ for the auxiliary holes alone, the uncertainty is $\pm 0.017 \mathrm{l} / \mathrm{s}$ $(0.035 \mathrm{cfm})$. For the specimen alone, therefore, the uncertainty is the square root of the sum of these two uncertainties squared, yielding an uncertainty of $\pm 0.6 \%$ :

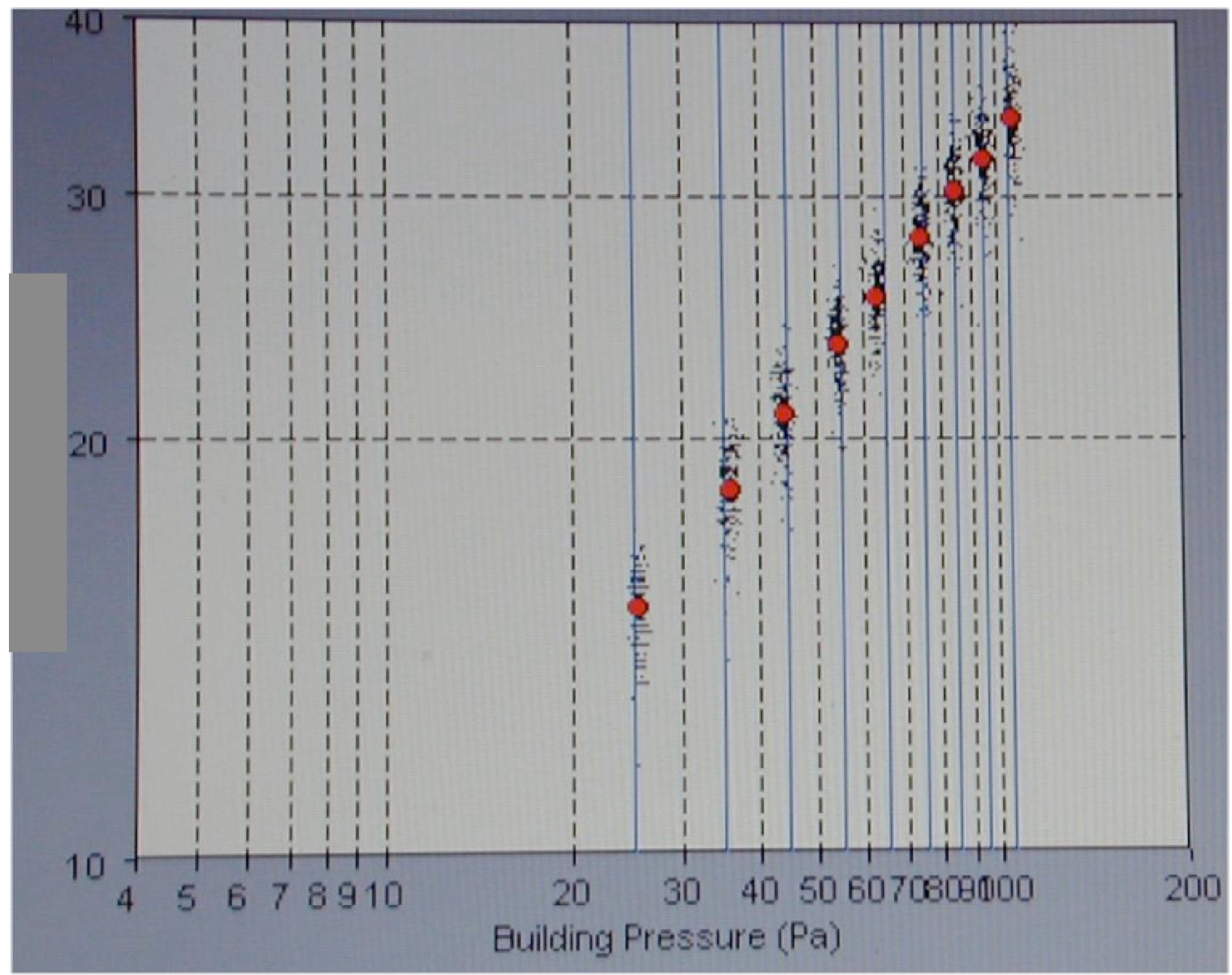

Figure 13. Example of the scatter about the average of 200 measurements at each building pressure that are made by the Automatic Performance Testing System (y-axis units of $\mathbf{c f m}$ ) 


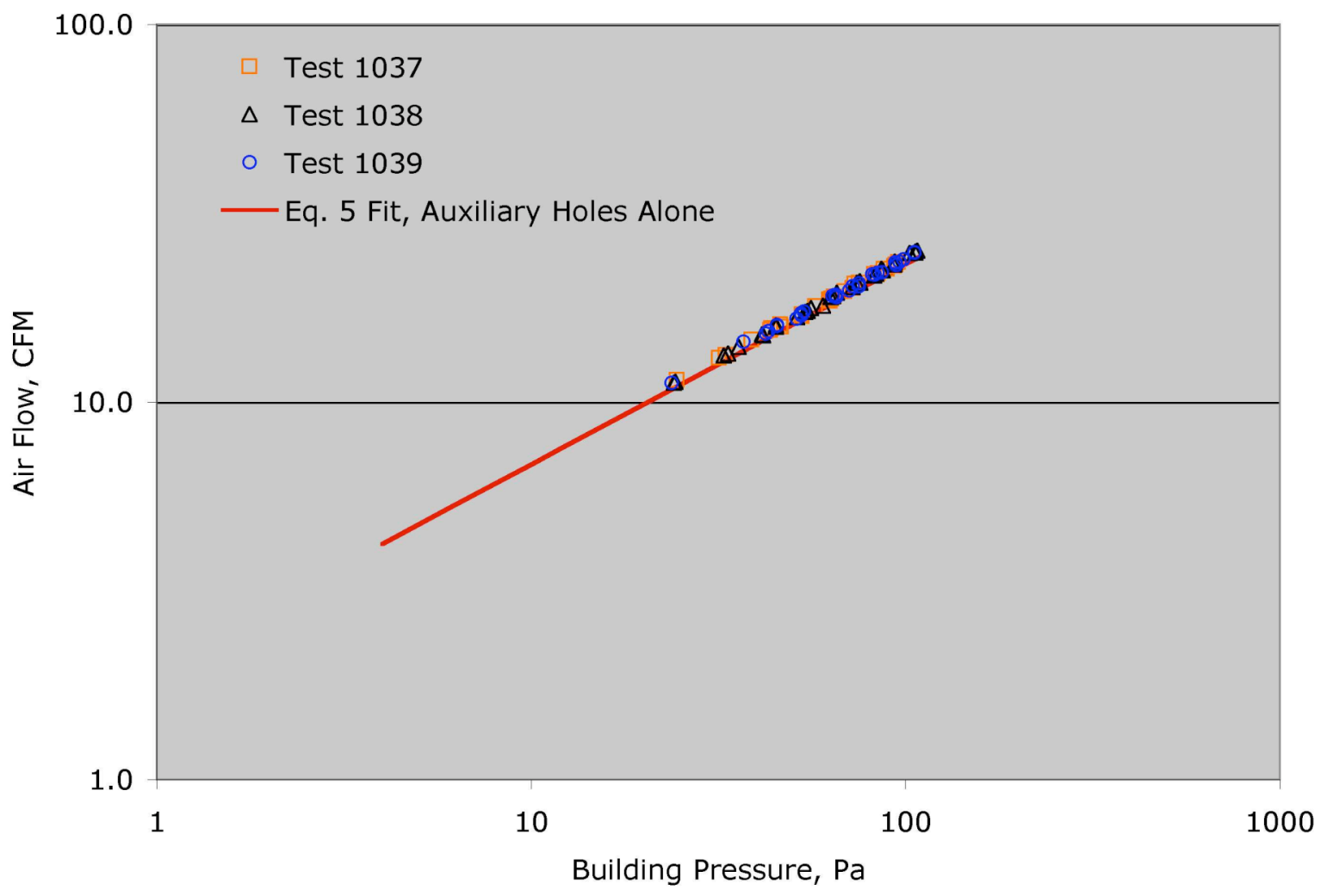

Figure 14. Raw test data for three replicate low leakage rate tests

This estimated uncertainty is well within the $\pm 5 \%$ guideline of ASTM E283-91. As a further test of the modified air leakage measurement technique, one window/wall configuration with an air leakage great enough to reach the range of the instrument without the use of the auxiliary holes was tested both directly and via the difference method. These two tests agreed within $3 \%$.

The absolute magnitude of the uncertainty for all of these tests varied by no more than a factor of 7. But the leakage rates themselves varied by a factor of more than 100 . Therefore, on a relative basis, the tests with very small leakage rates will have a greater uncertainty, especially for the ELA. Figure 14 shows the raw data for three such low-leakage rate tests, along with a curve fit for the air flow through the calibrated holes from Eq. 6. For these three tests the LBNL ELA varied from 0.0021 to $0.0044 \mathrm{in}^{2} / \mathrm{ft}$. When the data from all three replicate tests are combined into a single data set, the ELA is calculated at $0.0030 \mathrm{in}^{2} / \mathrm{ft}$. Table 5 summarizes the above example and these three tests, showing an uncertainty of $\pm 10 \%$ at $50 \mathrm{~Pa}$ and $\pm 90 \%$ at $4 \mathrm{~Pa}$. The uncertainty for a cross section of test results is shown later in this report.

Table 5. Calculation of uncertainties for three data sets (nomenclature as shown in Eqs. 7, 8, and 9)

\begin{tabular}{|l|c|c|c|c|c|c|c|c|c|}
\hline Pressure (Pa) & $\mathrm{N}_{\mathrm{A}}$ & $\begin{array}{c}\mathrm{S}_{\mathrm{A}} \\
(\%)\end{array}$ & $\begin{array}{c}\mathrm{U}_{95, \mathrm{~B}} \\
(\%)\end{array}$ & $\begin{array}{c}\mathrm{A} \\
(\mathrm{CFM})\end{array}$ & $\begin{array}{c}\mathrm{B} \\
(\mathrm{CFM})\end{array}$ & $\begin{array}{c}\mathrm{C} \\
(\mathrm{CFM})\end{array}$ & $\begin{array}{c}\mathrm{U}_{95, \mathrm{~B}} \\
(\mathrm{CFM})\end{array}$ & $\begin{array}{c}\mathrm{U}_{95, \mathrm{~A}} \\
(\mathrm{CFM})\end{array}$ & $\begin{array}{c}\mathrm{U}_{95, \mathrm{C}} \\
(\%)\end{array}$ \\
\hline 50 & 10 & 0.25 & 0.22 & 24.2 & 16.1 & 8.1 & 0.035 & 0.038 & 0.6 \\
\hline 50 & 3 & 0.25 & 0.22 & 16.6 & 16.0 & 0.6 & 0.035 & 0.048 & 10 \\
\hline 4 & 3 & 2.4 & 1.32 & 4.4 & 4.2 & 0.1 & 0.055 & 0.121 & 90 \\
\hline
\end{tabular}


In summary, the procedure and apparatus that were used appear to be sensitive enough to discern very small differences in the air leakage due to the various methods used to seal the gap around the perimeter of the window.

\subsection{Specimen Configurations}

The whole wall, with no window and with cedar lap siding, was the first configuration tested for air leakage. Because the critical air flow resistance was provided by the gypsum and plywood sheathing, tests were not repeated for the other siding materials.

As described previously, a vinyl flanged window and a wooden insert window were installed sequentially in the retrofit wall specimen. A storm window modification to the wooden insert window was also included in the thermal test schedule, but because the air leakage of interest here is that between the window and the wall framing, air leakage tests were not performed for that configuration.

A single test of the vinyl flanged window-wall combination was performed with the cedar lap siding in place. For this test, the exterior of the window frame was caulked directly to the siding. However, the window/wall joint was the subject of multiple modifications. To assure a repeatable and consistent condition on the wall exterior throughout the test schedule, the siding was removed and the bare plywood sheathing was used as the external wall surface for all the other air leakage tests.

Two different gap widths were tested, 1 and $1.9 \mathrm{~cm} \mathrm{(3/8} \mathrm{and} \mathrm{3/4} \mathrm{in.).} \mathrm{Good} \mathrm{building} \mathrm{practice}$ usually calls for the $1 \mathrm{~cm}$ spacing to allow for proper window alignment. The thicker gap was included in the test schedule to represent homes built with lesser quality workmanship.

The window trim details were varied throughout the experimental program. These trim pieces included a brick molding trim placed on the exterior side of the wooden insert window frame, and flat pieces of plywood used to represent typical interior trim sizes and placement.

In addition to the varied window trim details, five gap treatments available to remodelers were tested:

(1) Loose fiberglass stuffed into the gap has been commonly used to reduce the air flow. (Although good building practice calls for caulking and backer rod to be placed on top of the fiberglass, the fiberglass was tested independently here.)

(2)A bituminous tape product designed for this purpose was used to cover the joint between the window and the wall on the exterior side.

(3) A compressed foam tape was pre-applied to the side of the window frame before its placement in the wall. This tape then expanded to fill the gap after the window was in position.

(4) An aerosol foam sold for this application was blown into the gap and trimmed according to the product directions.

(5) An untreated open gap was included for comparison.

\subsection{Air Leakage Test Results}

The leakage for the retrofit base wall was measured to be $0.2 \pm 0.11 / \mathrm{s}(0.4 \pm 0.2 \mathrm{cfm})$ at $50 \mathrm{~Pa}$, or an LBL ELA of $0.23 \pm 0.12 \mathrm{~cm}^{2}\left(0.035 \pm 0.018 \mathrm{in}^{2}\right)$. This value was considered negligible, even 
given the large uncertainty. The American Society of Heating and Refrigerating, and Air Conditioning Engineers (ASHRAE) lists best estimate ELAs of $0.015 \%\left(0.0022 \mathrm{in}^{2} . / \mathrm{ft}^{2}\right)$ for walls with a continuous air barrier and $0.003 \%\left(0.005 \mathrm{in} .{ }^{2} / \mathrm{ft}^{2}\right)$ for walls with rigid sheathing. ${ }^{14}$ For the test specimen area, the ASHRAE estimated ELA would therefore be 0.9 to $2 \mathrm{~cm}^{2}$ ( 0.14 to 0.32 in. ${ }^{2}$ ). The retrofit base wall is indeed air tight.

For the walls with windows, the leakage is of course much greater, and is considered to represent the leakage of the gap between the window frame and the rough wall opening. Table 6 summarizes the air leakage test results in terms of the coefficient and exponent (from Eq. 2) of the leakage curve. To facilitate a comparison to the ASHRAE values, the LBNL ELA is given in terms of leakage area divided by window area, which in these tests was $0.77 \mathrm{~m}^{2}\left(12 \mathrm{ft}^{2}\right) .^{14}$ 
Table 6. Air leakage results for the gap between the window frame and the rough wall opening.

\begin{tabular}{|c|c|c|c|c|c|c|c|c|}
\hline \multirow[b]{2}{*}{ Gap Treatment } & \multicolumn{2}{|c|}{ Trim/Caulking* } & \multicolumn{2}{|c|}{ Eq. 2 (CFM) } & \multicolumn{2}{|c|}{ LBNL ELA } & \multicolumn{2}{|c|}{$\begin{array}{l}50 \text { Pa Flow } \\
\text { Rate }\end{array}$} \\
\hline & Interior & Exterior & $\mathbf{C}$ & $\mathbf{n}$ & $\mathrm{cm}^{2} / \mathbf{m}^{2}$ & $\mathrm{in}^{2} / \mathbf{f t}^{2}$ & $\mathbf{L} / \mathbf{s}$ & CFM \\
\hline \multicolumn{9}{|c|}{ Flanged Window, Gap Thickness 1 Cm (3/8 in.) } \\
\hline Open & Yes/No & $\mathrm{No} / \mathrm{Yes}$ & 1.2 & 0.61 & 4.5 & 0.023 & 6.1 & 12. \\
\hline Open & Yes/No & Siding/Yes & 0.63 & 0.66 & 2.5 & 0.013 & 3.9 & 8.2 \\
\hline Bituminous tape & Yes/No & No/No & 0.18 & 0.66 & 0.7 & 0.004 & 1.1 & 2.4 \\
\hline Fiberglass & Yes/No & $\mathrm{No} / \mathrm{No}$ & 0.15 & 0.71 & 0.6 & 0.003 & 1.1 & 2.3 \\
\hline Aerosol Foam & Yes/No & $\mathrm{No} / \mathrm{No}$ & 0.14 & 0.51 & 0.5 & 0.002 & 0.49 & 1.0 \\
\hline \multicolumn{9}{|c|}{ Insert Window, Gap Thickness $1 \mathrm{Cm}$ (3/8 in.) } \\
\hline Open & $\mathrm{No} / \mathrm{No}$ & Yes/Yes & 0.84 & 0.70 & 3.6 & 0.018 & 6.1 & 12. \\
\hline Open & $\mathrm{Yes} / \mathrm{No}$ & Yes/Yes & 0.74 & 0.70 & 3.2 & 0.016 & 5.3 & 11. \\
\hline Open & Yes/Yes & $\mathrm{No} / \mathrm{No}$ & 0.093 & 0.53 & 0.3 & 0.002 & 0.34 & 0.72 \\
\hline Open & Yes/Yes & Yes/Yes & 0.068 & 0.56 & 0.2 & 0.001 & 0.29 & 0.61 \\
\hline \begin{tabular}{|l|} 
Compressed foam \\
tape
\end{tabular} & $\mathrm{No} / \mathrm{No}$ & No/No & 0.32 & 0.66 & 1.3 & 0.007 & 2.0 & 4.3 \\
\hline $\begin{array}{l}\text { Compressed foam } \\
\text { tape }\end{array}$ & Yes/No & No/No & 0.26 & 0.69 & 1.1 & 0.006 & 1.8 & 3.8 \\
\hline \begin{tabular}{|l|l} 
Fiberglass \\
\end{tabular} & $\mathrm{No} / \mathrm{No}$ & Yes/Yes & 0.11 & 0.79 & 0.5 & 0.003 & 1.1 & 2.4 \\
\hline Fiberglass & Yes/No & Yes/Yes & 0.079 & 0.85 & 0.4 & 0.002 & 1.0 & 2.2 \\
\hline Fiberglass & Yes/Yes & Yes/Yes & 0.092 & 0.59 & 0.3 & 0.002 & 0.44 & 0.93 \\
\hline Bituminous tape & Yes/No & $\mathrm{No} / \mathrm{No}$ & 0.088 & 0.71 & 0.4 & 0.002 & 0.68 & 1.4 \\
\hline Bituminous tape & No/No & $\mathrm{No} / \mathrm{No}$ & 0.087 & 0.71 & 0.4 & 0.002 & 0.65 & 1.4 \\
\hline Aerosol Foam & Yes/No & No/No & 0.058 & 0.71 & 0.3 & 0.001 & 0.43 & 0.92 \\
\hline \multicolumn{9}{|c|}{ Flanged Window, Gap Thickness 2 Cm (3/4 in.) } \\
\hline Open & $\mathrm{No} / \mathrm{No}$ & No/No & 8.1 & 0.54 & 28. & 0.14 & 32. & 68. \\
\hline Open & Partial/No & No/No & 6.6 & 0.53 & 23. & 0.12 & 25. & 53. \\
\hline Open & Partial/No & $\mathrm{No} / \mathrm{No}$ & 6.5 & 0.54 & 22. & 0.11 & 25 & 53. \\
\hline Open & Yes/No & $\mathrm{No} / \mathrm{No}$ & 0.42 & 0.67 & 1.8 & 0.009 & 2.7 & 5.8 \\
\hline Fiberglass & $\mathrm{No} / \mathrm{No}$ & $\mathrm{No} / \mathrm{No}$ & 0.19 & 0.83 & 1.0 & 0.005 & 2.3 & 4.9 \\
\hline Fiberglass & Yes/No & $\mathrm{No} / \mathrm{No}$ & 0.15 & 0.76 & 0.7 & 0.004 & 1.4 & 2.9 \\
\hline Aerosol Foam & No/No & $\mathrm{No} / \mathrm{No}$ & 0.15 & 0.73 & 0.7 & 0.003 & 1.2 & 2.6 \\
\hline Bituminous tape & Yes/No & $\mathrm{No} / \mathrm{No}$ & 0.23 & 0.49 & 0.7 & 0.004 & 0.74 & 1.6 \\
\hline Bituminous tape & $\mathrm{No} / \mathrm{No}$ & $\mathrm{No} / \mathrm{No}$ & 0.19 & 0.54 & 0.6 & 0.003 & 0.74 & 1.6 \\
\hline Open & Yes/Yes & $\mathrm{No} / \mathrm{No}$ & 0.11 & 0.66 & 0.4 & 0.002 & 0.66 & 1.4 \\
\hline $\begin{array}{l}\text { *This column detai } \\
\text { joint. For example, } \\
\text { partial trim was apr } \\
\text { used. }\end{array}$ & $\begin{array}{l}\text { e trim and } \\
\text { s/No" me } \\
\text { and no ca }\end{array}$ & $\begin{array}{l}\text { xing used } \\
\text { at trim w } \\
\text { g was use }\end{array}$ & the int & ior and & $\begin{array}{l}\text { xterior } \\
\text { was no } \\
\text { that bot }\end{array}$ & $\begin{array}{l}\text { rfaces of } \\
\text { 'Partial// } \\
\text { rim and }\end{array}$ & wi & $\begin{array}{l}\text { W-wall } \\
\text { that a } \\
\text { ere }\end{array}$ \\
\hline
\end{tabular}


The caulking and trim around the window frame had a significant effect on the air leakage flows, as shown in Figure 15 (notice that the LBNL ELA is shown on a log scale on this figure in order to display all the results). These results indicate that the caulking is especially effective when applied at the interior wall frame interface. The relative effectiveness of the gap treatments used, without caulking, is displayed in Figure 16 and Figure 17. As discussed previously, the uncertainty for these tests varies over a much smaller range than the flow rates themselves, so the 95\% certainty ranges shown on Figure 16 for the ELA values are much broader than those on Figure 17 for the $50 \mathrm{~Pa}$ flow rates. Considering these error bounds, the bituminous tape and the aerosol foam appear to have about the same effectiveness. Examination of these results shows that the presence of interior trim is less important in assuring the performance of the bituminous tape and aerosol foam products than it is for the fiberglass and compressed foam tape applications.

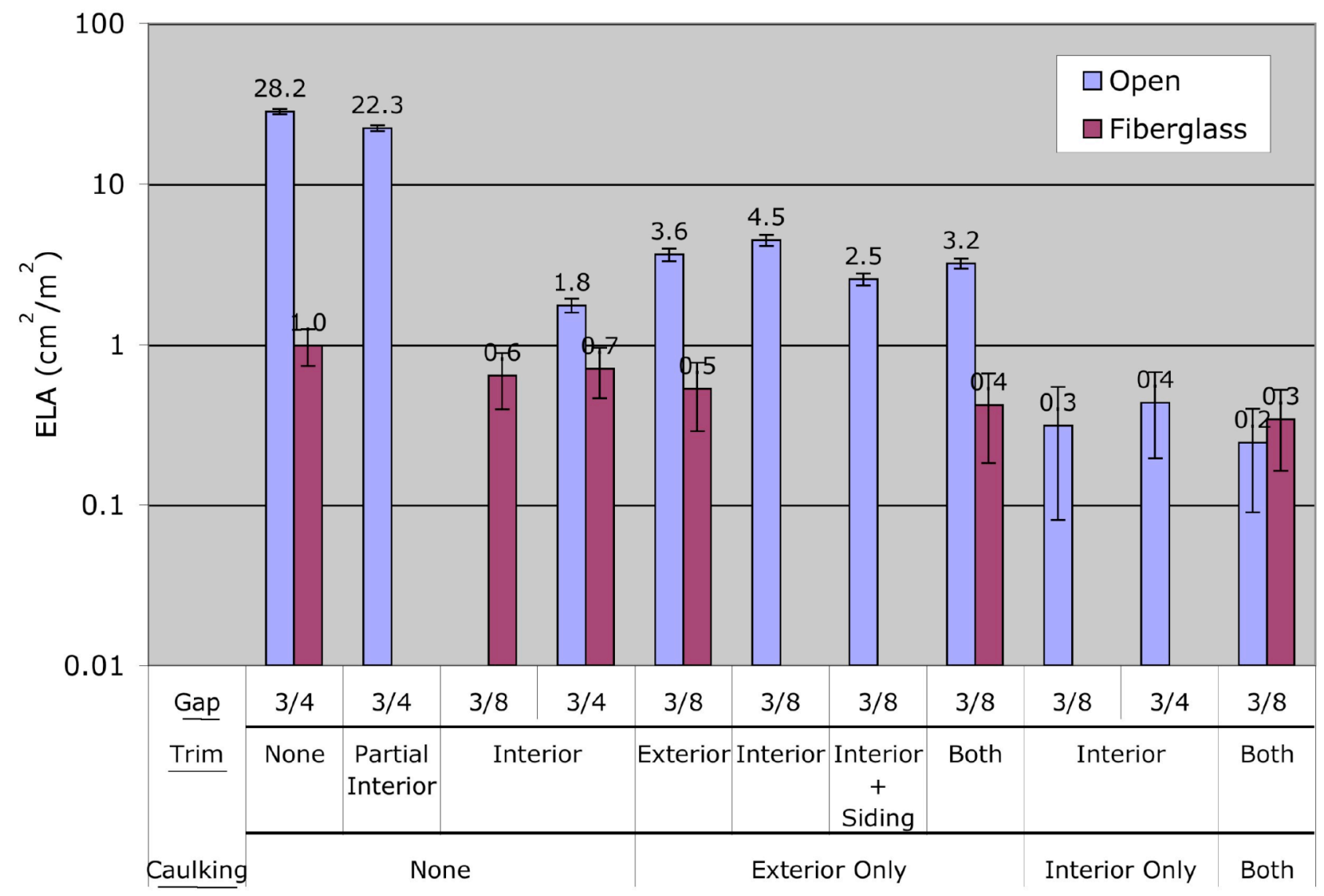

\section{Figure 15. Equivalent Leakage Area for open and fiberglass-stuffed window/wall joints for varying trim and caulking conditions.}

Considering not only the variability in initial application quality, but also the variability in application status over time, the Best Practice Guide included advice to use redundant techniques to reduce air leakage around windows. That is, consumers were advised to combine appropriate trim and caulking with an effective gap filler, such as foam, fiberglass, or foam tape, or an effective gap cover, such as the bituminous tape 
product.

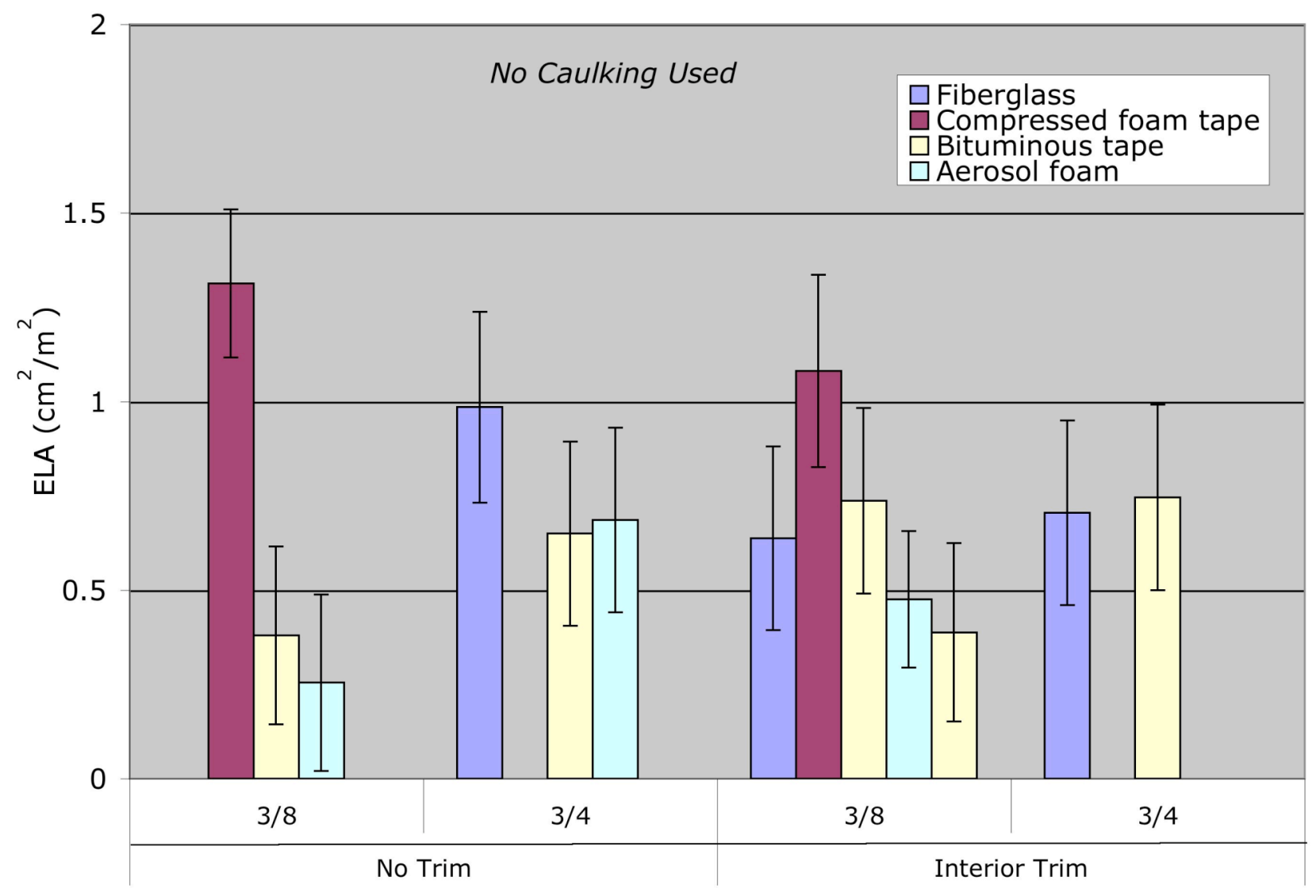

Figure 16. Equivalent Leakage Area for a number of window/wall joint sealing products.

The ELA values measured varied from a minimum of 0.2 to $0.4 \mathrm{~cm}^{2} / \mathrm{m}^{2}$ for sealing with aerosol foam, caulked inside trim and fiberglass in the gap, or a bituminous tape on the outside of the gap. They varied to a maximum of 2 to $3 \mathrm{~cm}^{2} / \mathrm{m}^{2}$ with very little sealing but at least some trim and caulking on the exterior surface. The totally open large gap with no trim or caulking produced an ELA of more than $20 \mathrm{~cm}^{2} / \mathrm{m}^{2}$, which should represent a worst case 
scenario.

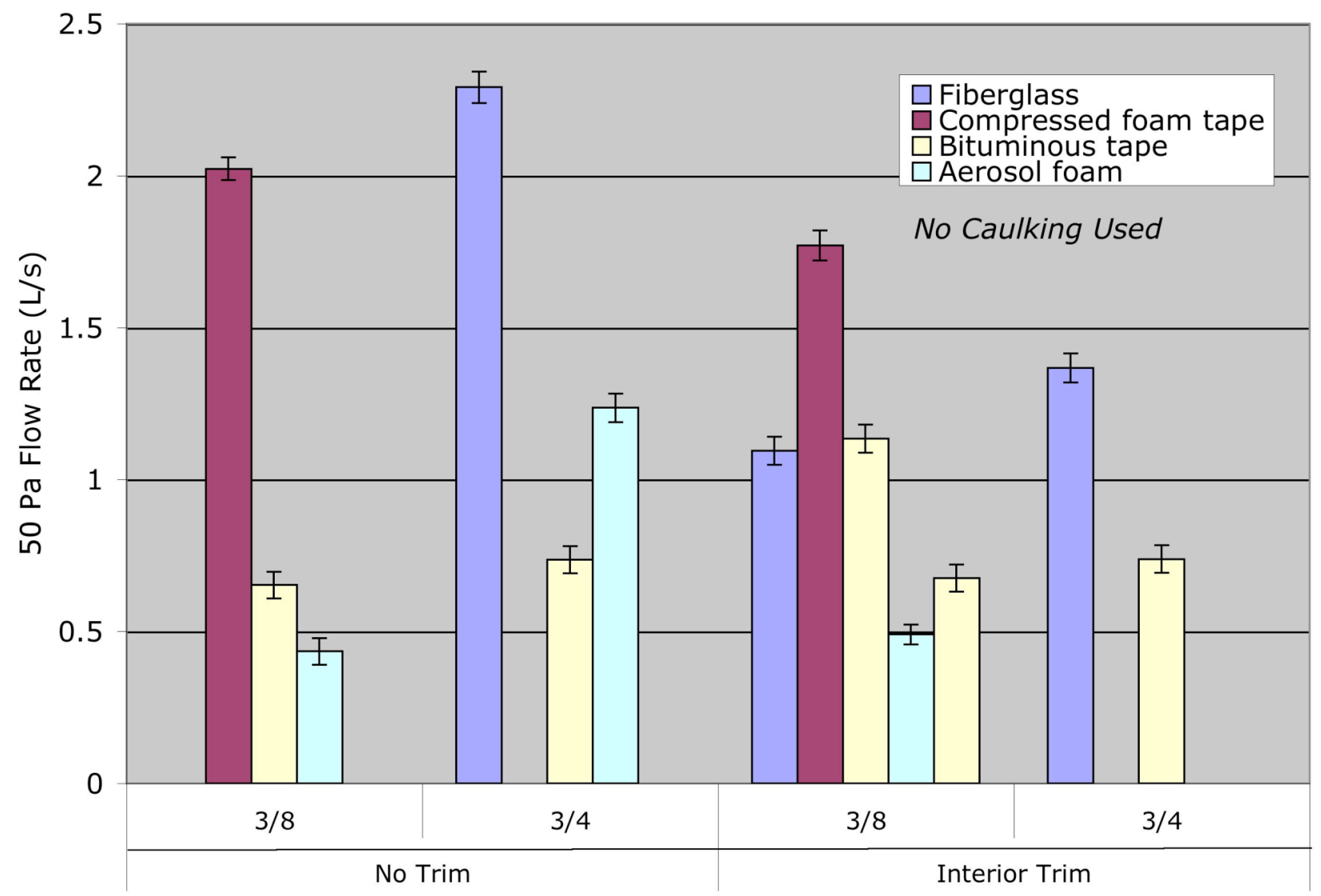

Figure 17. Air leakage flow at a pressure difference of $50 \mathrm{~Pa}$ for a number of window/wall joint sealing products.

For comparison, ASHRAE Fundamentals offers four entries for window framing: uncaulked masonry, caulked masonry, uncaulked wood and caulked wood. Each entry is assigned a best estimate, minimum and maximum ELA. Values of ELA for wood windows vary from 0.3 to 2.7 $\mathrm{cm}^{2} / \mathrm{m}^{2}$. This range matches very well with the results from the tests reported here. The ASHRAE best estimate for caulked windows is the same as their minimum. The best estimate for uncaulked windows is $1.7 \mathrm{~cm}^{2} / \mathrm{m}^{2}$, which is exactly what we achieved with the uncaulked full plywood "trim" for the larger gap size tested. The uncaulked inside trim for the insert window and the smaller gap size yielded the maximum $2.4 \mathrm{~cm}^{2} / \mathrm{m}^{2}$, even when exterior caulking was used. In summary, these test results are in general agreement with the ASHRAE suggested values and should lend support to their use. 


\section{Workshop}

Much useful guidance for home retrofit resides not on the web or in printed materials, but in the minds of contractors, builders, product developers, and researchers. Toward this end, a one-day workshop was convened to 'pick-the-brains' of such experts. The workshop participants are listed in Table 7.

Table 7. Workshop participants

\begin{tabular}{|l|l|}
\hline Robert Braun & Dow Consumer and Building Products \\
\hline Todd Bushburger & Protecto Wrap Company \\
\hline Claude Browne & Crane Performance Siding \\
\hline George Chrenka & NuWool Company \\
\hline Steve Duren & Illbruck Sealant Systems Inc. \\
\hline Brian Keith Hearon & Denver L. Hunt Company \\
\hline Terry Logee & U. S. Department of Energy \\
\hline John William Lubker & Pactiv Building Products \\
\hline Jerry Atchley & Oak Ridge National Lab \\
\hline Phillip Childs & \\
\cline { 1 - 1 } Andre Desjarlais & \\
\cline { 1 - 1 } Jan Kosny & \\
\cline { 1 - 1 } Thomas Petrie & \\
\cline { 1 - 2 } Therese Stovall & \\
\cline { 1 - 2 } Mark Ternes & \\
\cline { 1 - 2 } Bob Wendt &
\end{tabular}

\subsection{Workshop Objective}

The workshop was structured to address the following questions and topics:

- What are today's most common practices? Compare what's being done now to what could be achieved in a more comprehensive process. What works best? Where are there problems?

- If we could do a 'perfect' wall retrofit, what would that include? Considering thermal, air, moisture performance, what are the locations on the building exterior that should be targeted?

- What would the benefits of such a system be?

- Could such a system be marketed? How do you make it appealing and understandable to consumers? What is the current customer motivation? Who is the sales person? What are the difficulties in combining new systems into the current sales chain and installer chain? 
- To what extent can we use systems and tools now used in new construction?

- What should the system components be?

- What can we tell consumers today?

- What research and product development would help get us to a truly integrated wall system?

\subsection{General Discussion}

During the course of the discussion, a few common themes emerged.

Energy-saving retrofits are typically a 'piggy-back' effort, riding along with other projects designed to improve the appearances of a home or to reduce the need for periodic maintenance. Consumers tend to focus on R-value rather than air leakage and moisture, which might be more important than R-value.

Window retrofits are typically driven by loss of function (fogs up, etc.). About 10 to $40 \%$ of residing jobs also redo windows (depends on house age). The most common window installed as a retrofit is custom sized, solid vinyl, and non-flanged. When aluminum windows are replaced, you must remove the old frame. It is sometimes possible to use flanged windows as a retrofit, but not on houses with brick veneer.

Redundancy is needed on the window and trim. Test results show that foam, fiberglass, and tape performed about the same in sealing window edge air leaks, but in real houses redundancy may be needed as the house changes. One contractor noted that chinking with fiberglass usually doesn't stop air leakage in real homes. He advised against reliance on any single thing to do all tasks such as air seal, moisture seal, insulate, etc., especially siding systems that include unsealed joints.

In very old homes, it is important not to create interior moisture problems. For example, new foam insulation may create a problem because foam is an effective air retarder. Also, the old siding materials may have stored moisture. New insulation board would store much less water, so moisture migrating with air through the wall may condense. It is often better to let moisture "move". When you change the wall air leakage characteristics, you must consider the overall air leakage of the house and other systems, including the HVAC system and other ventilation fans. It was suggested that it would be easier to sell air barriers as a part of a retrofit job based on its value as a moisture barrier and mold prevention tool, not to stop air leakage.

Note that the ASTM 2112 standard mostly addresses the window/wall interface for new construction, but may be applicable to many retrofit installations. In general, we should try to move retrofits toward new construction practices, and to approximate new construction quality, including seals at the top and bottom of the wall. Just as with new houses, we should strive for an integrated house design, addressing factors of HVAC, indoor air quality, moisture management, and sound reduction.

\subsection{Construction Practices}

Much of the discussion centered on construction practices. Contractors will usually overlay new siding over old wood siding unless it is deteriorated. For residing on top of old siding, fan fold insulation provides a level supportive surface for siding, but does not have an extremely high $\mathrm{R}$ value. The contractors will remove old siding if it is aluminum or vinyl. In the Midwest, the old siding is often taken off, one inch of insulation board is added, and then new siding installed 
because occupants want more insulation. Another option is to remove old siding, add insulation from outside (blown in or board), and then air seal by taping joints in the insulation board or sheathing. Cellulose blown into the cavity insulates, retards air movement, and serves to mitigate moisture intrusion because it can store a significant amount of moisture. Some suggested the use of insulation board with taped joints and top seam as an air barrier, rather than housewrap, although there was some question as to whether to tape the bottom as the wall must drain.

When replacing both siding and windows, install replacement windows first, then install new siding. If you replace windows after siding, the job depends on what is behind the original cladding - what surface is available to tie into (for the draining plane and air sealing). Sometimes the housewrap/building paper is missing in a retrofit job, leaving the question of whether or not to seal the windows to the wood underlayment. When installing retrofit windows on a house with housewrap, the contractors use tape or self adhering flashing to achieve airtightness. To many consumers, low expansion foam is still seen as a possible problem in causing windows to bow and voiding warranties.

The contractors identified the windows as the weakest link in the wall, but pointed out the importance of getting other details correct. These details included dryer vents, electrical outlets, other penetrations through the wall, and insulation termination.

\subsection{Recommendations for Presentation Approaches in the Best Practices Guide}

The benefits should be detailed by region to reflect differences in climate and building practices, such as common materials and methods.

Show customers the potential energy savings. Provide some quantitative information so occupants can determine whether benefits will be reflected on their energy bill.

To move consumers to best practices, the guide must be simple. Consider whether numerical values should be used or if advice should be presented in terms of good/better/best. To move installers to best practices, provide information about the proper sequencing and interfacing of materials. It would be helpful to provide window rough opening treatments and details, along with information about how these details impact retrofit payback and durability.

Consumer education should be a combined effort of manufacturers, contractors, and government to provide one reliable/neutral source. The Internet should be used to encourage consumers to be proactive based on reliable information

\subsection{Advice for Future Research}

$\underline{\text { Real world issues }}$

- What is the effect of trim? In lab tests, the trim stopped air leaks because the trim covered the only leakage path available. Multiple paths are available in real houses.

- To address material and system durability, we need to measure the long term behavior of installed materials and/or wall systems as they age. What are the effects of house settling and other house movement?

- Develop a mold audit procedure based on a better understanding of the relationship between environmental conditions within a building system and mold growth habits.

- Develop a rating tool for retrofit systems, analogous to an automobile MPG rating. This could distinguish between standard and energy-efficient jobs, enabling customers to make an apples to 
apples comparison. Such a tool would, however, have liability associated with it. For example, if air leakage is involved, a blower door test would be required.

\section{Laboratory measurements and analysis}

- System integration compatibility studies (compatible materials - how they work together, degrade one another).

- Housewraps -What characteristics are desirable for different building types and climates?

- Develop a physical properties data base - materials and systems, including housewraps. 


\section{Modeling: Wall and Window Retrofits}

Our laboratory tests and those performed at LBNL established the thermal and infiltration characteristics of several common retrofit products. But a rational decision should be based on overall economics as well as the rated performance.

To explore this issue, the R-values measured for the wall and window retrofit options were used with whole house energy consumption correlations, shown in Eq. 9 and Table 8, from an extensive study of three house models in ten locations, see Figure $18 .^{15}$ These house models were produced previously to look at energy savings for a broad range of wall types and thermal
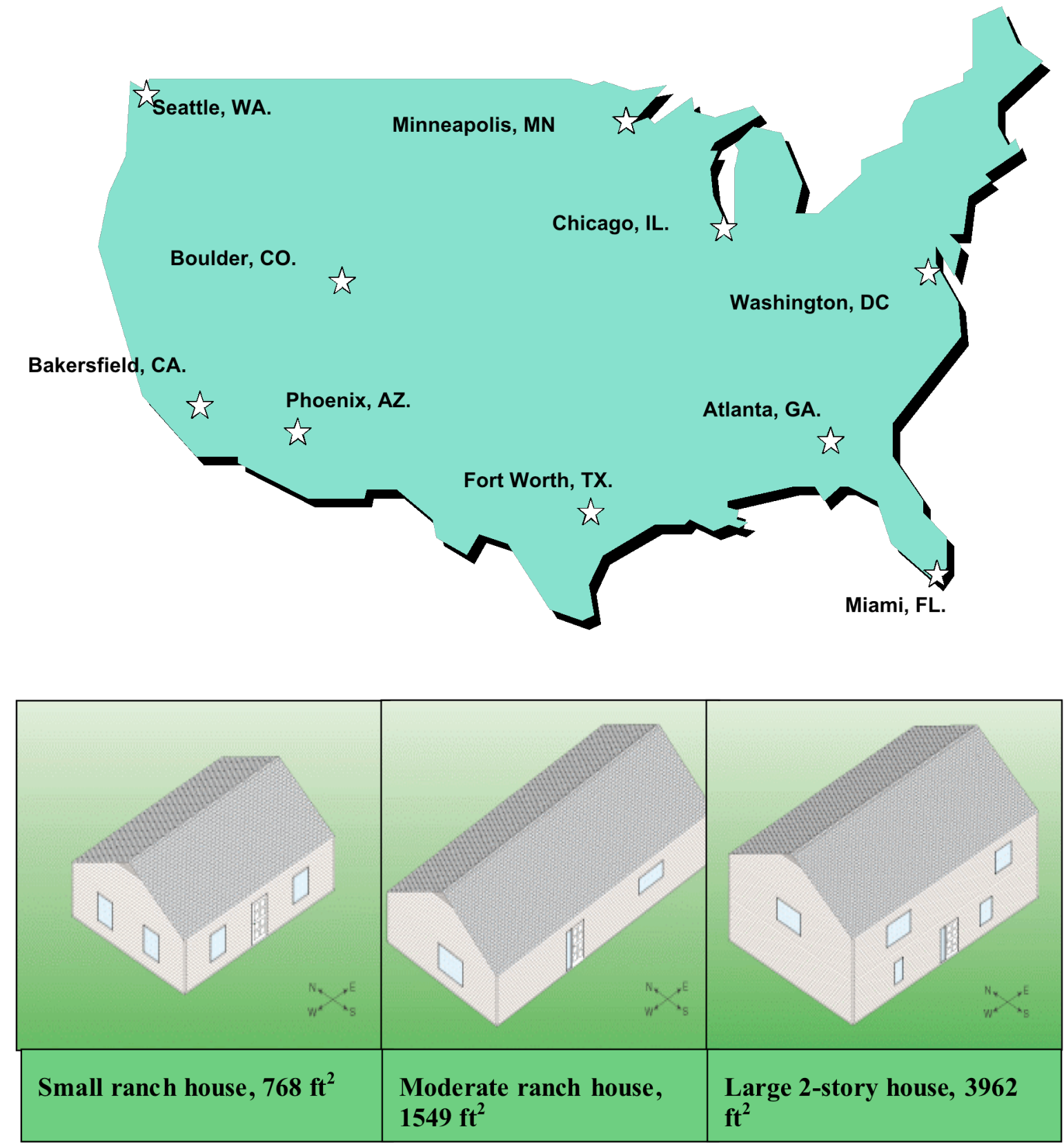

Figure 18. Locations and house designs used for savings estimates 
characteristics. The results, in the form of a reduction in heating and cooling loads, are shown in Table 9. Two bases were used for these energy savings calculations, reflecting the two possible initial conditions. The first is an uninsulated wall $\left(4.9 \mathrm{~h} \bullet \mathrm{ft}^{2} \bullet{ }^{\circ} \mathrm{F} / \mathrm{Btu}\right)$ and the second is an insulated wall $\left(10.6 \mathrm{~h} \cdot \mathrm{ft}^{2} \bullet{ }^{\circ} \mathrm{F} / \mathrm{Btu}\right)$.

$$
E=X\left(R_{\text {wall }}\right)^{Y} \quad \text { Eq. } 10
$$

where:

$E$ is annual energy consumption, MBtu/yr,

$X$ is the Coefficient from Table 8 ,

$R_{\text {wall }}$ is the R-value of the clear wall, American archaic units $\left(\mathrm{h} \bullet \mathrm{ft}^{2} \bullet{ }^{\circ} \mathrm{F} / \mathrm{Btu}\right)$, and

$Y$ is the Exponent from Table 8.

Table 8. Equation 9 parameters for heating and cooling energy consumption

\begin{tabular}{|l|l|r|r|}
\hline House from Figure 18 & City & Coefficient & Exponent \\
\hline Heating & & & \\
\hline Small Ranch & Atlanta & 34.3 & -0.345 \\
\hline & Bakersfield & 23.6 & -0.434 \\
\hline & Boulder & 67.1 & -0.291 \\
\hline & Chicago & 75.3 & -0.258 \\
\hline & Fort Worth & 26.2 & -0.397 \\
\hline & Miami & 2.36 & -0.768 \\
\hline & Minneapolis & 92.1 & -0.242 \\
\hline & Phoenix & 15.0 & -0.578 \\
\hline & Seattle & 58.9 & -0.290 \\
\hline & Sterling & 57.3 & -0.282 \\
\hline & Atlanta & 41.6 & -0.231 \\
\hline & Bakersfield & 27.2 & -0.288 \\
\hline & Boulder & 82.9 & -0.201 \\
\hline & Chicago & 95.9 & -0.177 \\
\hline & Fort Worth & 31.0 & -0.266 \\
\hline & Miami & 2.30 & -0.480 \\
\hline & Minneapolis & 118 & -0.166 \\
\hline & Phoenix & 15.8 & -0.384 \\
\hline & Seattle & 73.6 & -0.197 \\
\hline & Sterling & 71.8 & -0.192 \\
\hline & Atlanta & 67.6 & -0.291 \\
\hline & Bakersfield & 42.3 & -0.391 \\
\hline & Boulder & 132 & -0.271 \\
\hline & Chicago & 153 & -0.223 \\
\hline & Fort Worth & 50.6 & -0.327 \\
\hline & Margari & 3.97 & -0.487 \\
\hline
\end{tabular}




\begin{tabular}{|c|c|c|c|}
\hline House from Figure 18 & City & Coefficient & Exponent \\
\hline & Minneapolis & 189 & -0.207 \\
\hline & Phoenix & 25.0 & -0.492 \\
\hline & Seattle & 118 & -0.259 \\
\hline & Sterling & 117 & -0.245 \\
\hline \multicolumn{4}{|l|}{ COOLING } \\
\hline \multirow[t]{10}{*}{ Small Ranch } & Atlanta & 14.4 & -0.226 \\
\hline & Bakersfield & 22.3 & -0.213 \\
\hline & Boulder & 7.93 & -0.498 \\
\hline & Chicago & 7.43 & -0.399 \\
\hline & Fort Worth & 22.9 & -0.168 \\
\hline & Miami & 39.5 & -0.100 \\
\hline & Minneapolis & 6.17 & -0.422 \\
\hline & Phoenix & 41.8 & -0.194 \\
\hline & Seattle & 1.85 & -0.449 \\
\hline & Sterling & 10.4 & -0.283 \\
\hline \multirow[t]{10}{*}{ Moderate Ranch } & Atlanta & 16.6 & -0.190 \\
\hline & Bakersfield & 25.6 & -0.172 \\
\hline & Boulder & 7.72 & -0.417 \\
\hline & Chicago & 7.53 & -0.334 \\
\hline & Fort Worth & 27.7 & -0.136 \\
\hline & Miami & 51.1 & -0.086 \\
\hline & Minneapolis & 6.64 & -0.387 \\
\hline & Phoenix & 49.5 & -0.153 \\
\hline & Seattle & 1.73 & -0.379 \\
\hline & Sterling & 11.8 & -0.254 \\
\hline \multirow[t]{10}{*}{ Large 2-Story } & Atlanta & 28.4 & -0.205 \\
\hline & Bakersfield & 42.8 & -0.199 \\
\hline & Boulder & 12.8 & -0.481 \\
\hline & Chicago & 12.4 & -0.319 \\
\hline & Fort Worth & 47.2 & -0.130 \\
\hline & Miami & 86.6 & -0.093 \\
\hline & Minneapolis & 10.8 & -0.298 \\
\hline & Phoenix & 83.2 & -0.185 \\
\hline & Seattle & 2.88 & -0.451 \\
\hline & Sterling & 20.3 & -0.237 \\
\hline
\end{tabular}

To consider the sum of heating and cooling savings, it was necessary to convert these energy savings to dollars. Electricity and gas prices, taken from the ZipCode data base for each city, are shown in Table $10 .{ }^{16}$ The air conditioner was assumed to have an SEER of $9 \mathrm{Btu} / \mathrm{Wh}$ and the gas furnace a seasonal efficiency of $80 \%$. Duct losses were estimated at $20 \%$ for both seasons. 
These same house models and locations were also used to examine the impact of the air-leakage reduction products tested. This modeling effort used the DOE2.1E code and the ASHRAE handbook 'average' values for house component air leakage to place the retrofit window-wall gap reductions within the framework of the total house air leakage. The 'tight' window/wall gap size corresponds to the experimental results when the gap was filled with low-expansion polyurethane aerosol foam sealant, or when the gap face was covered with a special tape product. The 'moderate' condition corresponds to the experimental data when the gap was stuffed with fiberglass and the interior and exterior trim were caulked. The 'loose' condition corresponds to a foam tape product inserted into the gap. The range of annual energy cost savings for several cities is shown in Table 12. The annual savings for implementing the highest levels of insulation and the greatest reduction in air infiltration were about $7 \%$ for many cities. Lesser savings of around $1 \%$ resulted from lower levels of insulation and less rigorous air sealing efforts. The detailed results for multiple house types and gap treatments is found in Appendix B. These results were also used to generate the more visual savings bar charts included in the Best Practices Guide, included here in Appendix C. 
Table 9. Total house heating and cooling load savings (\%) due to wall retrofits for three prototypical houses

\begin{tabular}{|c|c|c|c|c|c|c|c|c|c|c|}
\hline \multirow{2}{*}{$\begin{array}{l}\text { Retrofit } \\
\text { Condition* }\end{array}$} & \multicolumn{5}{|c|}{ Cooling Load Savings (\%) } & \multicolumn{5}{|c|}{ Heating Load Savings (\%) } \\
\hline & W1 & W2 & W3 & W4 & W5 & W1 & W2 & W3 & W4 & W5 \\
\hline & \multicolumn{10}{|c|}{ Large 2-Story House } \\
\hline Atlanta & 18 & 4 & 5 & 6 & 9 & 25 & 6 & 7 & 8 & 13 \\
\hline Bakersfield & 18 & 4 & 5 & 6 & 9 & 32 & 8 & 9 & 11 & 17 \\
\hline Boulder & 38 & 9 & 11 & 13 & 21 & 23 & 5 & 6 & 8 & 12 \\
\hline Chicago & 27 & 6 & 8 & 9 & 14 & 20 & 4 & 5 & 6 & 10 \\
\hline Fort Worth & 12 & 3 & 3 & 4 & 6 & 28 & 7 & 8 & 9 & 14 \\
\hline Miami & 9 & 2 & 2 & 3 & 4 & 38 & 10 & 11 & 13 & 21 \\
\hline Minneapolis & 25 & 6 & 7 & 8 & 13 & 18 & 4 & 5 & 6 & 9 \\
\hline Phoenix & 17 & 4 & 4 & 5 & 8 & 38 & 10 & 11 & 13 & 21 \\
\hline Seattle & 36 & 9 & 11 & 12 & 19 & 23 & 5 & 6 & 7 & 12 \\
\hline \multirow[t]{2}{*}{ Sterling } & 21 & 5 & 6 & 7 & 11 & 21 & 5 & 6 & 7 & 11 \\
\hline & \multicolumn{10}{|c|}{ Moderate 1-story ranch house } \\
\hline Atlanta & 17 & 4 & 5 & 5 & 9 & 20 & 5 & 6 & 7 & 10 \\
\hline Bakersfield & 16 & 3 & 4 & 5 & 8 & 25 & 6 & 7 & 8 & 13 \\
\hline Boulder & 34 & 8 & 10 & 11 & 18 & 18 & 4 & 5 & 6 & 9 \\
\hline Chicago & 28 & 7 & 8 & 9 & 15 & 16 & 4 & 4 & 5 & 8 \\
\hline Fort Worth & 12 & 3 & 3 & 4 & 6 & 23 & 5 & 6 & 7 & 12 \\
\hline Miami & 8 & 2 & 2 & 2 & 4 & 38 & 9 & 11 & 13 & 20 \\
\hline Minneapolis & 32 & 8 & 9 & 11 & 17 & 15 & 3 & 4 & 5 & 8 \\
\hline Phoenix & 14 & 3 & 4 & 4 & 7 & 32 & 8 & 9 & 11 & 17 \\
\hline Seattle & 31 & 7 & 9 & 10 & 17 & 18 & 4 & 5 & 6 & 9 \\
\hline Sterling & 22 & 5 & 6 & 7 & 11 & 17 & 4 & 5 & 5 & 9 \\
\hline
\end{tabular}


Table 9. Total house heating and cooling load savings (\%) due to wall retrofits for three prototypical houses (cont.)

\begin{tabular}{|c|c|c|c|c|c|c|c|c|c|c|}
\hline \multirow[b]{2}{*}{$\begin{array}{l}\text { Retrofit } \\
\text { Condition* } \\
\end{array}$} & \multicolumn{5}{|c|}{ Cooling Load Savings (\%) } & \multicolumn{5}{|c|}{ Heating Load Savings (\%) } \\
\hline & W1 & $\mathbf{W 2}$ & W3 & W4 & & W1 & W2 & W3 & W4 & W5 \\
\hline & \multicolumn{10}{|c|}{ Small 1-story ranch house } \\
\hline Atlanta & 20 & 5 & 5 & 6 & 10 & 29 & 7 & 8 & 10 & 15 \\
\hline Bakersfield & 19 & 4 & 5 & 6 & 10 & 35 & 9 & 10 & 12 & 19 \\
\hline Boulder & 20 & 5 & 5 & 6 & 10 & 25 & 6 & 7 & 8 & 13 \\
\hline Chicago & 33 & 8 & 9 & 11 & 17 & 22 & 5 & 6 & 7 & 12 \\
\hline Fort Worth & 15 & 3 & 4 & 5 & 8 & 32 & 8 & 9 & 11 & 17 \\
\hline Miami & 9 & 2 & 2 & 3 & 5 & 53 & 15 & 17 & 20 & 31 \\
\hline Minneapolis & 34 & 8 & 10 & 12 & 18 & 21 & 5 & 6 & 7 & 11 \\
\hline Phoenix & 17 & 4 & 5 & 6 & 9 & 43 & 11 & 13 & 16 & 24 \\
\hline Seattle & 36 & 9 & 10 & 12 & 19 & 25 & 6 & 7 & 8 & 13 \\
\hline Sterling & 24 & 6 & 7 & 8 & 13 & 24 & 6 & 7 & 8 & 13 \\
\hline${ }^{*}$ Retrofit & \multicolumn{5}{|c|}{ Initial Condition } & \multicolumn{5}{|c|}{ Final Condition } \\
\hline$W 1$ & \multicolumn{5}{|c|}{ Uninsulated wall cavity } & \multicolumn{5}{|c|}{$\begin{array}{l}\text { Add cavity insulation and } 3 / 8 \text { in. fan-fold extruded } \\
\text { polystyrene with vinyl siding }\end{array}$} \\
\hline$W 2$ & \multicolumn{5}{|c|}{ Insulated cavity } & \multicolumn{5}{|c|}{$\begin{array}{l}\text { Add 3/8in. fan-fold extruded polystyrene with } \\
\text { vinyl siding }\end{array}$} \\
\hline$W 3$ & \multicolumn{5}{|c|}{ Insulated cavity } & \multicolumn{5}{|c|}{$\begin{array}{l}\text { Add 3/8in. fan-fold extruded polystyrene with foil } \\
\text { facing with vinyl siding }\end{array}$} \\
\hline$W 4$ & \multicolumn{5}{|c|}{ Insulated cavity } & \multicolumn{5}{|c|}{$\begin{array}{l}\text { Add } 1 / 2 \text { in.extruded polystyrene board with vinyl } \\
\text { siding }\end{array}$} \\
\hline$W 5$ & \multicolumn{5}{|c|}{ Insulated cavity } & \multicolumn{5}{|c|}{$\begin{array}{l}\text { Add lin. foil-faced polyisocyanurate foam with } \\
\text { vinyl siding }\end{array}$} \\
\hline
\end{tabular}


Table 10. Gas and electricity prices used to calculate annual savings

\begin{tabular}{|l|c|c|}
\hline City & Electricity $(\mathbf{c} / \mathbf{k W h})$ & Gas $\mathbf{( \$ \mathbf { M B t u } )}$ \\
\hline Atlanta & 7.66 & 10.50 \\
\hline Bakersfield & 9.92 & 9.85 \\
\hline Boulder & 6.73 & 9.63 \\
\hline Chicago & 8.35 & 8.87 \\
\hline Dallas & 8.44 & 9.47 \\
\hline Miami & 8.24 & 16.36 \\
\hline Minneapolis & 7.20 & 8.47 \\
\hline Phoenix & 7.55 & 11.89 \\
\hline Seattle & 5.19 & 9.87 \\
\hline Washington, DC & 7.47 & 12.73 \\
\hline
\end{tabular}

Table 11. Range of annual energy cost savings for multiple house types and wall retrofit options

\begin{tabular}{|c|c|c|c|}
\hline & \multicolumn{3}{|c|}{ Annual Energy Cost Savings (\%) } \\
\hline City & Average & Maximum & Minimum \\
\hline Atlanta & 3.5 & 7.6 & 1.2 \\
\hline Bakrsfld & 2.1 & 4.5 & 0.7 \\
\hline Boulder & 3.1 & 6.8 & 1.1 \\
\hline Chicago & 3.3 & 6.8 & 1.2 \\
\hline Dallas & 2.9 & 5.9 & 1.0 \\
\hline Miami & 1.7 & 3.0 & 0.7 \\
\hline Minneapolis & 3.3 & 6.9 & 1.2 \\
\hline Phoenix & 1.7 & 3.6 & 0.5 \\
\hline Seattle & 3.4 & 7.4 & 1.1 \\
\hline Washington DC & 3.5 & 7.7 & 1.2 \\
\hline
\end{tabular}




\section{Summary}

A Retrofit Best Practices Guide was developed to encourage homeowners to consider energy conservation issues whenever they modify their siding or windows. In support of this guide, an experimental program was implemented to measure the performance of a number of possible wall siding and window retrofit configurations, including thermal and air-leakage measurements.

For the clear wall, the increase in the thermal resistance was slightly greater than the R-value of the added insulation because of the dispersed air gaps between the old siding and the insulation as well as air gaps between the insulation and the new siding.

The change in overall wall R-value for the walls that contained a window is less than that of the clear walls because the major heat transfer path in this wall is the window itself. However, the energy savings in the wall with a window were about the same magnitude as those measured in the clear wall. This is most likely attributable to the greater proportion of wall framing present in the wall with a window construction, because external insulative sheathing is effective in reducing heat transfer through such framing heat transfer paths.

Experimental data from the wall-window assembly show that the performance of the singlepaned window with a low-e storm is almost as good as that of a replacement vinyl-framed double-paned window, confirming previous experimental results for these windows.

It is difficult to characterize the air leakage qualities that may be affected during a window retrofit job because there is such a wide variation in window size, relative to rough opening size, and workmanship. Nevertheless, a new test apparatus was designed to take measurements in a geometry representative of a typical retrofit window, and was sensitive enough to discern very small differences in the air leakage due to the various methods used to seal the gap around the perimeter of the window. The retrofit base wall was very nearly air tight. For the walls with windows, the leakage was of course much greater. The caulking and trim around the window frame, as well as the gap treatments used, had a significant effect on the air leakage flows. Considering not only the variability in initial application quality, but also the variability in application status over time, the Best Practice Guide included advice to use redundant techniques to reduce air leakage around their windows. That is, consumers were advised to combine appropriate trim and caulking with an effective gap filler, such as foam, fiberglass, or foam tape, or an effective gap cover, such as the bituminous tape. The air leakage experimental data reported here are comparable to those reported in the ASHRAE Fundamentals for window framing.

A computer model was also used to provide information for the Best Practices Guide. The experimental data for walls and windows were used in conjunction with this model to estimate the total annual energy savings for several typical houses in a number of different locations. 


\section{References}

1 “Improving America's Housing 2003, Measuring the Benefits of Home Remodeling,", Joint Center for Housing Studies of Harvard University.

${ }^{2}$ Retrofit Best Practices Guide: How to Save Energy When You Fix Up the Outside of Your Not-So-New House, ORNL/TM-2003/286, January 2004, http:/www.ornl.gov/sci/roofs+walls/facts/RetrofitBestPractices/homeownerguide15b1.pdf, shown in Appendix $\mathrm{C}$

${ }^{3} \mathrm{http}: / /$ www.irs.gov/newsroom/article/0,,id=154657,00.html

${ }^{4}$ J. Klems and G. Kelly, Symposium paper KC-03-12-1, ASHRAE Transactions, Vol. 109 Part 2, Jun

${ }^{5}$ ASHRAE Handbook of Fundamentals, American Society of Heating, Refrigerating, and Air Conditioning Engineers, Atlanta, GA, 2005

${ }^{6}$ Kosny, J. and Desjarlais, A. O., "Influence of Architectural Details on the Overall Thermal Performance of Residential Wall Systems," Journal of Thermal Insulation and Building Envelopes, Vol. 18, July 1994.

${ }^{7}$ ASTM International, West Conshohocken PA, 19428-2959, www.ASTM.org

${ }^{8}$ J. Klems and G. Kelly, Symposium paper KC-03-12-1, ASHRAE Transactions, Vol. 109 Part 2, June 28-July 2, 2003

9 ASTM E283-91 (reapproved 1999) "Standard Test Method for Determining Rate of Air Leakage Through Exterior Windows, Curtain Walls and Doors Under Specified Pressure Differences Across the Specimen, ASTM International, PA

${ }^{10}$ Sherman, M.H. and D. T. Grimsrud, "Infiltration-pressurization correlations: Simplified physical modeling”, ASHRAE Transactions 86 (2):778, 1980

${ }^{11}$ M. H. Sherman and D. T. Grimsrud, "Measurement of Infiltration Using Fan Pressurization and

Weather Data," Proceedings of the Air Infiltration Instrumentation and Measuring Techniques: 1st AIC Conference, Windsor Great Park, Berkshire, UK, October 6-8, 1980, pp 277-322

${ }^{12}$ The Minneapolis Blower Door ${ }^{\mathrm{TM}}$, The Energy Conservatory, Minneapolis, MN, www.energyconservatory.com

${ }^{13}$ Ronald H Dieck, MEASUREMENT UNCERTAINTY METHODS AND APPLICATIONS, Second Edition, The Instrumentation, Systems, and Automation Society, Research Triangle Park, NC, 1997

${ }^{14}$ ASHRAE Handbook of Fundamentals, 2001, Table 1 in Chap. 26

${ }^{15}$ Kosny, J. et al, "Energy Benefits of Application of Massive Walls in Residential Buildings," PERFORMANCE OF EXTERIOR ENVELOPES OF WHOLE BUILDINGS VIII:

INTEGRATION OF BUILDING ENVELOPES, Conference Proceedings, Dec. 2-7, 2001, Clearwater Beach, FL, ASHRAE

${ }^{16}$ T.K. Stovall, SUPPORTING DOCUMENTATION FOR THE 1997 REVISION TO THE DOE INSULATION FACT SHEET, ORNL-6907, August, 1997, ADDENDUM published, 2002 


\section{Appendix A Literature Resources}

The online site for Home Energy (http://homeenergy.org/)contains a wealth of helpful information. Some of the articles you may want to read include:

- "Energy-Efficient Window Retrofits: Install With Care"

- “ 'Superwindow' Retrofits Show Significant Energy Savings”

- "Don't Throw that Window Out the Window!"

- "Energy Efficient Remodeling-Grab the Opportunity"

- "Creating Windows of Energy-Saving Opportunities"

- "Selecting Windows for Energy Efficiency"

- "What Should I Do About My Windows?"

The following are web sites for consumer guides on how windows work and other helpful ideas:

www.uoxray.uoregon.edu/phys161/consumer_guide.pdf

http://www.eere.energy.gov/buildings/homes/buyingwindows.cfm

How to select an energy efficient window: www.efficientwindows.org

A large number of useful technology fact sheets are available from DOE. These were developed for new home construction, but contain a wealth of information helpful to people retrofitting existing homes as well, especially if your retrofit project includes adding on to your home. Go to the DOE Building Technology publications web site. Among other topics, these fact sheets include detailed information about insulating floors, basements, and crawlspaces; detailed information about air-sealing, especially between the ceiling and attic; and information about choosing and installing a weather resistant barrier on the exterior wall beneath the new siding.

LBNL HVAC Best Practices Guide (http://ducts.lbl.gov/HVACRetrofitguide.html).

Researchers at LBNL have developed and licensed an aerosol duct sealing technology (see http://ducts.lbl.gov/aerosol/index.html ). Tests on a number of houses have shown that this method can be $50 \%$ more effective than traditional techniques, and requires less labor than other approaches. You can read about these test results at:

http://www.ornl.gov/ webworks/cppr/y2001/rpt/112576.pdf

ASTM E2112 Standard Practice for Installation of Exterior Windows, Doors and Skylights Vinyl Siding Institute (http://vinylsiding.org/)

Vinyl Siding Installation from Fine Home Building 


\section{Appendix B: Detailed Model Results}

Table 12. Total house heating and cooling loads with differences in the window/wall gap treatment for three different prototypical houses.

\begin{tabular}{|c|c|c|c|c|c|c|}
\hline City & $\begin{array}{l}\text { Window/wall } \\
\text { gap size }\end{array}$ & $\begin{array}{c}\text { House } \\
\text { Size }\end{array}$ & $\begin{array}{c}\text { Cooling } \\
\text { (kWh) }\end{array}$ & $\begin{array}{c}\text { Heating } \\
\text { (MBtu) }\end{array}$ & $\begin{array}{l}\text { Annual } \\
\text { Cost (\$) }\end{array}$ & Saving (\%) \\
\hline Atlanta & Tight & small & 2040 & 12.4 & $\$ 277$ & 2.9 \\
\hline Atlanta & Tight & medium & 2520 & 18.3 & $\$ 392$ & 3.7 \\
\hline Atlanta & Tight & large & 3900 & 25.4 & $\$ 559$ & 7.6 \\
\hline Atlanta & Moderate & small & 2040 & 12.5 & $\$ 279$ & 2.3 \\
\hline Atlanta & Moderate & medium & 2530 & 18.4 & $\$ 394$ & 3.1 \\
\hline Atlanta & Moderate & large & 3920 & 26.3 & $\$ 574$ & 5.1 \\
\hline Atlanta & Loose & small & 2050 & 12.7 & $\$ 282$ & 1.2 \\
\hline Atlanta & Loose & medium & 2540 & 18.7 & $\$ 399$ & 1.8 \\
\hline Atlanta & Loose & large & 3930 & 26.6 & $\$ 579$ & 4.2 \\
\hline Atlanta & Open & small & 2060 & 12.8 & $\$ 285$ & 0.0 \\
\hline Atlanta & Open & medium & 2560 & 19.1 & $\$ 407$ & 0.0 \\
\hline Atlanta & Open & large & 3970 & 28.0 & $\$ 604$ & 0.0 \\
\hline Bakersfield & Tight & small & 3630 & 6.9 & $\$ 277$ & 1.7 \\
\hline Bakersfield & Tight & medium & 4510 & 10.6 & $\$ 374$ & 2.3 \\
\hline Bakersfield & Tight & large & 7270 & 12.7 & $\$ 537$ & 4.5 \\
\hline Bakersfield & Moderate & small & 3630 & 7.0 & $\$ 278$ & 1.3 \\
\hline Bakersfield & Moderate & medium & 4510 & 10.7 & $\$ 376$ & 1.9 \\
\hline Bakersfield & Moderate & large & 7320 & 13.1 & $\$ 546$ & 2.9 \\
\hline Bakersfield & Loose & small & 3640 & 7.1 & $\$ 280$ & 0.7 \\
\hline Bakersfield & Loose & medium & 4530 & 10.8 & $\$ 379$ & 1.1 \\
\hline Bakersfield & Loose & large & 7330 & 13.3 & $\$ 549$ & 2.4 \\
\hline Bakersfield & Open & small & 3650 & 7.2 & $\$ 282$ & 0.0 \\
\hline Bakersfield & Open & medium & 4550 & 11.0 & $\$ 383$ & 0.0 \\
\hline Bakersfield & Open & large & 7400 & 13.9 & $\$ 562$ & 0.0 \\
\hline Boulder & Tight & small & 600 & 28.0 & $\$ 440$ & 2.6 \\
\hline Boulder & Tight & medium & 680 & 40.7 & $\$ 634$ & 3.2 \\
\hline Boulder & Tight & large & 1020 & 53.5 & $\$ 838$ & 6.8 \\
\hline Boulder & Moderate & small & 600 & 28.1 & $\$ 442$ & 2.1 \\
\hline Boulder & Moderate & medium & 680 & 40.9 & $\$ 637$ & 2.6 \\
\hline Boulder & Moderate & large & 1030 & 54.9 & $\$ 858$ & 4.5 \\
\hline Boulder & Loose & small & 600 & 28.4 & $\$ 447$ & 1.1 \\
\hline Boulder & Loose & medium & 680 & 41.4 & $\$ 645$ & 1.5 \\
\hline Boulder & Loose & large & 1030 & 55.3 & $\$ 865$ & 3.8 \\
\hline Boulder & Open & small & 610 & 28.7 & $\$ 452$ & 0.0 \\
\hline Boulder & Open & medium & 690 & 42.0 & $\$ 655$ & 0.0 \\
\hline Boulder & Open & large & 1050 & 57.5 & $\$ 899$ & 0.0 \\
\hline Chicago & Tight & small & 680 & 35.1 & $\$ 513$ & 2.9 \\
\hline Chicago & Tight & medium & 770 & 50.8 & $\$ 734$ & 3.7 \\
\hline Chicago & Tight & large & 1410 & 73.5 & $\$ 1,074$ & 6.8 \\
\hline Chicago & Moderate & small & 680 & 35.3 & $\$ 516$ & 2.3 \\
\hline Chicago & Moderate & medium & 770 & 51.1 & $\$ 739$ & 3.0 \\
\hline Chicago & Moderate & large & 1420 & 75.4 & $\$ 1,101$ & 4.5 \\
\hline Chicago & Loose & small & 690 & 35.7 & $\$ 522$ & 1.2 \\
\hline
\end{tabular}




\begin{tabular}{|c|c|c|c|c|c|c|}
\hline City & $\begin{array}{l}\text { Window/wall } \\
\text { gap size }\end{array}$ & $\begin{array}{c}\text { House } \\
\text { Size }\end{array}$ & $\begin{array}{l}\text { Cooling } \\
\text { (kWh) }\end{array}$ & $\begin{array}{c}\text { Heating } \\
\text { (MBtu) }\end{array}$ & $\begin{array}{l}\text { Annual } \\
\text { Cost (\$) }\end{array}$ & Saving (\%) \\
\hline Chicago & Loose & medium & 770 & 51.8 & $\$ 749$ & 1.7 \\
\hline Chicago & Loose & large & 1420 & 76.0 & $\$ 1,110$ & 3.7 \\
\hline Chicago & Open & small & 690 & 36.2 & $\$ 529$ & 0.0 \\
\hline Chicago & Open & medium & 780 & 52.8 & $\$ 762$ & 0.0 \\
\hline Chicago & Open & large & 1440 & 79.1 & $\$ 1,153$ & 0.0 \\
\hline Dallas & Tight & small & 3990 & 8.1 & $\$ 279$ & 2.6 \\
\hline Dallas & Tight & medium & 5020 & 12.0 & $\$ 379$ & 3.3 \\
\hline Dallas & Tight & large & 8700 & 16.8 & $\$ 597$ & 5.9 \\
\hline Dallas & Moderate & small & 4000 & 8.2 & $\$ 281$ & 2.0 \\
\hline Dallas & Moderate & medium & 5040 & 12.1 & $\$ 381$ & 2.7 \\
\hline Dallas & Moderate & large & 8780 & 17.5 & $\$ 610$ & 3.9 \\
\hline Dallas & Loose & small & 4030 & 8.3 & $\$ 284$ & 1.0 \\
\hline Dallas & Loose & medium & 5080 & 12.4 & $\$ 386$ & 1.6 \\
\hline Dallas & Loose & large & 8810 & 17.7 & $\$ 614$ & 3.2 \\
\hline Dallas & Open & small & 4050 & 8.4 & $\$ 287$ & 0.0 \\
\hline Dallas & Open & medium & 5120 & 12.7 & $\$ 392$ & 0.0 \\
\hline Dallas & Open & large & 8930 & 18.7 & $\$ 635$ & 0.0 \\
\hline Miami & Tight & small & 8300 & 0.3 & $\$ 331$ & 1.7 \\
\hline Miami & Tight & medium & 10680 & 0.5 & $\$ 429$ & 2.2 \\
\hline Miami & Tight & large & 17630 & 0.9 & $\$ 712$ & 3.0 \\
\hline Miami & Moderate & small & 8330 & 0.3 & $\$ 332$ & 1.3 \\
\hline Miami & Moderate & medium & 10720 & 0.5 & $\$ 431$ & 1.8 \\
\hline Miami & Moderate & large & 17800 & 0.9 & $\$ 719$ & 1.9 \\
\hline Miami & Loose & small & 8380 & 0.3 & $\$ 335$ & 0.7 \\
\hline Miami & Loose & medium & 10800 & 0.5 & $\$ 434$ & 1.0 \\
\hline Miami & Loose & large & 17850 & 1.0 & $\$ 722$ & 1.6 \\
\hline Miami & Open & small & 8440 & 0.3 & $\$ 337$ & 0.0 \\
\hline Miami & Open & medium & 10900 & 0.5 & $\$ 439$ & 0.0 \\
\hline Miami & Open & large & 18120 & 1.0 & $\$ 733$ & 0.0 \\
\hline Minneapolis & Tight & small & 540 & 44.1 & $\$ 602$ & 2.9 \\
\hline Minneapolis & Tight & medium & 540 & 63.6 & $\$ 860$ & 3.6 \\
\hline Minneapolis & Tight & large & 1180 & 92.6 & $\$ 1,266$ & 6.9 \\
\hline Minneapolis & Moderate & small & 540 & 44.4 & $\$ 606$ & 2.3 \\
\hline Minneapolis & Moderate & medium & 540 & 64.0 & $\$ 865$ & 3.0 \\
\hline Minneapolis & Moderate & large & 1200 & 95.0 & $\$ 1,298$ & 4.6 \\
\hline Minneapolis & Loose & small & 550 & 44.9 & $\$ 613$ & 1.2 \\
\hline Minneapolis & Loose & medium & 550 & 64.8 & $\$ 876$ & 1.7 \\
\hline Minneapolis & Loose & large & 1200 & 95.8 & $\$ 1,308$ & 3.8 \\
\hline Minneapolis & Open & small & 550 & 45.5 & $\$ 620$ & 0.0 \\
\hline Minneapolis & Open & medium & 560 & 66.0 & $\$ 892$ & 0.0 \\
\hline Minneapolis & Open & large & 1220 & 99.6 & $\$ 1,360$ & 0.0 \\
\hline Phoenix & Tight & small & 7200 & 2.9 & $\$ 312$ & 1.3 \\
\hline Phoenix & Tight & medium & 9220 & 4.6 & $\$ 416$ & 1.8 \\
\hline Phoenix & Tight & large & 14570 & 5.5 & $\$ 624$ & 3.6 \\
\hline Phoenix & Moderate & small & 7210 & 3.0 & $\$ 313$ & 1.0 \\
\hline Phoenix & Moderate & medium & 9240 & 4.7 & $\$ 417$ & 1.5 \\
\hline Phoenix & Moderate & large & 14660 & 5.8 & $\$ 632$ & 2.4 \\
\hline Phoenix & Loose & small & 7230 & 3.0 & $\$ 315$ & 0.5 \\
\hline Phoenix & Loose & medium & 9270 & 4.7 & $\$ 420$ & 0.8 \\
\hline
\end{tabular}




\begin{tabular}{|c|c|c|c|c|c|c|}
\hline City & $\begin{array}{l}\text { Window/wall } \\
\text { gap size }\end{array}$ & $\begin{array}{c}\text { House } \\
\text { Size }\end{array}$ & $\begin{array}{l}\text { Cooling } \\
\text { (kWh) }\end{array}$ & $\begin{array}{c}\text { Heating } \\
\text { (MBtu) }\end{array}$ & $\begin{array}{l}\text { Annual } \\
\text { Cost (\$) }\end{array}$ & Saving (\%) \\
\hline Phoenix & Loose & large & 14700 & 5.8 & $\$ 634$ & 2.0 \\
\hline Phoenix & Open & small & 7250 & 3.1 & $\$ 316$ & 0.0 \\
\hline Phoenix & Open & medium & 9310 & 4.8 & $\$ 423$ & 0.0 \\
\hline Phoenix & Open & large & 14880 & 6.2 & $\$ 647$ & 0.0 \\
\hline Seattle & Tight & small & 170 & 25.6 & $\$ 398$ & 2.8 \\
\hline Seattle & Tight & medium & 180 & 37.8 & $\$ 588$ & 3.3 \\
\hline Seattle & Tight & large & 260 & 51.6 & $\$ 802$ & 7.4 \\
\hline Seattle & Moderate & small & 170 & 25.7 & $\$ 401$ & 2.2 \\
\hline Seattle & Moderate & medium & 180 & 38.1 & $\$ 591$ & 2.8 \\
\hline Seattle & Moderate & large & 260 & 53.0 & $\$ 823$ & 4.9 \\
\hline Seattle & Loose & small & 170 & 26.0 & $\$ 405$ & 1.1 \\
\hline Seattle & Loose & medium & 180 & 38.5 & $\$ 598$ & 1.6 \\
\hline Seattle & Loose & large & 260 & 53.5 & $\$ 831$ & 4.1 \\
\hline Seattle & Open & small & 170 & 26.3 & $\$ 410$ & 0.0 \\
\hline Seattle & Open & medium & 180 & 39.1 & $\$ 608$ & 0.0 \\
\hline Seattle & Open & large & 260 & 55.8 & $\$ 866$ & 0.0 \\
\hline $\begin{array}{c}\text { Washington } \\
\text { DC }\end{array}$ & Tight & small & 1320 & 24.7 & $\$ 539$ & 2.9 \\
\hline $\begin{array}{c}\text { Washington } \\
\text { DC }\end{array}$ & Tight & medium & 1530 & 36.0 & $\$ 771$ & 3.6 \\
\hline $\begin{array}{c}\text { Washington } \\
\text { DC }\end{array}$ & Tight & large & 2870 & 51.2 & $\$ 1,119$ & 7.7 \\
\hline $\begin{array}{c}\text { Washington } \\
\text { DC }\end{array}$ & Moderate & small & 1330 & 24.9 & $\$ 542$ & 2.3 \\
\hline $\begin{array}{l}\text { Washington } \\
\text { DC }\end{array}$ & Moderate & medium & 1540 & 36.3 & $\$ 776$ & 3.0 \\
\hline $\begin{array}{c}\text { Washington } \\
\text { DC }\end{array}$ & Moderate & large & 2900 & 52.6 & $\$ 1,150$ & 5.2 \\
\hline $\begin{array}{c}\text { Washington } \\
\text { DC }\end{array}$ & Loose & small & 1340 & 25.2 & $\$ 549$ & 1.2 \\
\hline $\begin{array}{c}\text { Washington } \\
\text { DC }\end{array}$ & Loose & medium & 1550 & 36.8 & $\$ 786$ & 1.7 \\
\hline $\begin{array}{c}\text { Washington } \\
\text { DC }\end{array}$ & Loose & large & 2920 & 53.2 & $\$ 1,161$ & 4.3 \\
\hline $\begin{array}{c}\text { Washington } \\
\text { DC }\end{array}$ & Open & small & 1340 & 25.5 & $\$ 555$ & 0.0 \\
\hline $\begin{array}{c}\text { Washington } \\
\text { DC }\end{array}$ & Open & medium & 1560 & 37.4 & $\$ 800$ & 0.0 \\
\hline $\begin{array}{l}\text { Washington } \\
\text { DC }\end{array}$ & Open & large & 3000 & 55.6 & $\$ 1,213$ & 0.0 \\
\hline
\end{tabular}




\section{Appendix C: Retrofit Best Practices Guide}


 \\ How to Save Energy When You \\ Fix Up the Outside of Your Not-So-New House}

The Challenge and the Opportunity 1

Step 1: Your House Today 1

How does a house "work"? 1

Inspecting your house 2

Moisture 4

Walls 4

Windows 4

Step 2: Your Options 5

Replacement Windows 5

Storm Windows 7

Walls 7

How Much Can You Save? 10

Step 3: Choosing Your Contractor 11

Other Energy Saving Opportunities in Your Home 12

Attics 13

Basements and Crawlspaces 14

Where To Find Out More 15

For the Homeowner 15

For the Builder/Contractor 15

Acknowledgements 16

House Inspection Checklist 17

Window Replacement Checklist 18

Appendix A: Savings Estimates for Ten Cities 19
The Challenge and the Opportunity

Few people add siding or change their windows just to reduce their energy bills. But whatever your reasons for retrofitting your home, this will be an important opportunity to improve your home's energy efficiency. Not only will this reduce your utility bills, it will also improve your comfort level and improve our environment.

Retrofitting your house is a big deal, and you shouldn't underestimate the effort that will be required to plan the job properly. The energy conservation rewards can be great, but there are also pitfalls that you'll want to avoid. That's what this Best Practices Guide is all about. We can't cover all the issues in these few pages, but we'll tell you some things you need to know if you're changing your siding or windows, and tell you where to learn more about other changes you may want to make to your house.

What exactly is a 'best practice'? To put this guide together, we've tested products, talked to contractors and manufacturers, and reviewed the results from a large number of house retrofits. Of course, 'best' will vary according to the situation. That's why you must start with a careful examination of your house and its existing condition.

\section{Step 1: Your House Today}

\section{How does a house "work"?}

Step back and take a good look at your house. Think of your house as a machine. It may not seem like something so complicated, but it's made up of a 
large number of small parts and connections between these parts. If any of these parts or connections are damaged, they will cause problems in other parts of the structure. When a new part is added onto the house, or an existing part is replaced, it has to be done carefully. Just as you wouldn't want to leave a wrench in the gears of a machine, you don't want to change your house in a way that interferes with any of the existing working parts.

This can be tricky because it involves appreciating what is working well, which can be much more difficult than spotting problems. Most often, these nearly invisible 'gears' are related to moisture management - both keeping moisture out of your house and making sure that any moisture that does get into your house has an escape path. The rain plane (see "Rain Plane" box) on the exterior walls is one such working system.

Your house is also built with back up systems that you probably take for granted. For example, your bathrooms should be vented to the outside so that moisture doesn't enter the rest of your house or attic. But the fans may be too small, or may not run long enough (especially if you turn them off because they're noisy). In this case, the back-up system is the ventilation within the house and attic spaces. If you change that back-up system, the bathroom moisture could become a problem, even though you haven't changed the bathroom itself.

The windows are another complicated system. They serve multiple functions, letting in light and sometimes air, but keeping out rain and bad weather. Windows are especially important from an energy conservation standpoint. As Fig. 1 shows, energy travels many paths through a window unit. A variety of window designs have evolved to reduce the energy traveling through each of

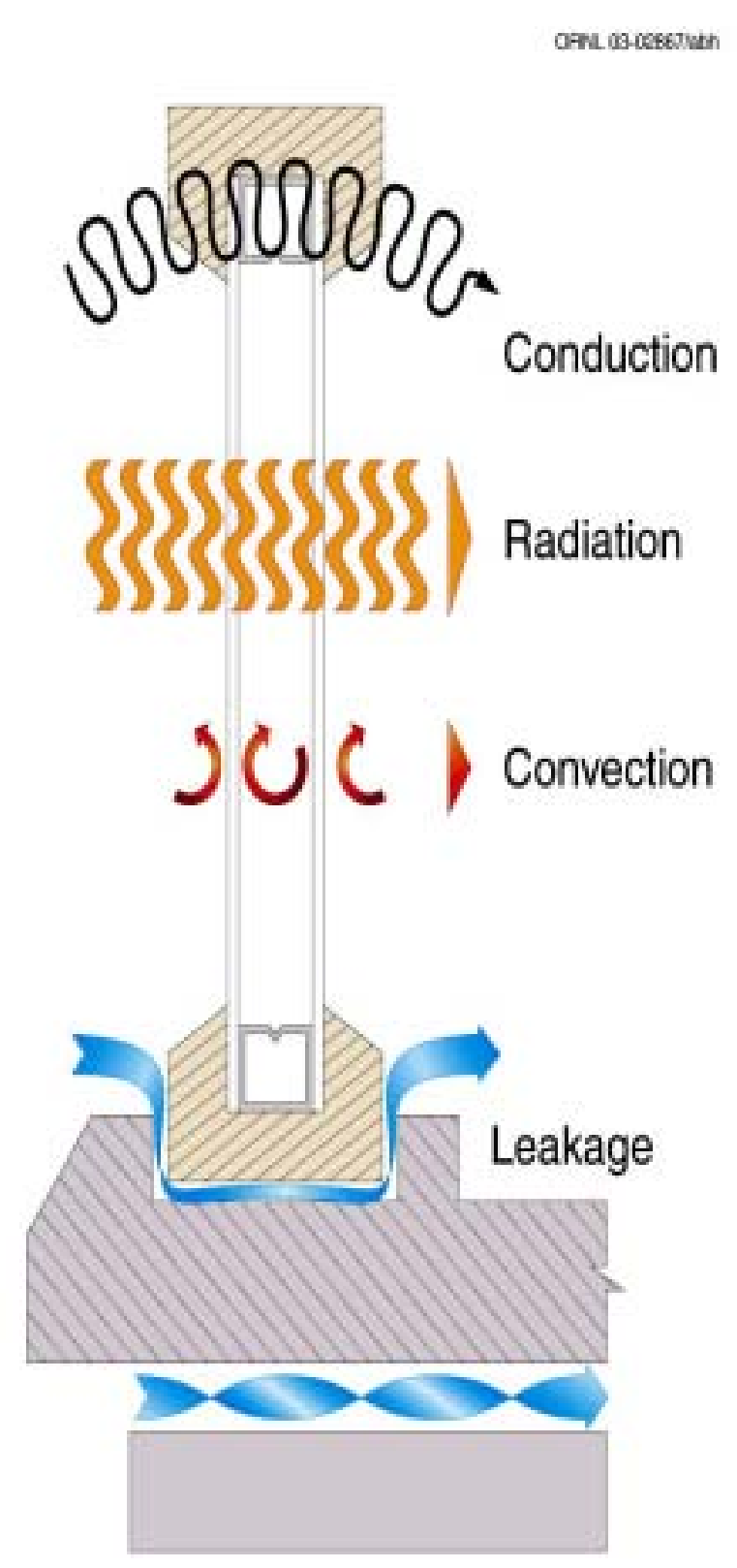

Figure 1. Energy paths through a

these paths, while still providing the open views and light you want in your home.

\section{Inspecting your house}

A checklist is available at the back of this guide to help you organize your home retrofit inspection. Another extensive checklist, designed for new homes but useful for retrofit as well, is available as a 
The RAIN PLANE is the true boundary between the inner and outer portions of your wall. The location of the rain plane is especially important when you replace your windows or add siding, because the window flashing for every window must be properly integrated with this rain plane surface, which is not necessarily the exterior siding surface. If you seal the frames improperly, or to the wrong surface, you will likely allow water to get inside the wall cavities beneath the window frames, where it will eventually damage the insulation and wood framing.

Many people think that all the rain is stopped on the outside of their siding. But many siding systems are actually designed to breath so that the wall system can dry out after the rain stops. In a home with wood, aluminum, or vinyl siding, there is a small air space between the siding and the exterior building sheathing. This sheathing is usually covered with housewrap or with asphalt felt building paper, see Fig. 2.

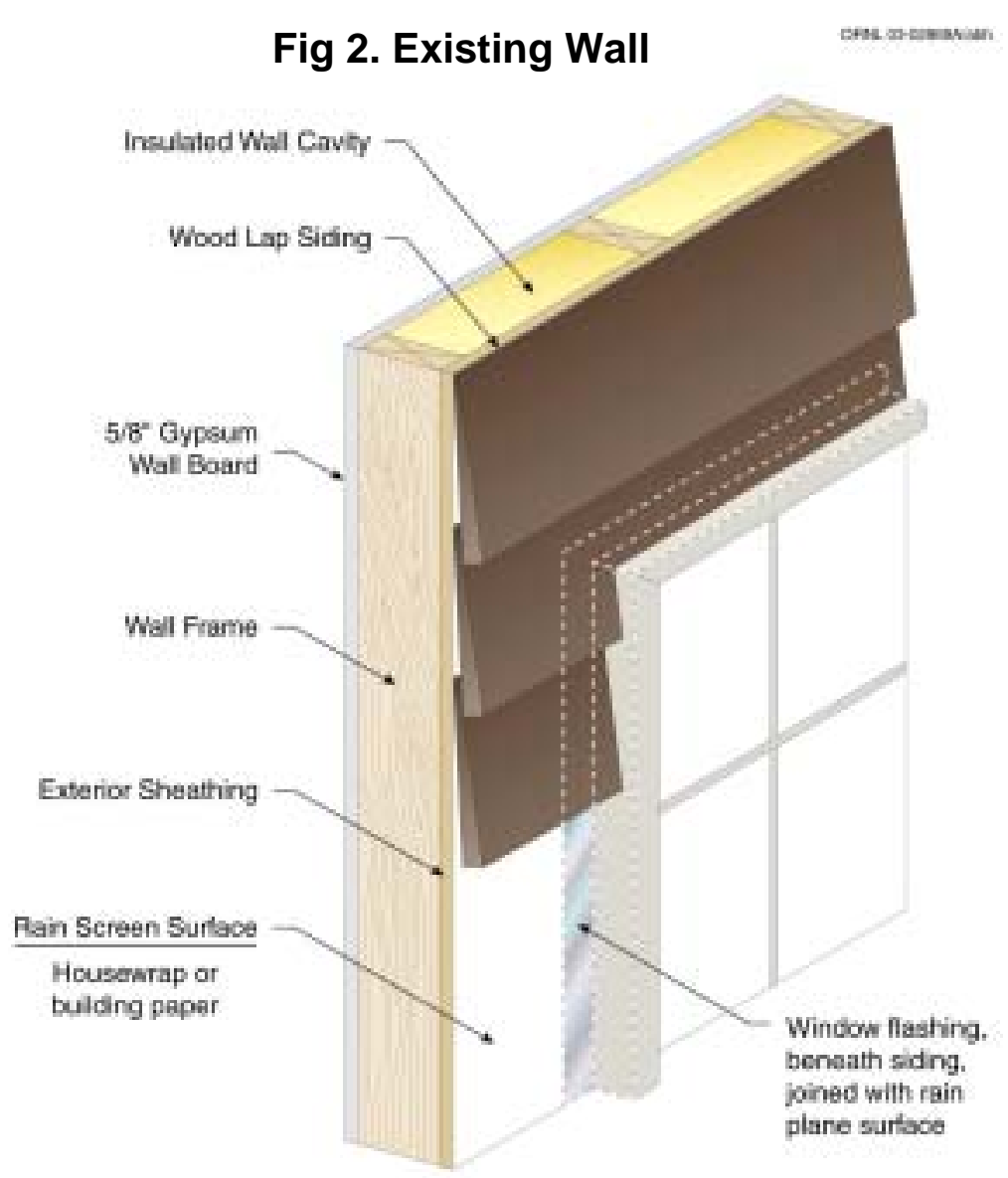

Fig. 3. Retrofit Wall

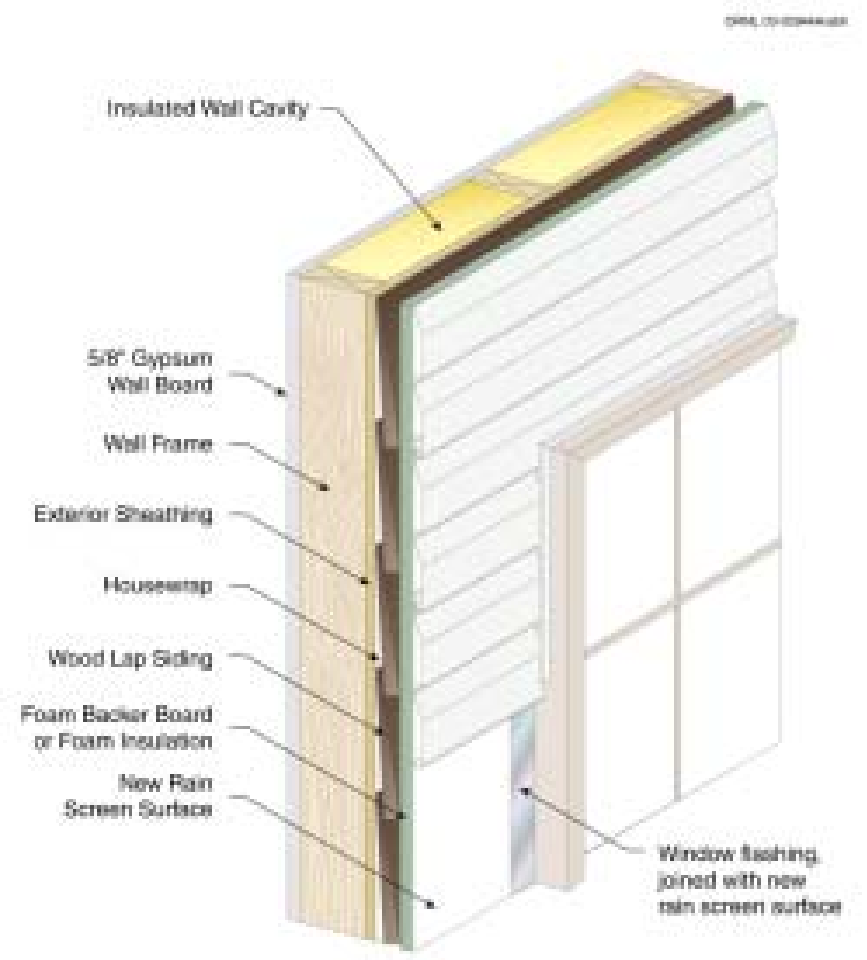

This surface is the true rain plane, because this is the barrier that keeps rain out of the interior of the wall. (Usually there are openings at the bottom of the wall to allow most of the trapped water to drain, while air circulation through the weep holes in the siding is used to dry out the rest.)

So when you add new siding on top of old (see Fig. 3), you often move the rain plane to a new location, usually to the exterior surface of the new siding's underlayment! 
technology fact sheet on DOE's Building Technology publications web site.

\section{Moisture}

Whole books have been written about moisture management in buildings. These books are filled with horror stories about buildings that have failed due to moisture. Many of these reference sources are listed in the back of this guide, and a bit of homework on your part now could save you time, trouble, and money. We can't duplicate all that information here, but will cover a few key concepts that are directly associated with common building retrofits. In general, there are two goals in moisture management: (1) keep water out and (2) provide escape paths for any moisture that does get into your house. These escape paths are especially important because few houses are built perfectly enough to keep out all water and because moisture also enters your house in other ways. For example, when you breathe you are putting moisture into your home.

If you find blistered paint, peeling or bubbled wallpaper, rotten windowsills, stained paint, mildew, or mold, you have a moisture problem. You need to investigate until you find the root of the problem. Don't just fix the visible symptoms. For example, blistered paint is usually caused by moisture trapped between the surface and the paint. If you just scrape and re-paint the wall without fixing the moisture source, the new paint will probably blister too. Similarly, cleaning up a moldy surface isn't a permanent fix if moisture is still available to support the growth of new mold colonies.

Besides looking for moisture problems, you also need to figure out how moisture is managed successfully within any building component that you'll be changing. For example, if you are going to replace siding that shows no signs of moisture damage, look to see how that siding was installed. Very often you'll find a ventilation space behind the siding, and you'll want to include this design element in your retrofit siding job.

Walls

This is the time to find out whether or not your walls are properly insulated. You need to look for both cavity insulation and insulating sheathing. You may be able to see into the wall cavity by removing a switch cover or an electrical outlet cover (after turning off the breaker or removing the fuse for the outlet), or by looking in your attic if any of the exterior rooms have a dropped ceiling. Go to DOE's Energy Savers web site for more details on how to safely perform this inspection.

If you are going to install new siding on your house, you will need to remove a small piece of your existing siding to find out how the wall was constructed. You'll be able to see whether insulating sheathing is already in place, and whether the housewrap or building paper is in good condition. You'll also be able to identify the location of the current rain plane (see "Rain Plane" box).

\section{Windows}

Your house may have more than one type of window, and the outdoor exposure and installation quality could vary, so check each and every window. You will find a checklist for this purpose at the back of this guide. Identify the types of windows in place: the number of panes, the framing material(s), and any labels that indicate special coatings or safety glass. Look at the window sills and the walls beneath the windows for signs of moisture or rotting wood. Look at the condition of the caulking and weather stripping. Check the operability of each window - does it open and close properly? Consider the orientation and shading of each window. They could influence your choice of special coatings 
for replacement or storm windows. Think back to some cold days last winter - do you remember any particular drafty locations near your windows? Look at the trim fit and caulking between the wall and the window on both the inside and outside of your house.

\section{Step 2: Your Options}

If you are both residing your walls and replacing windows, it's best to do it all together as a single job with a qualified contractor who can take that opportunity to carefully incorporate the window flashing into the wall's rain plane (see Rain Plane box). This is also the best approach if the new siding will make your wall thicker, because the new window jambs can be sized to fit the new wall thickness.

If you have to do window and wall retrofits separately, either for budget or convenience reasons, DO THE WINDOWS FIRST. Also, remember to plan for the new wall thickness when you order the jambs for your new windows.

Keep installation details in mind too. We all know that increasing the R-values of walls or windows will save energy, but controlling air and moisture leaks can be just as important.

\section{Replacement Windows}

When you choose new windows, you'll be balancing performance and price. Think about the long-term consequences when you make that decision. Better quality windows will save significant amounts of energy by reducing window heat losses and air leaks. Better windows will also reduce condensation which will in turn reduce window sill moisture problems. There are a number of features to consider when comparing windows: window type, number of panes, frame materials, special coatings, and gas fillers. The Efficient Windows Collaborative can help you select an energy-efficient window.

The window type is often selected to match the original windows, but you may want to consider other types as well. From an energy conservation standpoint, windows that compress a gasket, rather than a sliding seal, will typically allow less air to leak in and out of your house. So you should consider casement or awning windows even if your existing windows are double or single-hung sliding windows.

Most consumers understand that singlepane windows lose more energy than double-pane or triple-pane windows because of the insulating air space between the layers. But the multiple panes of glass will also reduce the solar heat gain entering your house (see Fig. 4). Sometimes special inert gases are used to fill the space between panes and reduce the heat losses still further. Coatings may also be placed on the glass to reduce the radiation energy loss (or gain, during the summer) while still permitting visible light to pass through the window. The window label (see "Window Labels" box) will help you consider all these energy performance factors.

The frame also influences the energy performance of the window. Frames can be made from a variety of materials. Aluminum is light, strong, and durable but has a high thermal conductance. Wood offers good insulating value but must be protected from the weather. Vinyl is a very versatile plastic with good insulating value that can be reinforced to increase its strength. Fiberglass has good structural strength and durability and requires minimal maintenance. Hollow sections of a fiberglass frame can be insulated to further decrease heat loss. 

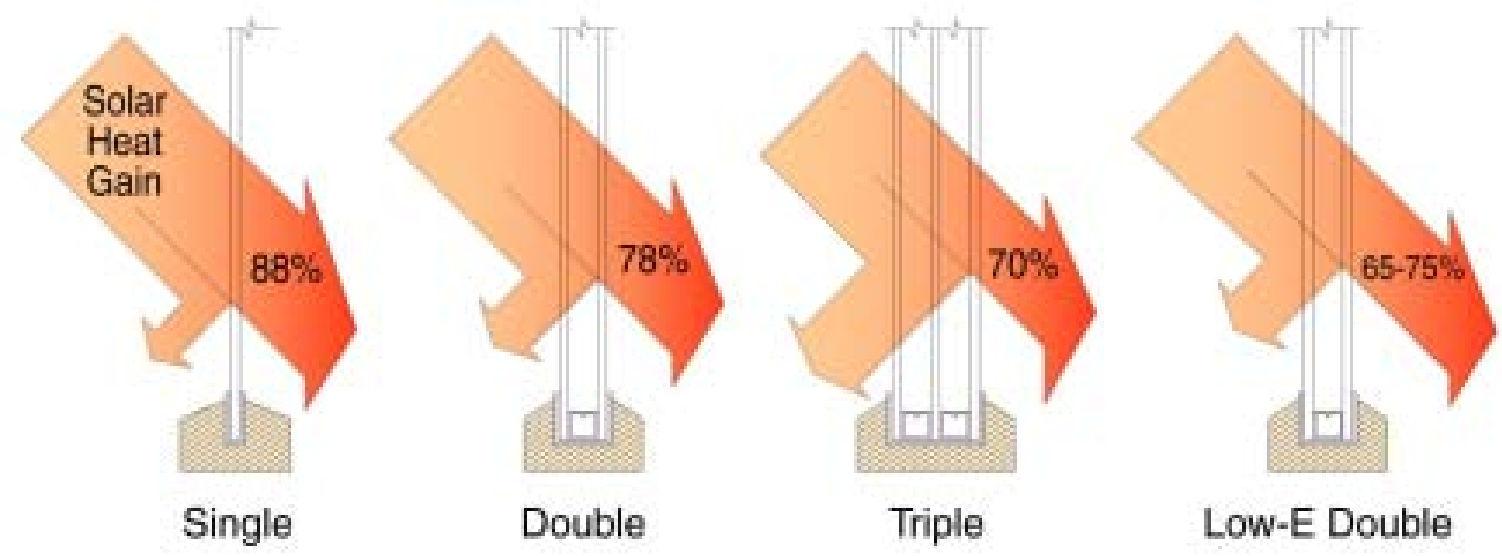

Figure 4. Solar heat transmission and reflection

There are other important factors to consider in selecting your replacement windows. One expert offers the following advice,

"The first step in installing a window correctly is to install the correct window. Use safety glass if required, get the proper grade, don't violate egress requirements, and make sure the window fits in the rough opening with the clearance recommended by the manufacturer."."

\section{WINDOW LABELS}

It can be difficult to compare windows. Fortunately the National Fenestration Rating Council (NFRC) has devised a label to summarize the energy performance characteristics of windows. This label may look complicated at first glance, but the NFRC web site gives a complete explanation. If you don't have time to learn all the terminology, use this abbreviated key to compare window labels:

\begin{tabular}{|l|l|l|}
\hline U-factor & $\begin{array}{l}\text { Lower is better } \\
\text { Range: } 0.2 \text { to } 1.2\end{array}$ & $\begin{array}{l}\text { Non-solar heat flow through } \\
\text { both glass and frame }\end{array}$ \\
\hline Solar Heat Gain & $\begin{array}{l}\text { Lower is better, } \\
\text { especially in the South } \\
\text { Range: } 0 \text { to } 1\end{array}$ & $\begin{array}{l}\text { Fraction of the sun's energy } \\
\text { that hits the window that will } \\
\text { enter your home }\end{array}$ \\
\hline Visible Transmittance & $\begin{array}{l}\text { Higher is better } \\
\text { Range: } 0 \text { to } 1\end{array}$ & $\begin{array}{l}\text { Fraction of visible light that } \\
\text { gets through the window } \\
\text { Air Leakage }\end{array}$ \\
$\begin{array}{l}\text { Lower is better } \\
\text { Range: } 0 \text { to } 1\end{array}$ & $\begin{array}{l}\text { Measure of the air that can } \\
\text { leak through cracks in the } \\
\text { window assembly }\end{array}$ \\
\hline$\underline{\text { Condensation }}$ & $\begin{array}{l}\text { Higher is better } \\
\text { Range: } 0 \text { to } 100\end{array}$ & $\begin{array}{l}\text { Measure of water condensing } \\
\text { out of air on window surface }\end{array}$ \\
\hline
\end{tabular}

Many window manufacturers participate in the Energy Star labeling program as well. Windows bearing the Energy Star label are likely to conserve more energy than those that don't. You can find out about this labeling system, and get additional information at the Energy Star window web site. 
Building codes change over time, and safety glass may be required even if the old window was standard glass. Egress requirements are especially important because they ensure that occupants can escape, and fire fighters can enter, if the need arises.

It's impossible to overstress the importance of getting all the details correct when you install new windows. Installation mistakes can lead to windows that don't operate properly or can cause serious moisture problems due to water intrusion into the wall structure. If you plan to do the job yourself, be sure and seek out the detailed instructions found for replacement windows in the "Where To Find Out More" section of this guide.

One of these details is the gap between the rough opening in your wall and the window frame. This can be an unseen Achilles heel for both air and water to get into your house. After the window installation is complete, this gap may be hidden by interior and exterior trim, so it's important to seal this gap before the trim is installed. The best method is to fill the space with a low-pressure polyurethane aerosol foam sealant. You should select a product marketed specifically for door and window installation and proven not to exert excessive pressure build during cure. This foam usually does the best job of stopping both air and moisture, but be careful to follow the directions so that you don't cause your window frame to bow (which can make it difficult or impossible to open and close the window!) Two alternative methods are to use a specialty tape product sold for this specific purpose, or to use backer rod and caulk. One traditional method used to seal this gap is to loosely stuff it full of fiberglass before applying and caulking the trim. This traditional method does a moderate job of stopping airflow through the gap, but can still allow moisture diffusion through the space. So if you use fiberglass, you should apply caulk in the gap as well. Whichever method you use to seal this gap, keep in mind that perfection is hard to achieve, and harder still to maintain. So you should be sure that the interior and exterior trims are properly installed and caulked as an additional line of defense against air and moisture.

\section{Storm Windows}

Storm windows often represent an economic compromise, because their cost is usually much less than replacement windows, and they have the potential to save nearly as much energy. This is especially true for some of the new storm window products that are available with a low-e coating. As with replacement windows, it is important to pay careful attention to sealing all air leakage pathways when mounting the storm windows.

\section{Walls}

If you're going to put new siding on your house, you have two big opportunities to save energy (see Fig. 5). The greatest saving potential is for those houses that were built with little or no wall insulation in the wall cavity (the space between the studs). The second best place to save energy is with foam sheathing placed beneath the new siding. The thicker foam sheathing products will save more energy, but you may be limited by the thickness of your window and door jambs.

1. If you've learned during your house inspection that your wall cavities are poorly insulated, or uninsulated, this is a great opportunity to blow insulation into this empty space. People are often reluctant to tackle this job because it involves cutting small holes into their home's exterior walls, and the patched holes are sometimes noticeable. But if you're putting up new siding, the patches 
will be hidden anyway! This step will save you more energy, and more heating and cooling dollars, than anything else you can do to your walls. You'll need to hire a contractor to do this job and you can choose either loose-fill cellulose or fiberglass. (See the DOE Insulation Fact Sheet for more information about different forms of insulation.) In either case, be sure to talk about the finished R-value of the fill material - you want at least R11- and you want to talk about their method for ensuring that the entire cavity is filled and remains filled. One such method is called the 'dense-pack' method. This method not only prevents settling within the cavity and reduces air leakage through the wall, but also offers a higher R-value than insulation blown in at lower densities.

2. If you're removing your old siding, you will have easy access to your original sheathing layer. It will usually be possible to place a foam sheathing layer on top of the original sheathing before adding the new siding. The thicker this foam is, the more energy you will save. Foil-faced products can also increase your savings (be sure the reflective side faces the open

OANL 03-02504laben

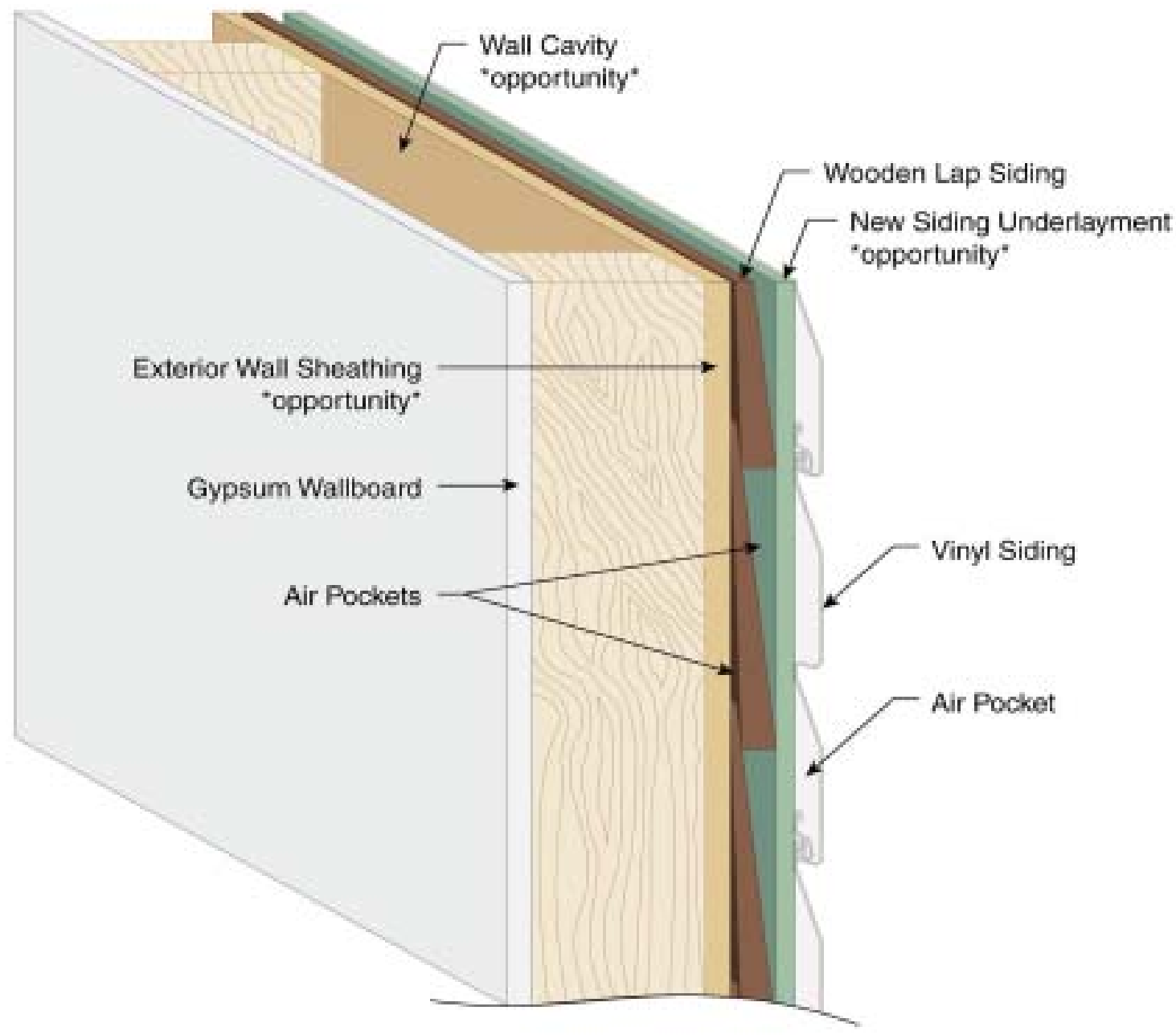

Figure 5. "Opportunity" locations to consider when you add new siding to your home. 
air spaces behind the new siding, not the solid surface of the old sheathing). Foam sheathing boards act as a vapor retarder, so be sure your windows and doors are properly integrated with the outside of this new layer to avoid moisture intrusion between the original sheathing and the new foam sheathing (or underlayment). See the previous "Rain Plane" box.

3. If you're placing new siding on top of the old siding, you'll have to provide a flat supportive surface for the new siding. Often, $1 / 4$ " or $3 / 8$ " foam is used to provide that flat surface. But you can increase your energy savings by choosing a foilfaced foam and/or a thicker foam underlayment. The trick here is figuring out the thickest foam you can use without having to extend all the window and door jambs, because that can be a costly procedure. (If you're replacing most or all of your windows at the same time, the extra cost for extended jambs may be
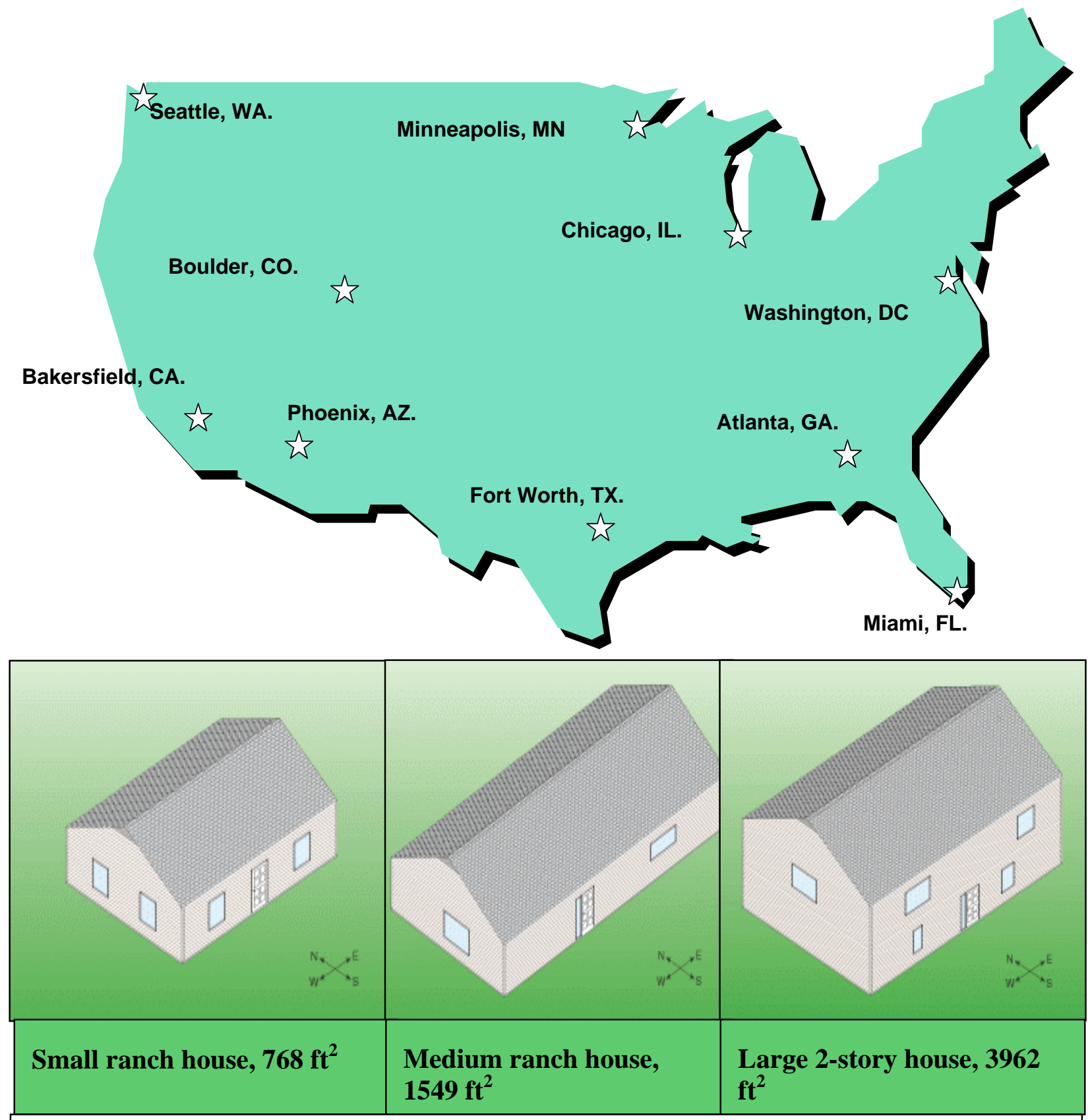

Figure 6. Locations and house designs used for savings estimates 
reasonable.) If you choose a foil-faced product, be sure the reflective side faces the largest open air spaces, which could be facing either the new or the old siding (see the "air pocket" locations in Fig. 5).

\section{How Much Can You Save?}

Every house is different, and your savings will depend just as much on the condition of your home before you retrofit your walls and windows as it does on the retrofit you choose. That said, it helps to have some idea of the savings you could expect. We've used a combination of experimental measurements and home energy modeling to estimate the savings for three different houses in ten different cities, shown in Fig. 6. To get an idea of the savings you can expect, choose the city which best represents your climate from Fig. 6. Then go to the corresponding Fig. 7 in Appendix A. This figure shows the estimated annual heating and cooling energy cost for the three 'typical' houses used in these calculations. You can pull out your own past utility bills to see whether your energy costs are similar. (You can usually tell how much of your bill is due to heating and cooling by comparing your winter and summer bills to those for the spring and fall months when you don't use very much heating or air conditioning. Be sure to keep any recent fuel or electricity price changes in mind when you make this comparison.)

So how much can you save by adding insulation to your exterior walls? The Fig. 8 for your selected city from Appendix A shows the range of savings calculated for these three modeled houses, as a percent of annual heating and cooling costs. Remember that these savings depend upon the condition of your home before you make any changes. If your house inspection revealed empty wall

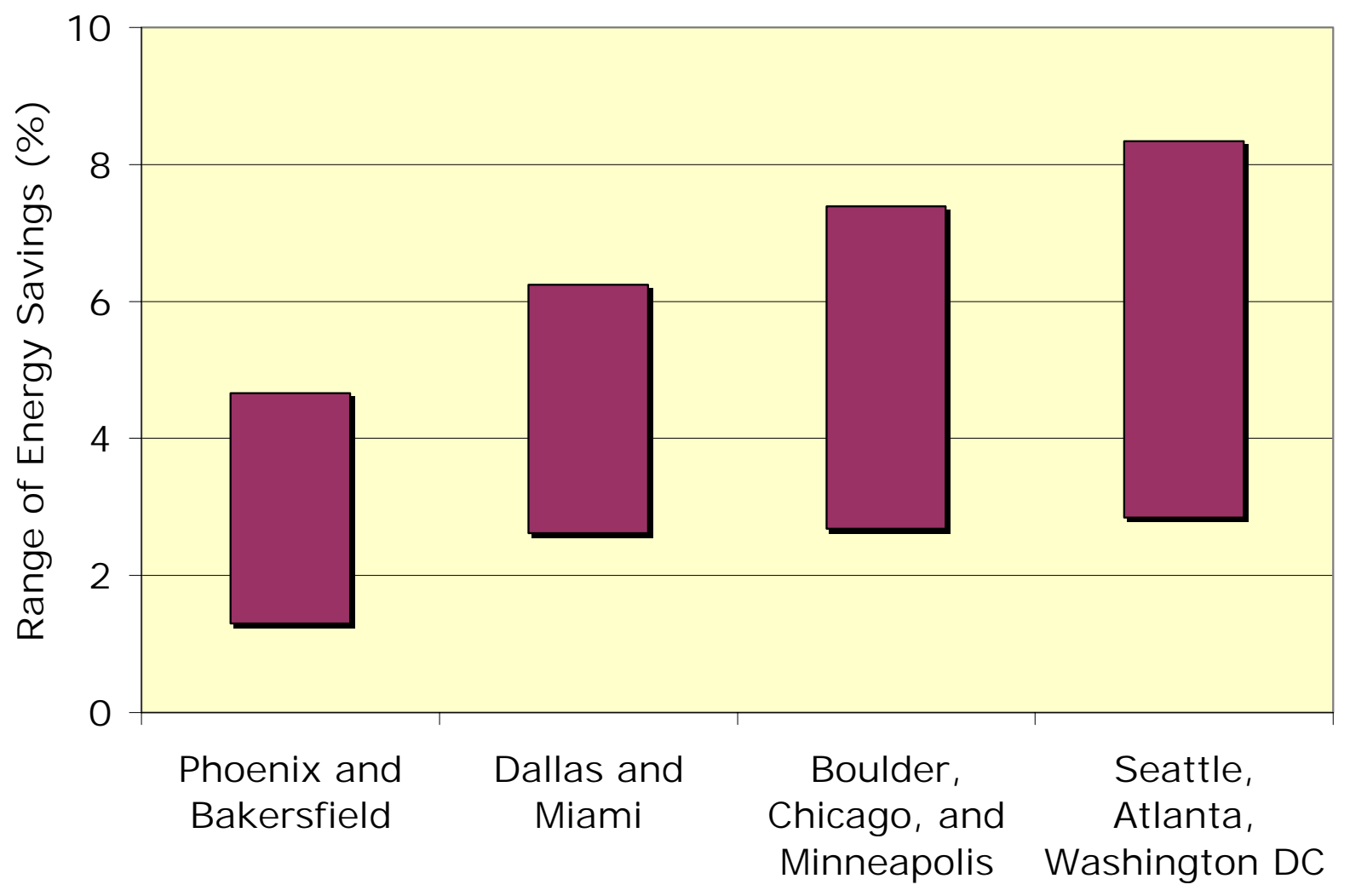

Figure 9. Range of annual energy savings you can achieve by properly sealing all gaps between your window frames and walls. 
cavities, Fig. 8 shows that filling those cavities with blown-in insulation and adding a $3 / 8$ " insulating board beneath new vinyl siding will save about $20 \%$ of your heating and cooling costs.

The energy lost to infiltration varies widely from one house to another. Air infiltrates your house in numerous locations, wherever two exterior walls meet, or where the walls meet the ceiling, as well as the locations you typically think about, around your windows and doors. To get a feel for the energy saving potential of sealing these leaks, we looked at the savings for sealing only those cracks between the windows and the walls. These savings also depend on the initial condition of these window/wall joints. The window/wall sealing savings estimates shown in Fig. 9 assume that the gap between the windows and the rough wall framing was poorly sealed to start. If you think the pre-existing condition was reasonably good, your savings will of course be less. The range of savings shown in Fig. 9, for example from 3 to $8 \%$ for Seattle, reflects only the window arrangements in our three house models. If you have many windows, your savings could be near the top of the range. If you have few or smaller windows, your savings could be closer to the bottom of the range.

The above discussion and Fig. 9 address savings for improving the seal between your windows and the wall framing. Estimating savings for replacing the entire window units is even more complex, because the energy lost through your windows depends not only on the temperature difference, but also on the energy that radiates through the glass. This radiation heat transfer includes solar gains that increase your air conditioning costs. Windows also radiate warmth from your house into the cold outside environment during the winter and increase your heating costs. So your savings will depend on the condition of your original windows, the windows' orientation, your climate, and even the location of your trees.

A series of long-term tests were made to compare a modern vinyl replacement double-paned window and the addition of several different types of storm windows to a single-paned wood-framed window. (These windows were allowed to be as 'leaky' as average windows during the tests.) Looking at Fig. 10, you can see that the replacement window saved almost half of the energy lost through the single pane wooden-framed window. But the storm windows also saved significant energy, especially the low-e coated storm windows. So if replacement windows are too expensive for your budget, try to find some of the new low-e coated storm windows, because they can save almost as much energy.

\section{Step 3: Choosing Your Contractor}

It is impossible to overstress the importance of this step - don't skimp on time or effort here. Your contractor will become your 'expert', and will ultimately control the quality of the job, so find out as much as possible about all the candidates. Costs can vary widely, but also consider the quality of the proposed work and materials. Low cost bids may reflect not only the use of lesser products, but also the use of untrained or inexperienced workers. Proper training is crucial when it comes to installing windows and siding. So ask your contractor about the training and experience of the people who will perform the actual installation. 


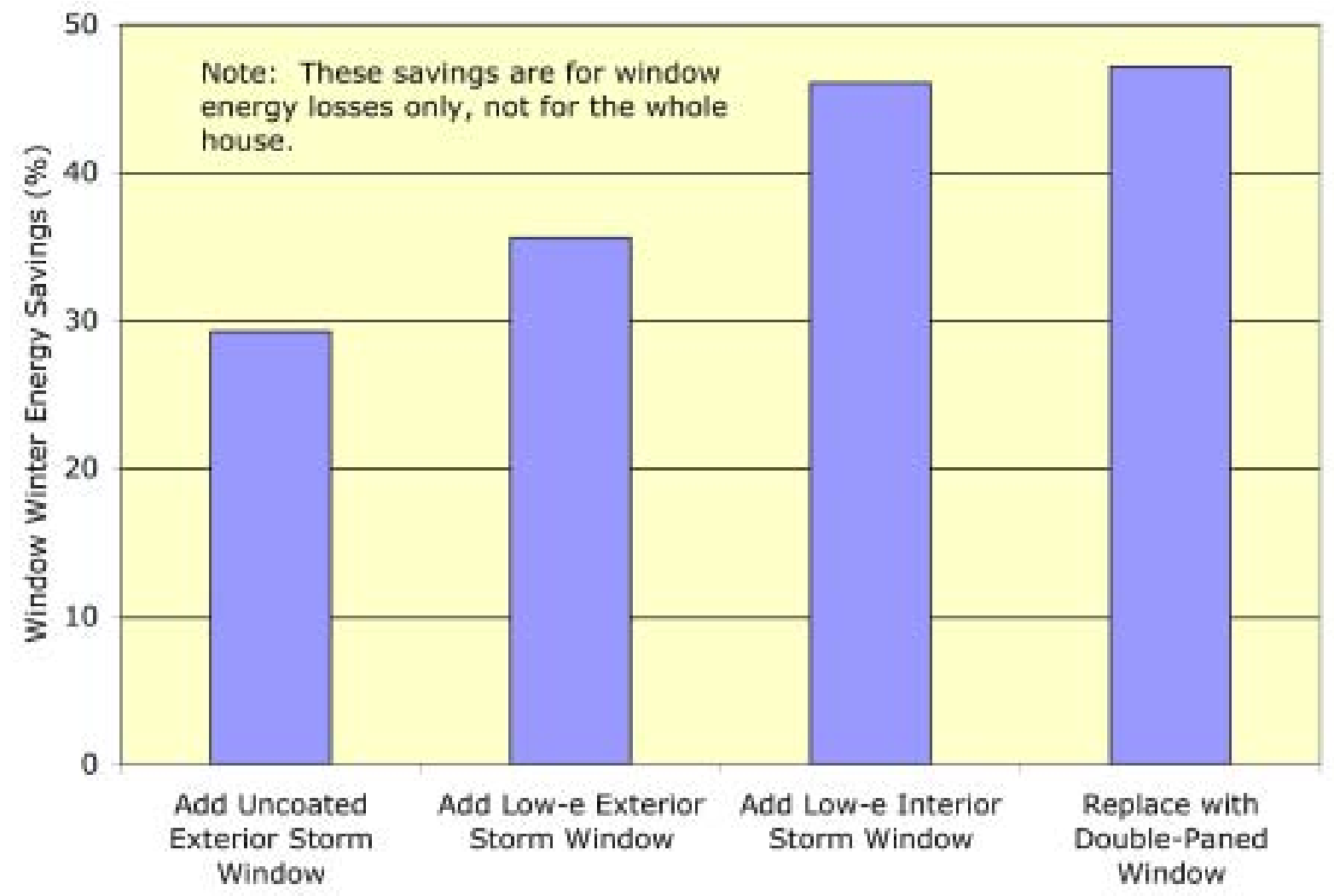

Figure 10. Winter window energy savings compared to a single-paned woodframed window, not counting solar energy gains through the window.

Ask for local references and names of previous customers who will allow you to inspect their homes. If possible, check into jobs that have been complete for at least a year, because some problems don't appear until long after a job is done. Ask about the contractor's experience with homes similar to yours in style and materials, and with retrofit projects similar to yours. Call your local Better Business Bureau. Many people neglect this step until after they have problems, and then find that other customers have had similar problems with the same contractor. Of course, make sure the contractor is properly licensed, bonded, and insured and that all local building permit regulations are followed.

Inspect the job in progress - often! Don't be afraid to ask questions or to stop the work to confer with your contractor. Getting it done right the first time is your goal.

\section{Other Energy Saving Opportunities in Your Home}

While improving the outside of your house, you may also want to consider other energy improvements to your attic or foundation. The amount of insulation recommended for attics, basements, and crawlspaces for your region can be found by using the ZipCode calculator. This tool can also tell you whether or not you need to add insulation, depending on how much you already have in place.

If you want to consider a broad variety of energy conservation measures for your house, including appliances and lighting, the Department of Energy has provided two web-based tools, the Home Energy Saver and the Home Energy Advisor, for your use. These tools will ask you a few simple questions about your house and suggest different things you can do to 


\section{DUCTS Play an Important Role in Energy Conservation}

If you are looking around in your attic, basement, or crawlspace, you may find ductwork that carries conditioned air from your furnace and air conditioner to the rest of your home. These ducts probably aren't your primary focus, but one of the most important retrofits you can make is to seal all the leaks in that ductwork. You could be losing $20 \%$ or more of your heating and cooling energy to air leaking in and out of your ducts. Some utilities offer duct testing programs, so you may want to give them a call. Otherwise, Fig. 11 shows the joints that you should check. One common

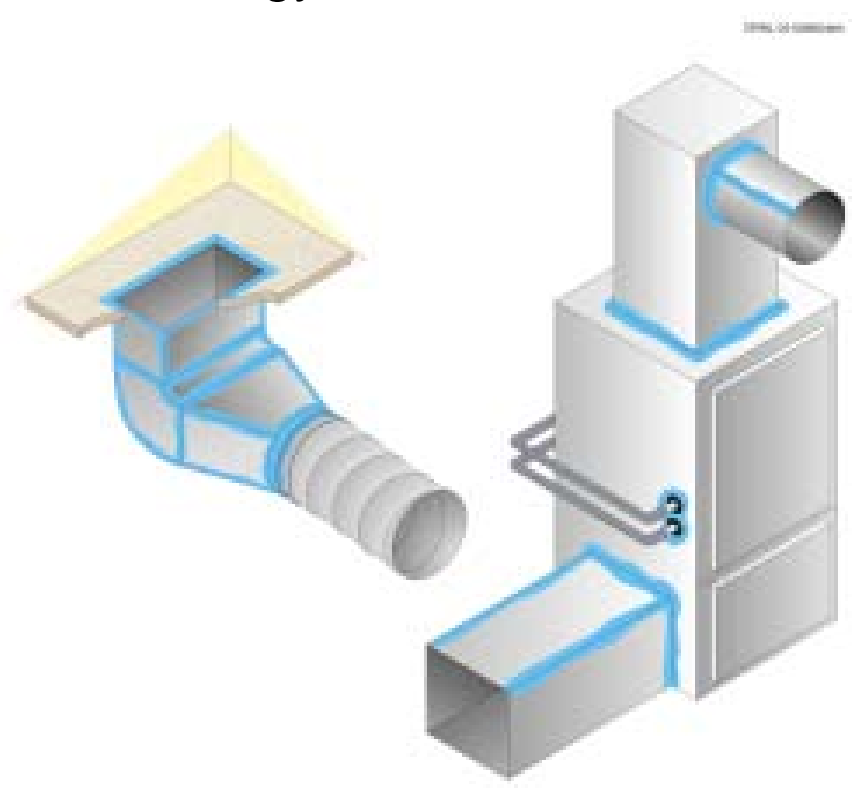

Figure 11. Duct leak locations leakage area that is always

accessible is the joint between your ductwork and the registers on the floor or wall. Please don't use standard duct tape for any duct repair; it won't stay in place more than a year or two. Special fiberglass tape, heat-sealed aluminum tape, or mastic should be used for the job. These sealants should be labeled "UL 181A" for rigid ducts and "UL181B" for flexible ducts. You can find more complete guidance in both sealing and insulating your ducts in another DOE factsheet at DOE's Building Technology publications web site and in the DOE HVAC Best Practices Guide. Because many duct leaks are in inaccessible locations, researchers at LBNL have developed and licensed an effective aerosol duct sealing technology.

save energy. The Home Energy Advisor also provides estimated savings.

\section{Attics}

There are four key things to look for in your attic. (1) Are there ducts running through the attic? (2) How is the attic ventilated? (3) How much insulation is already in the attic? (4) Is the attic properly sealed to keep air and moisture from the house out of the attic?

If you find ductwork in your attic, examine it closely to look for leaky joints or loose insulation (see box). Check your attic ventilation to be sure that it hasn't been blocked by insulation. This can happen to soffit vents if baffles (often made from foam or cardboard) haven't been placed to hold back loose-fill insulation. You should check the thickness and type of insulation on the attic floor. The Insulation Fact Sheet can help you translate this information into the R-value for your existing insulation level.

Before adding any insulation to the floor of your attic, it is important to check for duct problems (see "Ducts" box) and to seal all air passageways between the attic and the rest of your house. It's very important to keep air and moisture from your house out of the attic because it's not only a significant energy loss, but could also lead to moisture problems in the attic. These air passageways will 
include light fixtures, kitchen soffits, vent pipes, duct chases, open partition walls, etc. Look for ventilation fans, especially over your kitchen and bathrooms. The ventilation fans should never vent into the attic directly. They must be routed into vents that exhaust outside the house. The Department of Energy has published a detailed fact sheet with complete instructions on how to find and seal these leaks. See DOE's Building Technology publications web site. (Safety first: some recessed light fixtures require ventilation to remove heat. Be sure not to cover these recessed fixtures with insulation unless they are specially-rated IC fixtures. Also, don't get insulation too close to hot flues or other sources of heat.)

In general, it's seldom economical to add more insulation if you already have R-30 or more. But if you have less than 10 inches of insulation in your attic, you may need more depending upon your heating fuel and climate. Before adding insulation, be sure you've corrected any ventilation or moisture problems that you identified during your inspection. Another DOE fact sheet gives detailed guidance for installing attic insulation, see DOE's Building Technology publications web site.

In summary, the best attic advice we can give you here is to seal and insulate the ductwork, seal air leaks between the house and the attic, then add insulation to the attic floor if necessary to bring it up to the level recommended for your area.

\section{Basements and Crawlspaces}

When you inspect your basement or crawl space, look for whether or not 1) plumbing pipes and/or ducts run though the space, 2)the crawl space is ventilated, 3)there is plastic sheeting on the crawl space ground, 4)moisture/water is present, 5)the floor above the space is insulated, and 6)the walls are insulated. If you do find pipes or ducts, check their insulation and look for leaks in the duct joints (see "Ducts" box).

If you find moisture or water under your house, it is critical that you fix this problem before you do anything else. For more information about how to keep the space under your house dry, go to the moisture page from the Insulation Fact Sheet or the Moisture Control Handbook.

Crawl spaces can be treated either by insulating the floor above and ventilating the crawl space, or by insulating the walls of the crawl space and not ventilating the space. Your choice will depend on your local building code (some codes still require ventilated crawl spaces), whether you have ducts and pipes in the space, and whether you already have floor insulation. From an energy performance point of view, an unventilated crawl space with wall insulation is the best choice. But if you already have floor insulation above your crawlspace, it's probably not economical to insulate the crawl space walls as well. Whether or not your crawlspace is ventilated, you should have the ground covered with a thick plastic sheet to keep the ground moisture away from your house. See the Builder's Foundation Handbook and a DOE technical fact sheet at DOE's Building Technology publications web site for more detailed instructions.

If you choose a ventilated crawl space arrangement and the floor above the crawlspace is not insulated, you could save energy by insulating that surface. If however, pipes in the crawlspace have been heated by energy leaking through your floor, you will need to make other arrangements to prevent the pipes from freezing during cold weather. These arrangements can include pipe insulation and adding a thermostatically-controlled heat-tape product available at most hardware stores. 
If you have ductwork in your crawlspace, the most important retrofit you can make is to seal and insulate that ductwork (see "Ducts" box).

If you have an unheated basement, you can choose to insulate the floor above the basement, but you must pay attention to any piping or ductwork that runs through the basement. Many basements fall into a "semi-conditioned" category - these basements are not deliberately supplied with heating, but ductwork running through the basement provides adequate heat so that the space can be used for laundry or workshop purposes. These basements can be made more comfortable by adding wall insulation (without a moisture retarder), which will also provide modest energy savings.

If your basement is conditioned and the walls are not insulated, you can save energy by adding wall insulation. These energy savings will be even more pronounced if you've already improved the energy performance of the rest of your house. Your best bet is to use insulation without a moisture retarder because that could lead to moisture problems on your basement walls.

\section{Where To Find Out More}

\section{For the Homeowner}

Home Energy, the online site for "the magazine of home performance" contains a wealth of helpful information.

"No-Regrets Remodeling" a book available from Home Energy Magazine. 1997.

Consumer guides on how windows work and other helpful ideas www.uoxray.uoregon.edu/phys $161 /$ consu mer guide.pdf http://www.eere.energy.gov/buildings/ho mes/buyingwindows.cfm
How to select an energy efficient window; www.efficientwindows.org

A large number of useful technology fact sheets are available from DOE. These were developed for new home construction, but also contain a wealth of information helpful to people retrofitting existing homes, especially if your retrofit project includes adding on to your home. Go to the DOE Building Technology publications web site. Among other topics, these fact sheets include detailed information about insulating floors, basements, and crawlspaces; air-sealing, especially between the ceiling and attic; and choosing and installing a weather resistant barrier on the exterior wall beneath the new siding.

The Canada Mortgage and Housing Corporation has prepared a helpful package of advice for renovation projects.

You can learn more about the relative merits of different wall construction methods by visiting the Whole Wall Calculator.

\section{For the Builder/Contractor}

If you are a builder or contractor, here are some additional resources:

ASTM E2112 Standard Practice for Installation of Exterior Windows, Doors and Skylights

\section{Vinyl Siding Institute}

Vinyl Siding Installation from Fine Home Building

Home Energy's Guide to Training Programs.

American Architectural Manufactures Association, certified window installation training: Installation Masters 
Builder's Guide - Mixed Climate; Builder's Guide - Cold Climate; Builder's Guide - Hot-Dry \& Mixed Dry Climates. By Joseph Lstiburek. Energy Efficient Building Association 1998.

LBNL HVAC Best Practices Guide.

\section{Acknowledgements}

This guide was sponsored by the Building America Existing Buildings Program within the Office of Energy Efficiency and Renewable Energy of the $U$. S. Department of Energy. The direction and participation of the project manager, Terry Logee, was much appreciated.

A workshop was held to gather input for this guide from manufacturers, contractors, and researchers.

Participants in this workshop were instrumental in the final content of the document, and included: Robert Braun from Dow Consumer and Building Products, Todd Bushburger of Protecto Wrap Company, Claude Browne from Crane Performance Siding, George Chrenka of the NuWool Company, Steve Duren of Illbruck Sealant Systems, Inc., Brian Keith Hearon of the Denver L. Hunt Company, Terry Logee from the Department of Energy, and John William Lubker of Pactiv Building Products. Oak Ridge National Laboratory researchers participating included Jerry Atchley, Phillip Childs, Andre Desjarlais, Jan Kosny, Thomas Petrie, Therese Stovall, Mark Ternes, and Bob Wendt.

Thanks are due to Pactiv Building Products for contributing fan-fold extruded polystyrene siding underlayment products and to Certainteed Corporation for contributing the vinyl siding that was used during the experimental portion of this effort.
A team of researchers, including Joe Klems and Guy Kelly at LBNL, tested window performance at the MoWitt facility and shared the windows with us for our window/wall performance testing. See Symposium paper KC-03-12-1, ASHRAE Transactions, Vol. 109 Part 2 , June 28 July 2, 2003

Extensive experimental work at ORNL was performed to increase our understanding of the thermal and infiltration performance of wall retrofit combinations. These efforts were directed by Jan Kosny, Thomas Petrie, Phillip Childs, and Jerry Atchley.

Figures 1 and 4 taken from the Consumer's Guide to Buying EnergyEfficient Windows and Doors, used by permission from Natural Resources Canada, Office of Energy Efficiency 


\section{House Inspection Checklist}

Use this checklist as a handy reminder. More details can be found in the Best Practice Guide.

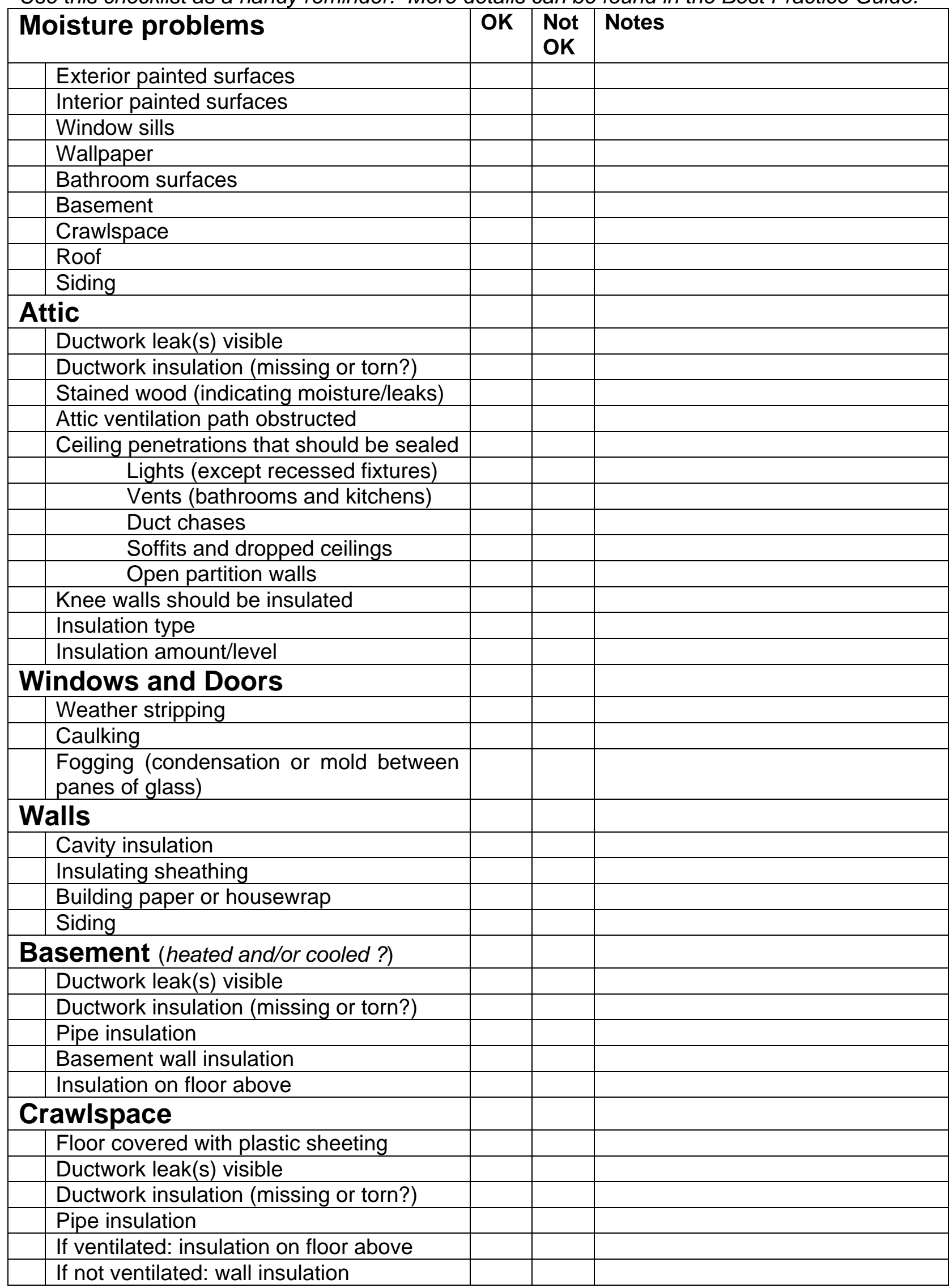




\section{Window Replacement Checklist}

\begin{tabular}{|l|l|l|l|l|l|}
\hline Number & Size & $\begin{array}{l}\text { Glazing } \\
\text { (single, double, } \\
\text { or triple pane) }\end{array}$ & $\begin{array}{l}\text { Frame } \\
\text { (wood, vinyl, } \\
\text { or aluminum) }\end{array}$ & $\begin{array}{l}\text { Type } \\
\text { (sliding or } \\
\text { hinged) }\end{array}$ & $\begin{array}{l}\text { Notes } \\
\text { (Besides general condition, } \\
\text { include label information: } \\
\text { safety glass, low-e coating, } \\
\text { gas fillers, etc.) }\end{array}$ \\
\hline $\begin{array}{l}\text { Facing South and West (consider shading to reduce solar heat gain } \\
\text { during the summer) }\end{array}$ \\
\hline \\
\hline
\end{tabular}


Appendix A: Savings Estimates for Ten Cities 


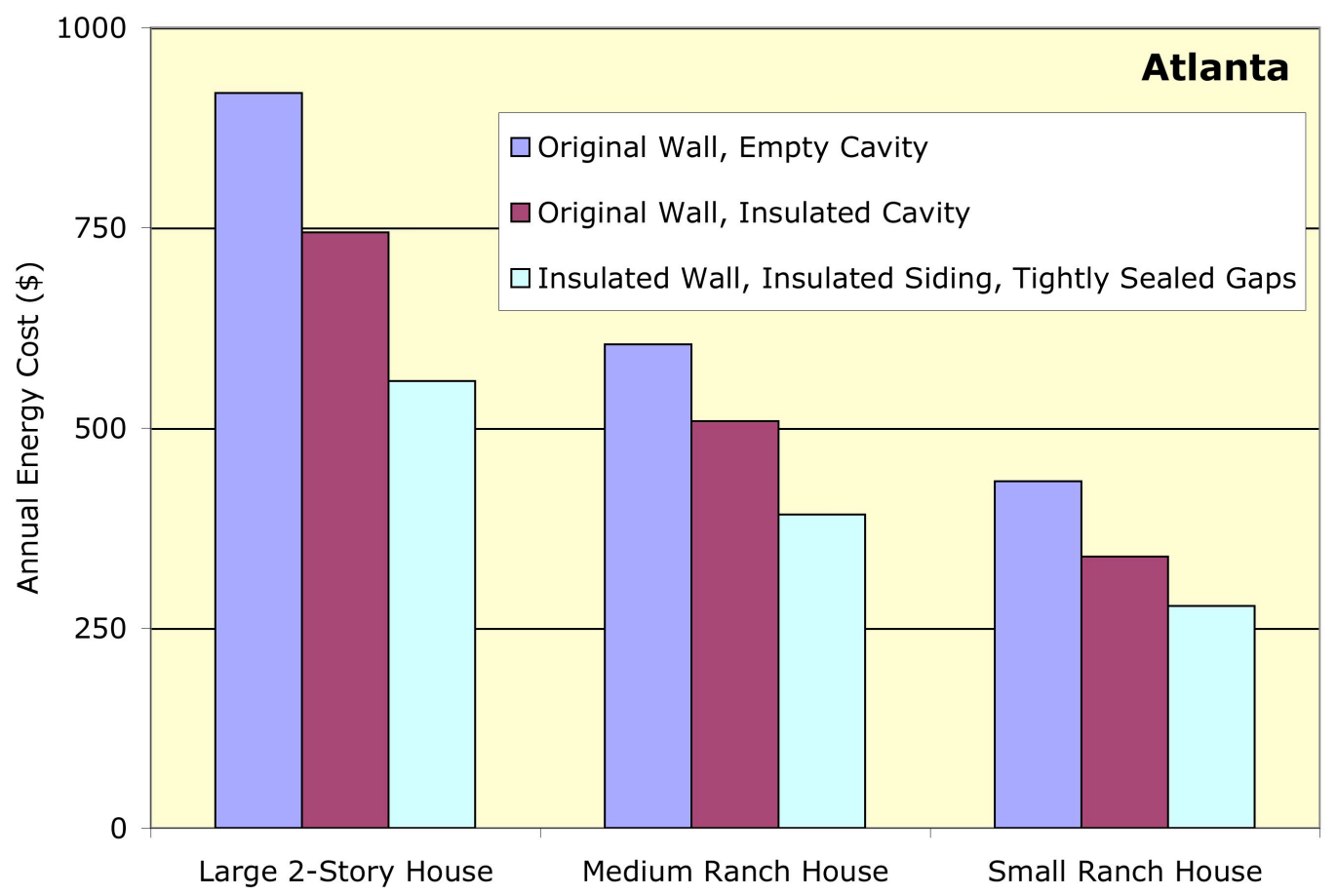

Figure 7. Annual Energy Costs

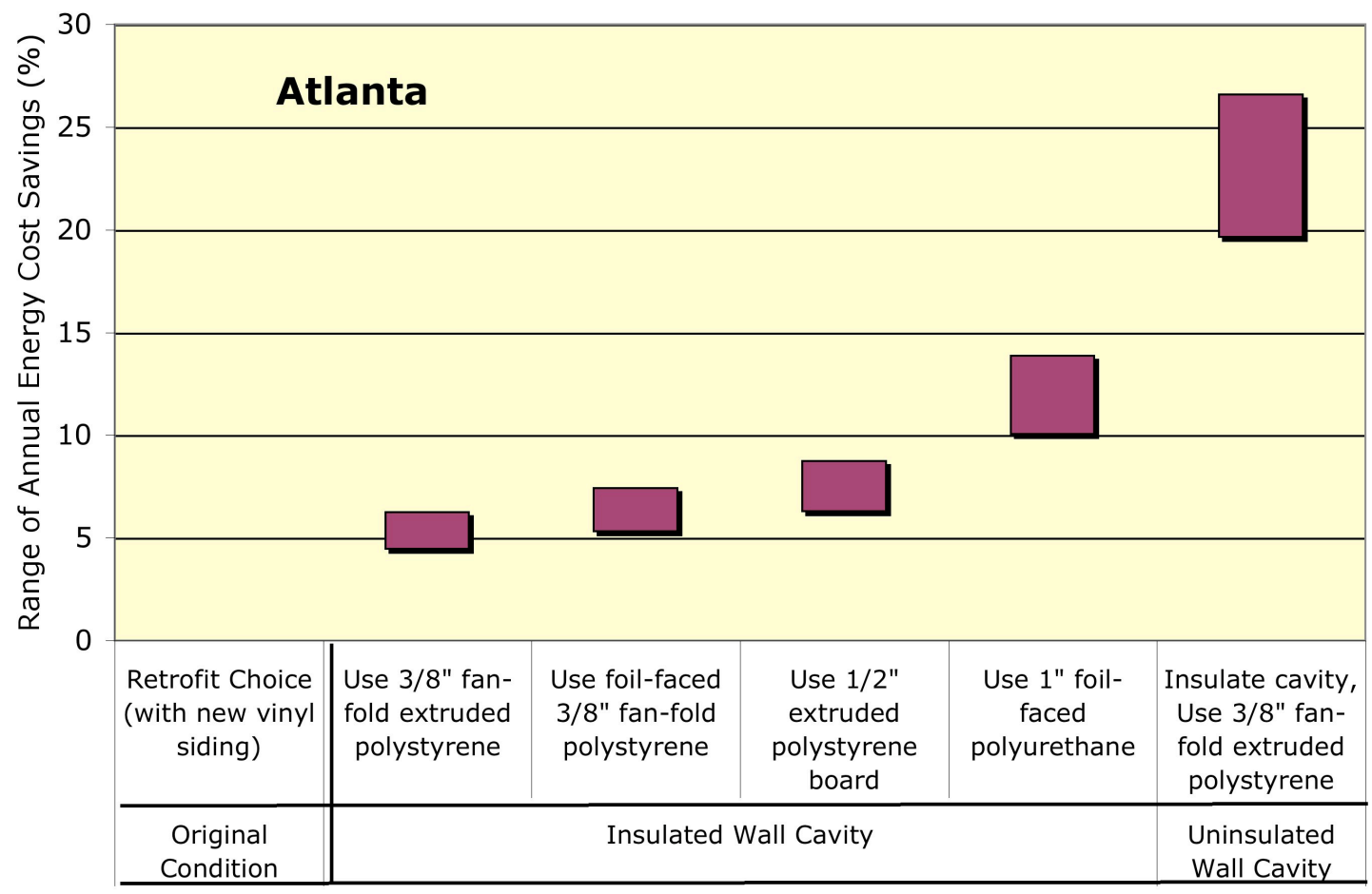

Figure 8. Potential Annual Heating and Cooling Energy Savings for Different Wall Retrofit Options 


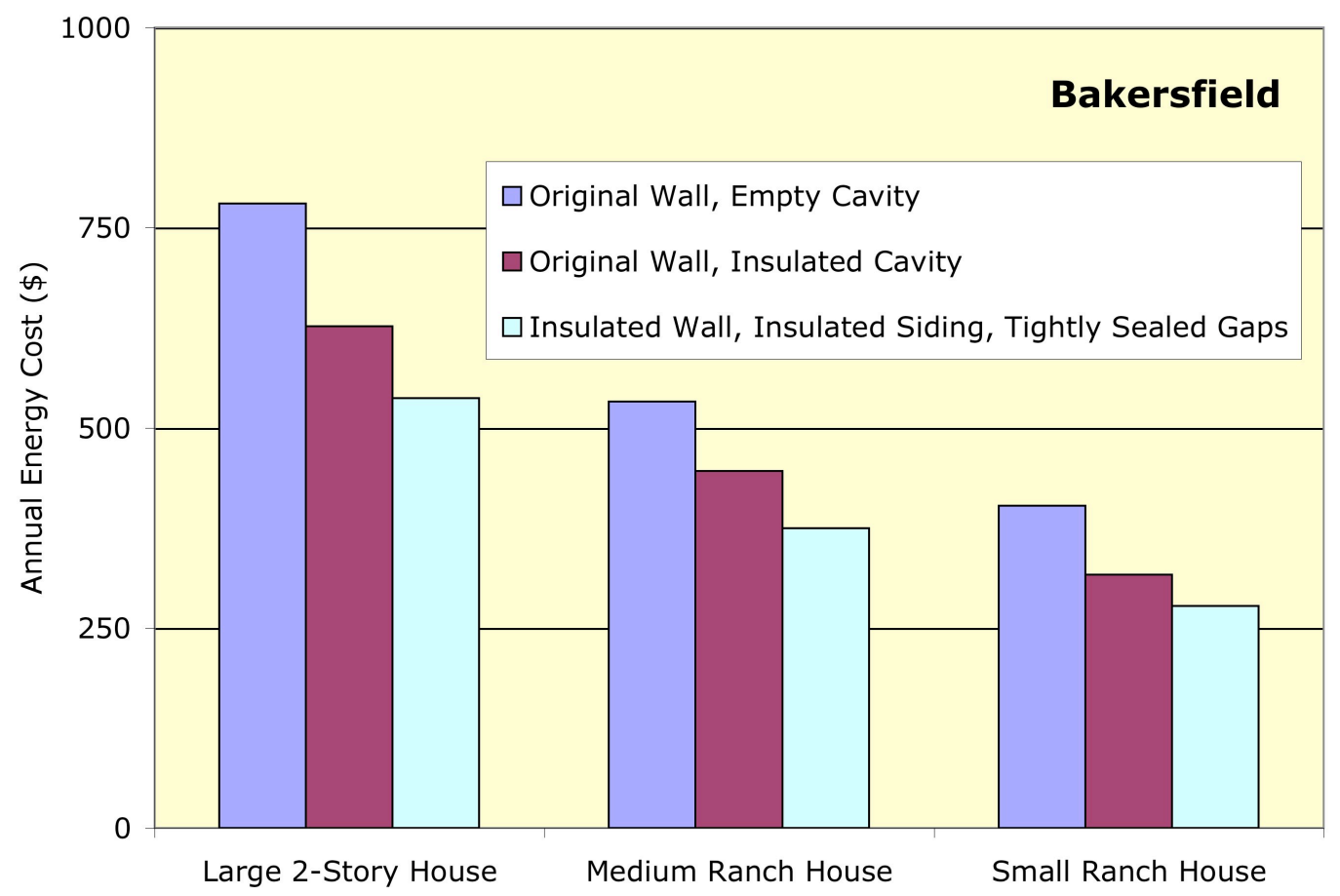

Figure 7. Annual Energy Costs

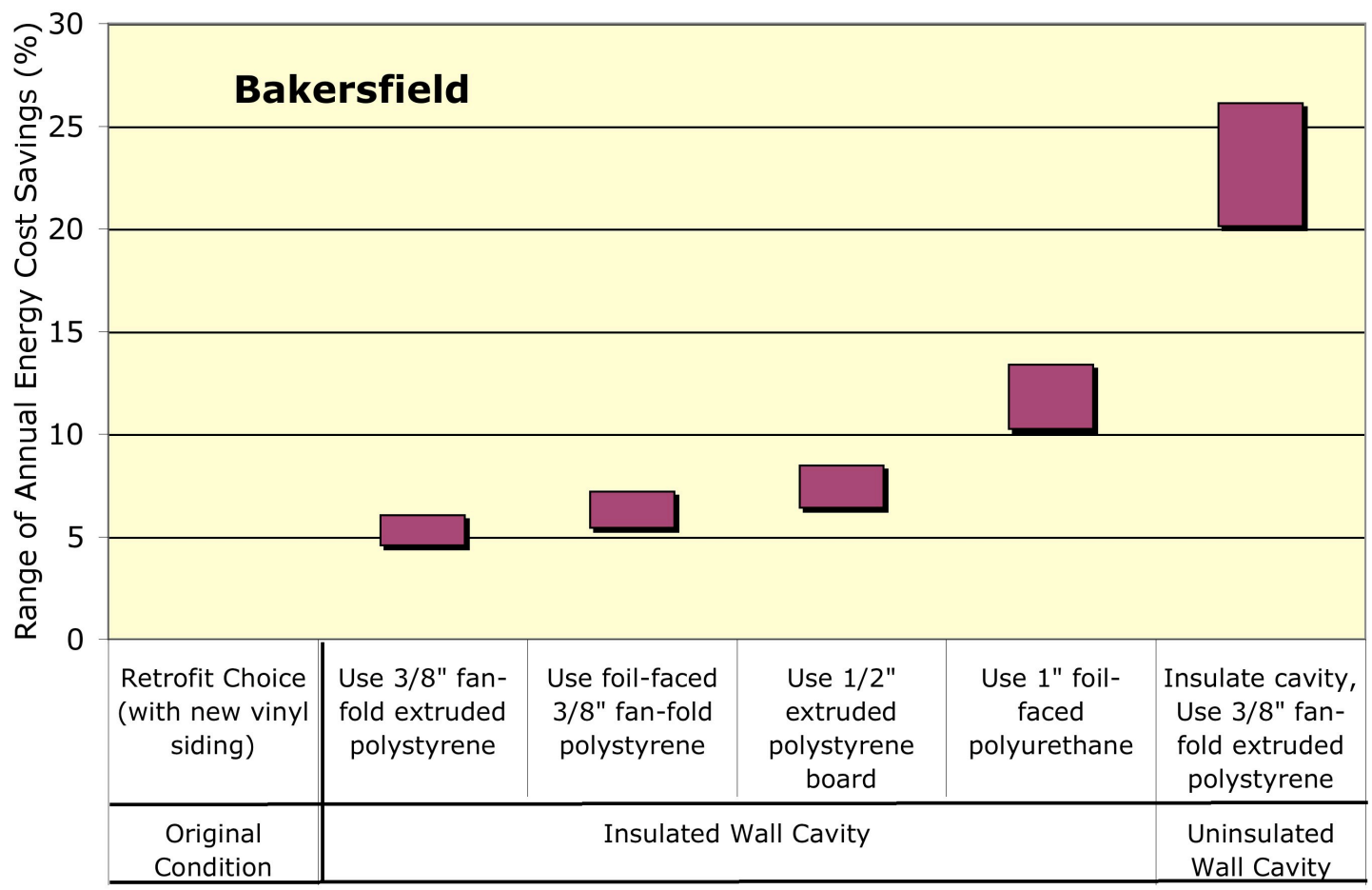

Figure 8. Potential Annual Heating and Cooling Energy Savings for Different Wall Retrofit Options 


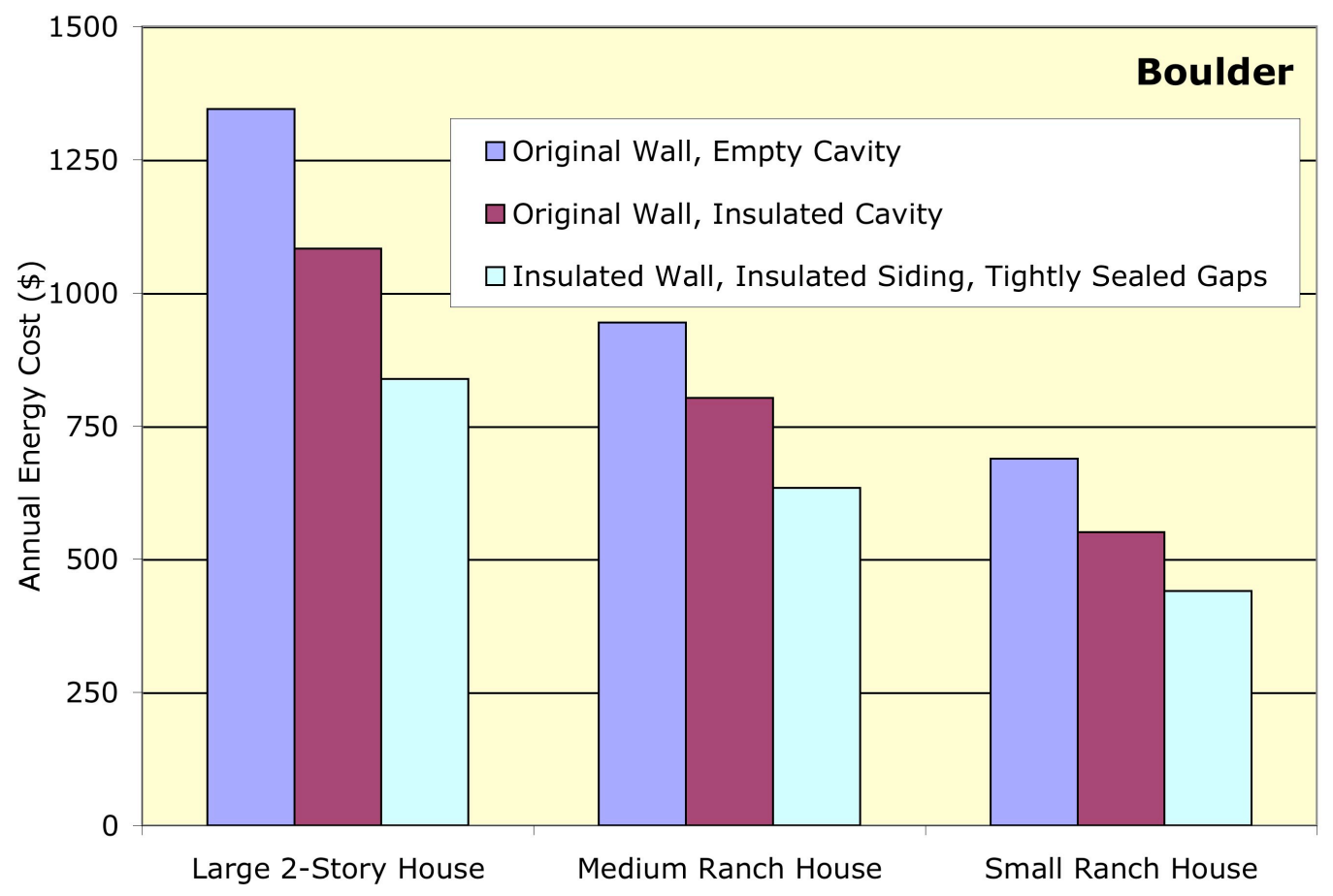

Figure 7. Annual Energy Costs

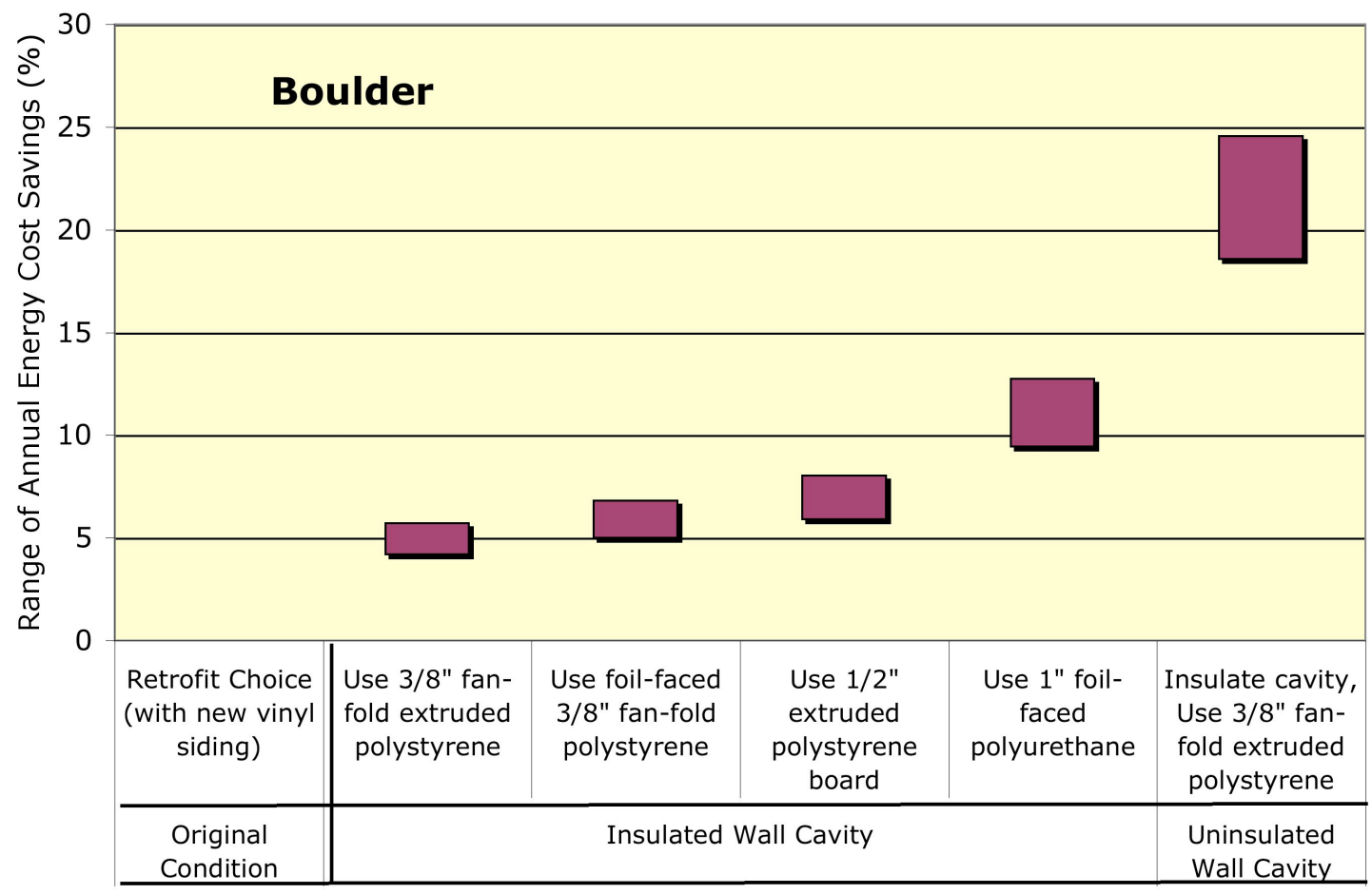

Figure 8. Potential Annual Heating and Cooling Energy Savings for Different Wall Retrofit Options 


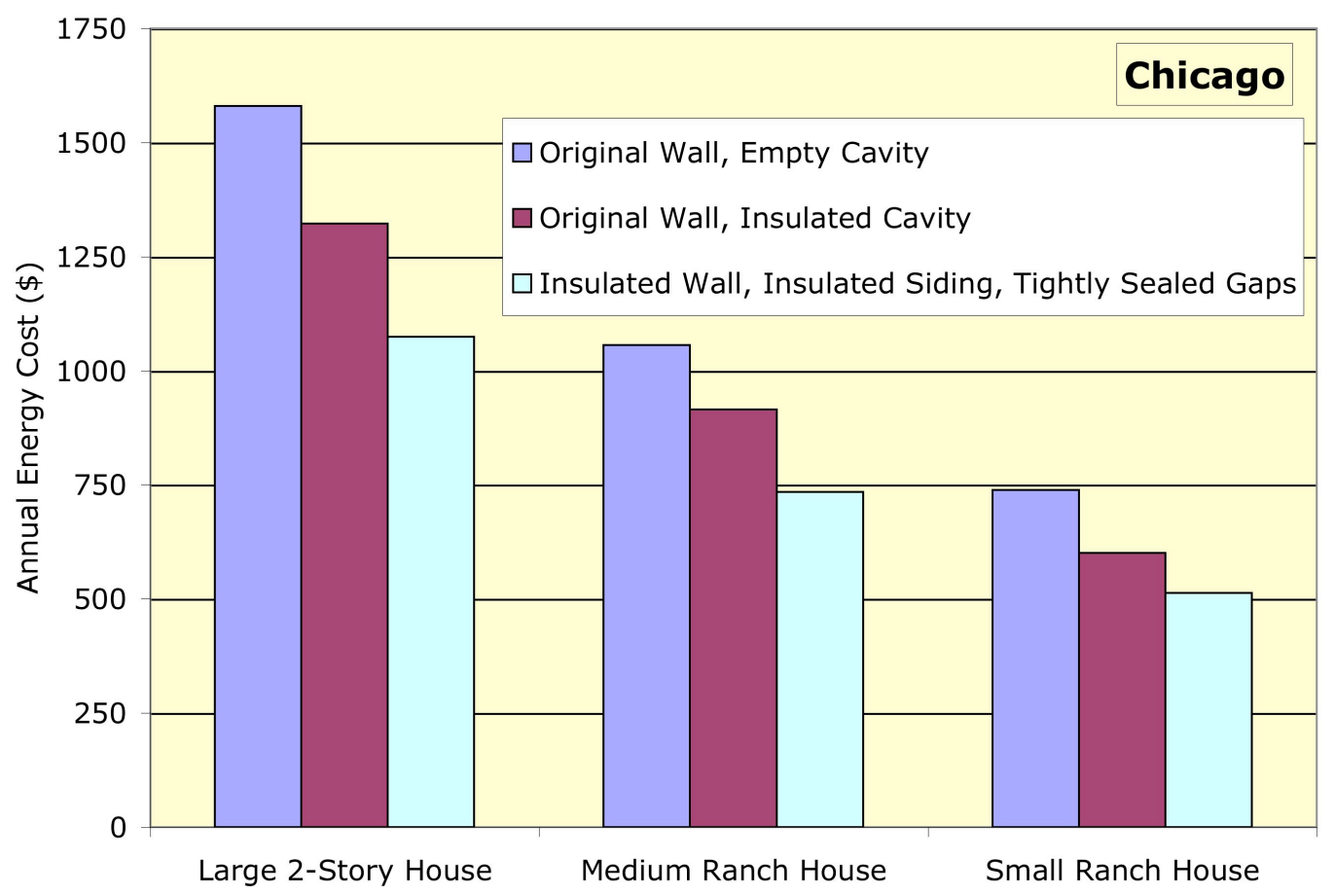

Figure 7. Annual Energy Costs

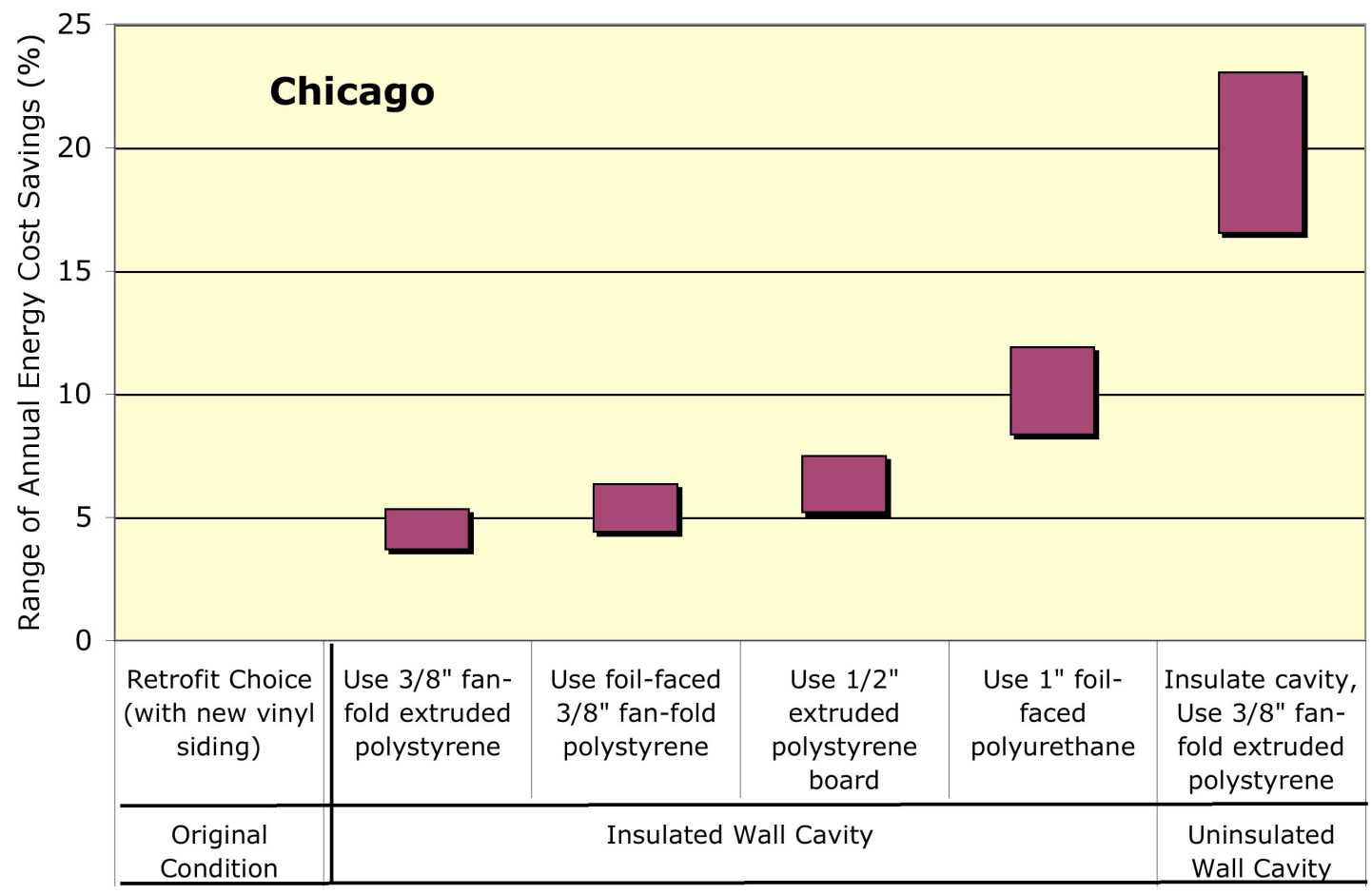

Figure 8. Potential Annual Heating and Cooling Energy Savings for Different Wall Retrofit Options 


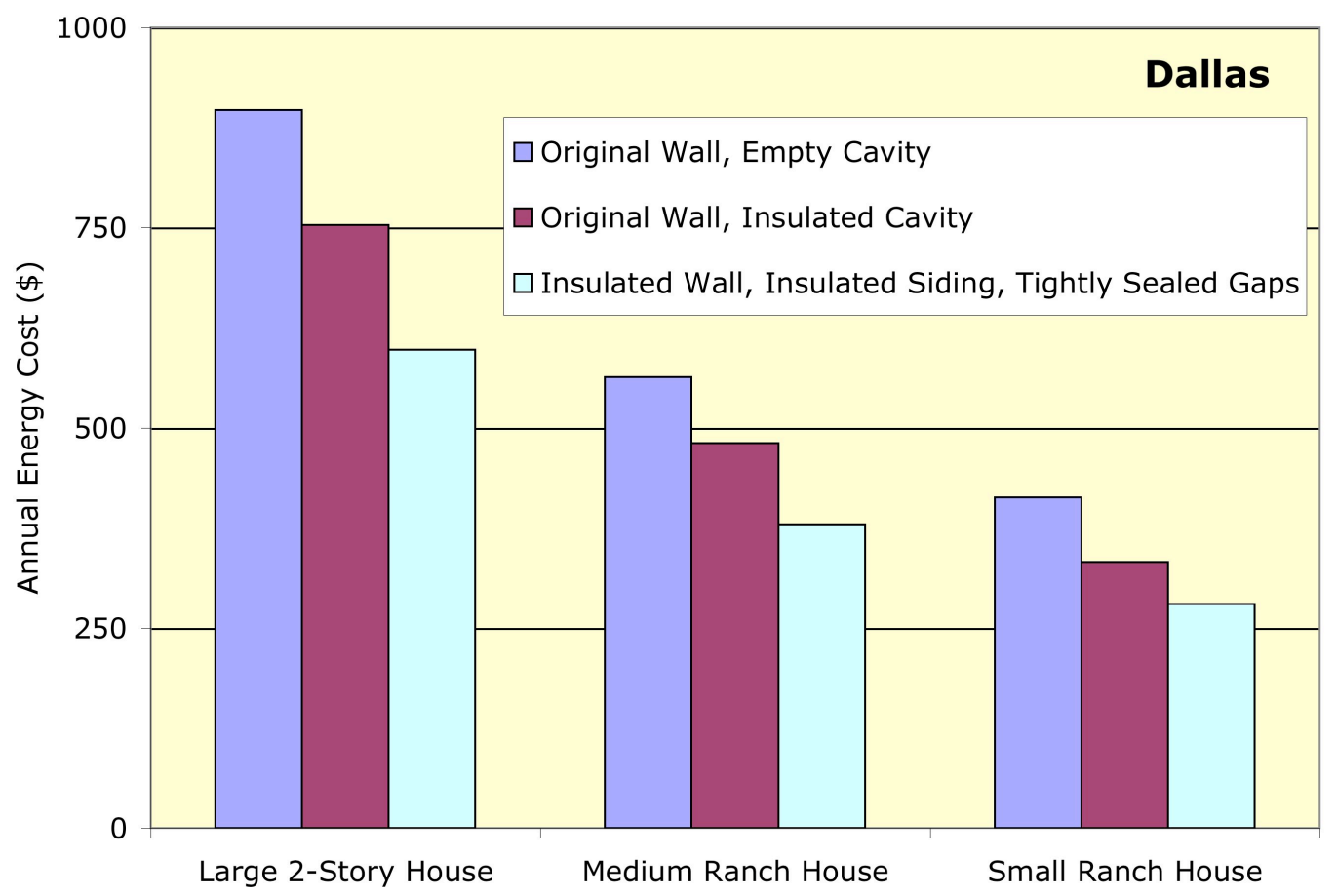

Figure 7. Annual Energy Costs

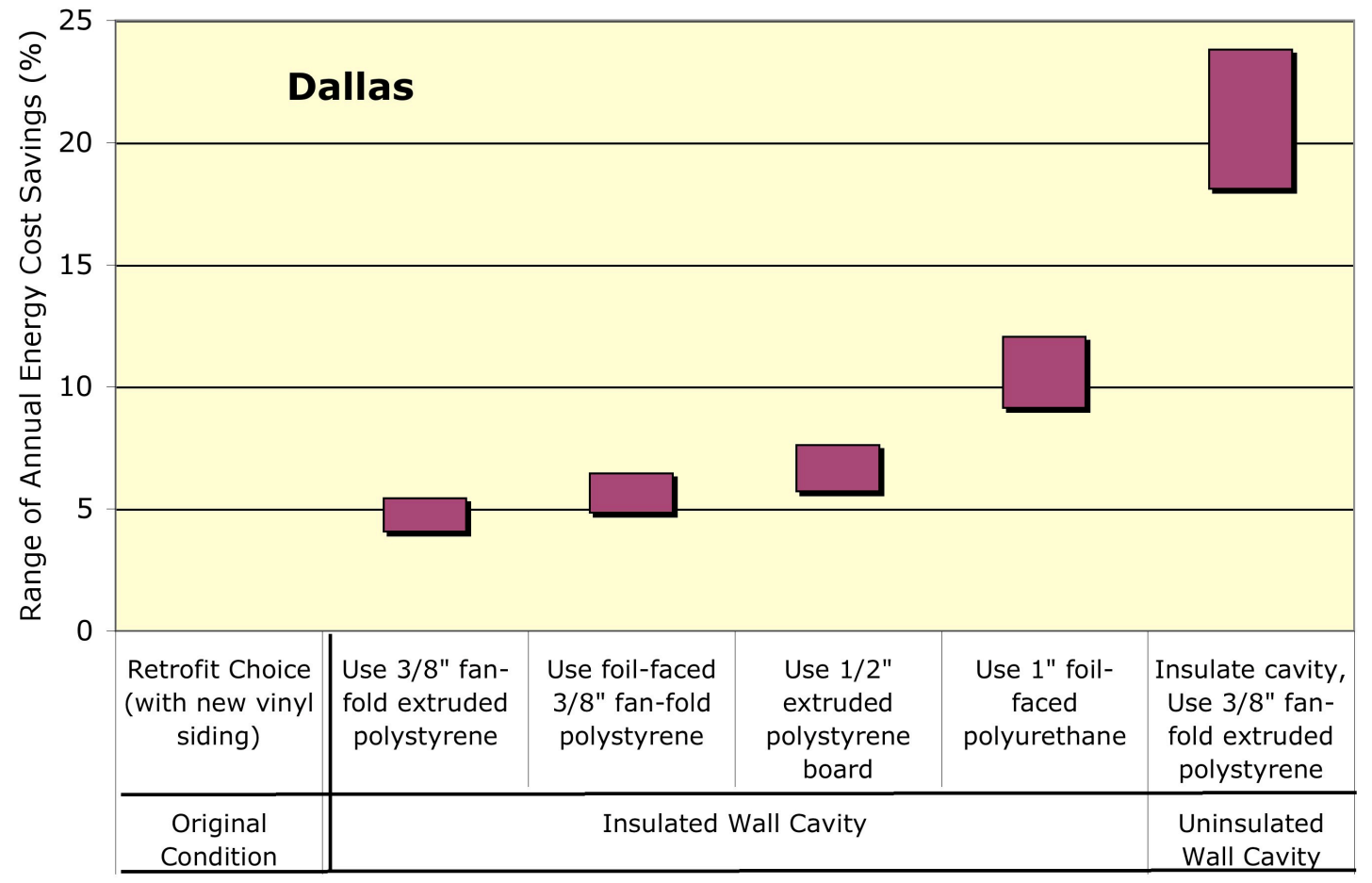

Figure 8. Potential Annual Heating and Cooling Energy Savings for Different Wall Retrofit Options 


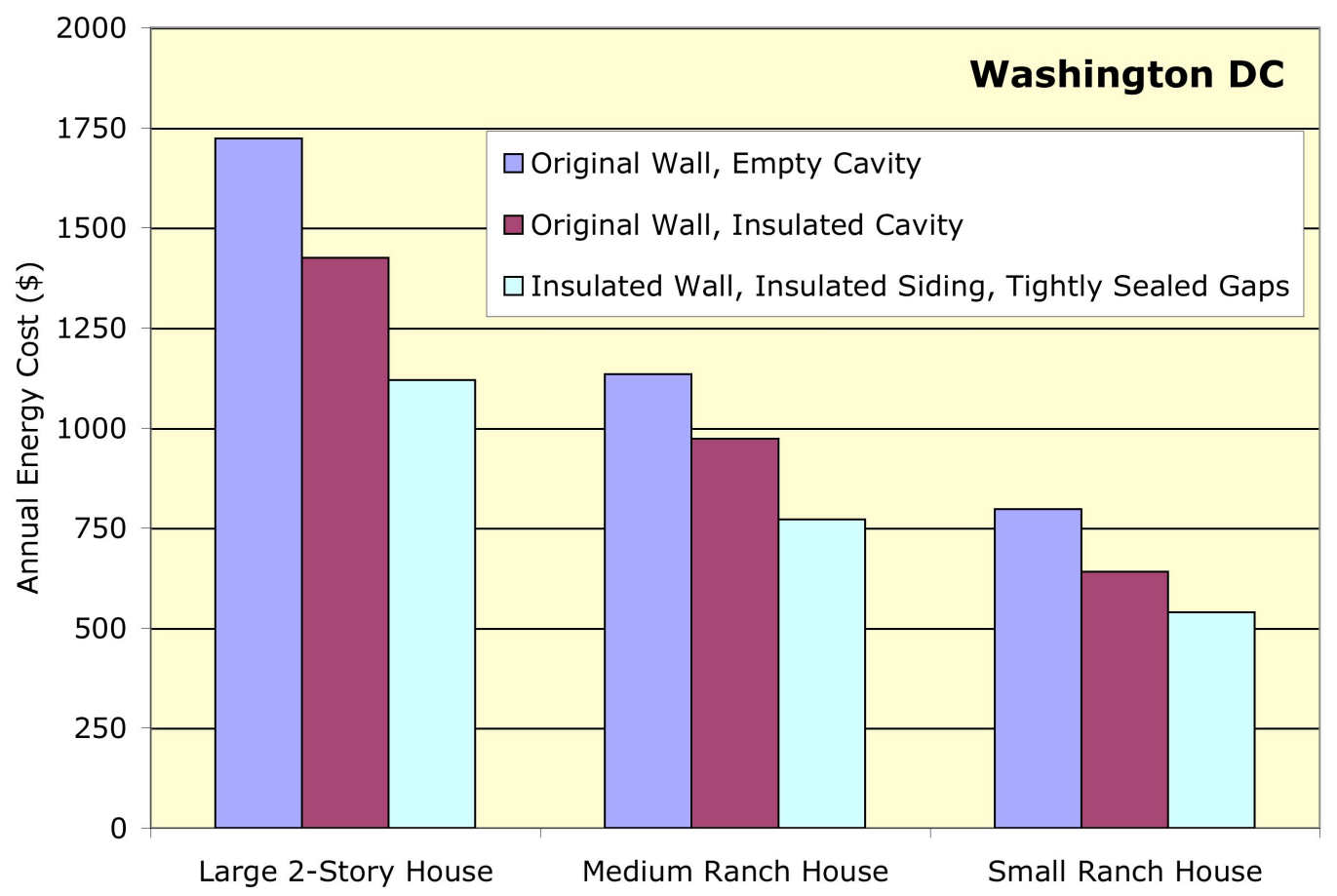

Figure 7. Annual Energy Costs

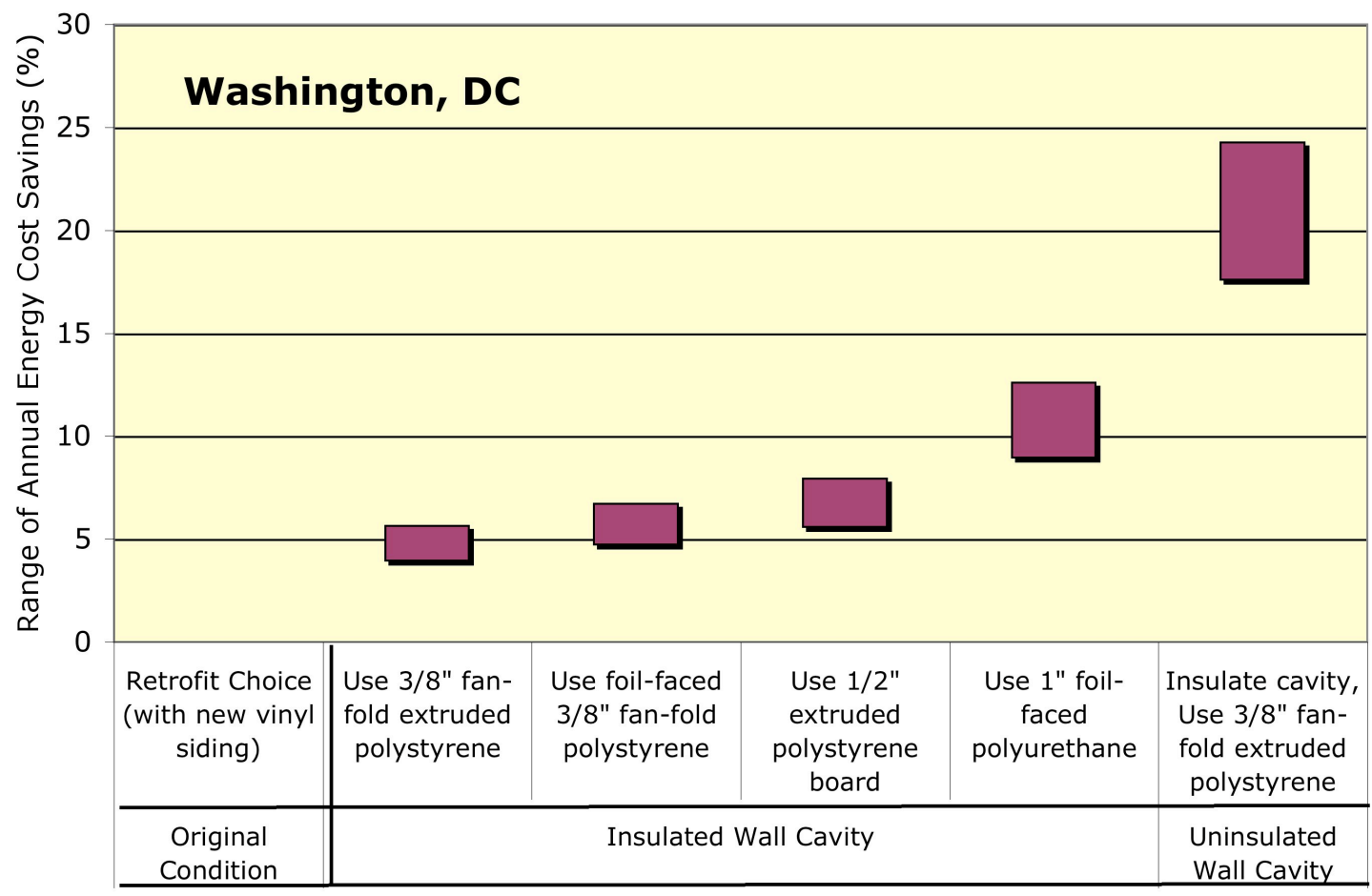

Figure 8. Potential Annual Heating and Cooling Energy Savings for Different Wall Retrofit Options 


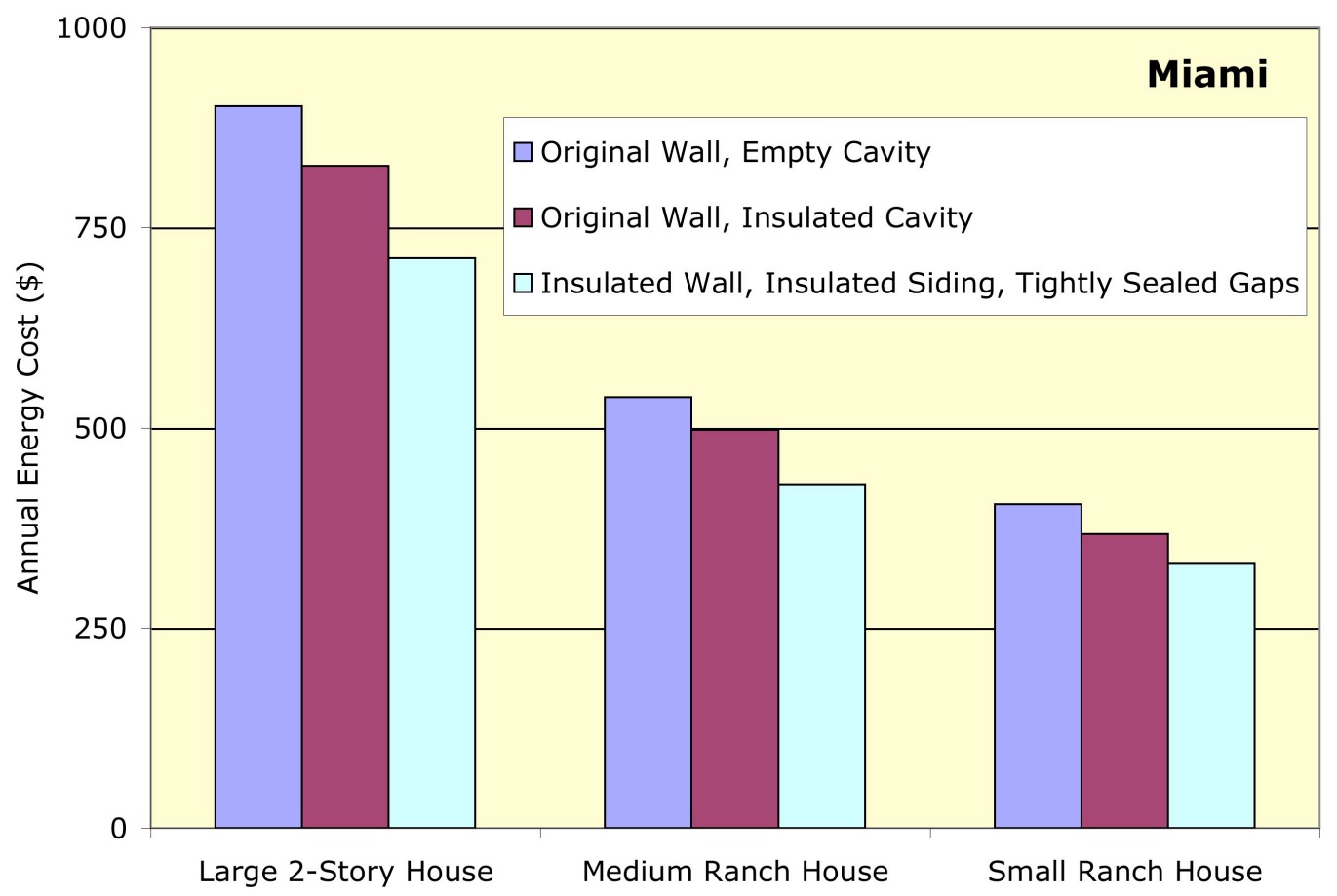

Figure 7. Annual Energy Costs

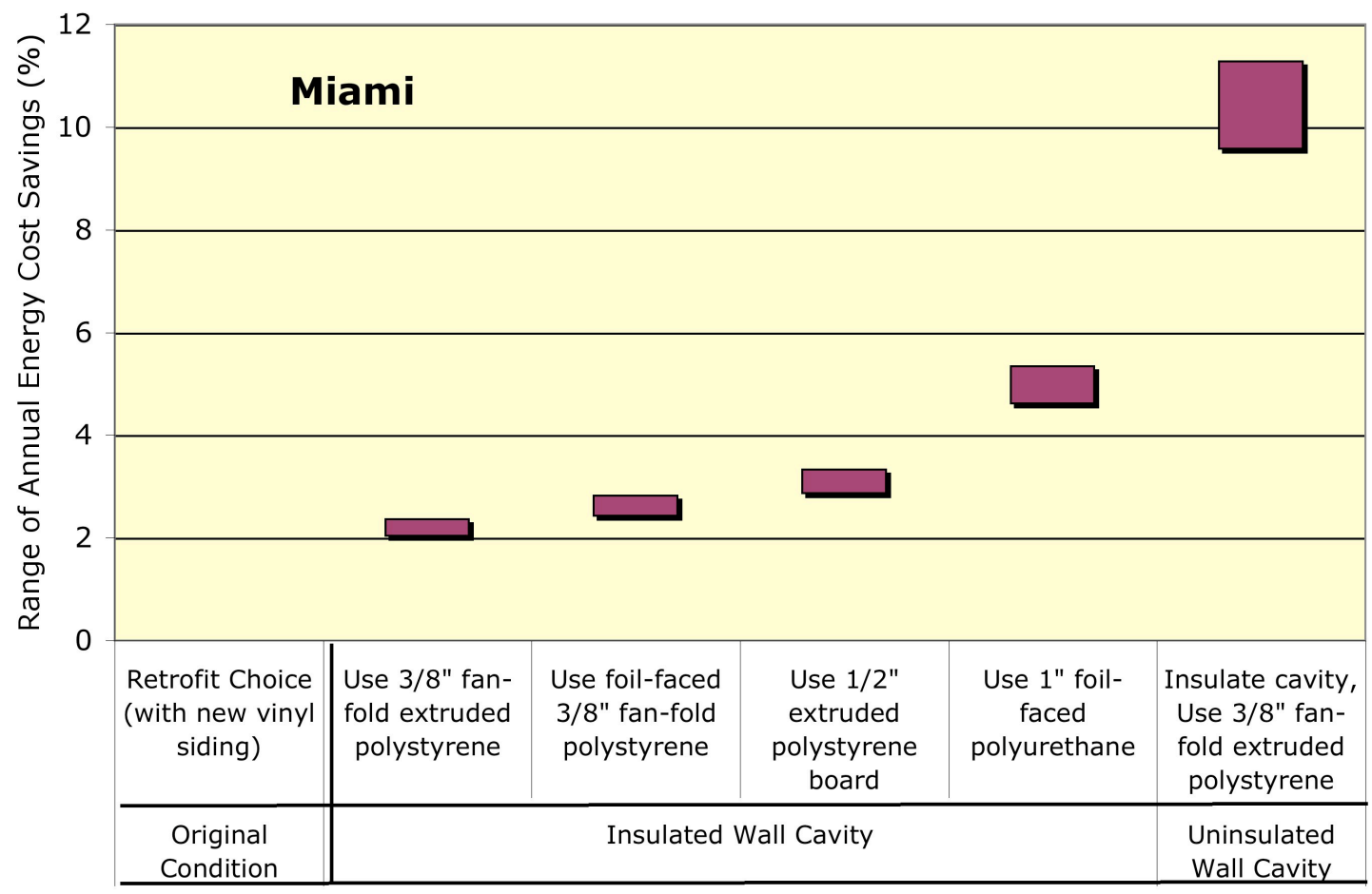

Figure 8. Potential Annual Heating and Cooling Energy Savings for Different Wall Retrofit Options 


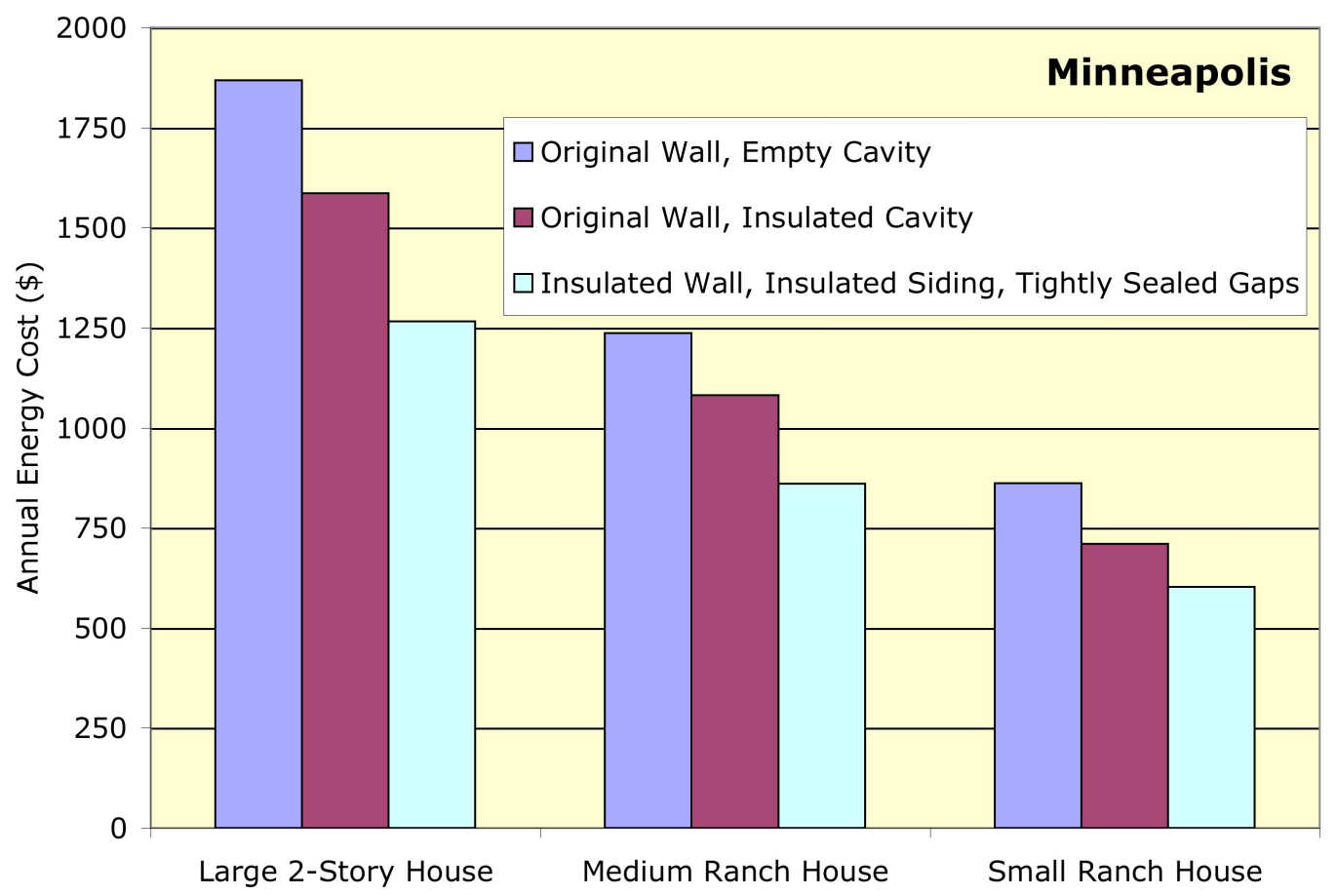

Figure 7. Annual Energy Costs

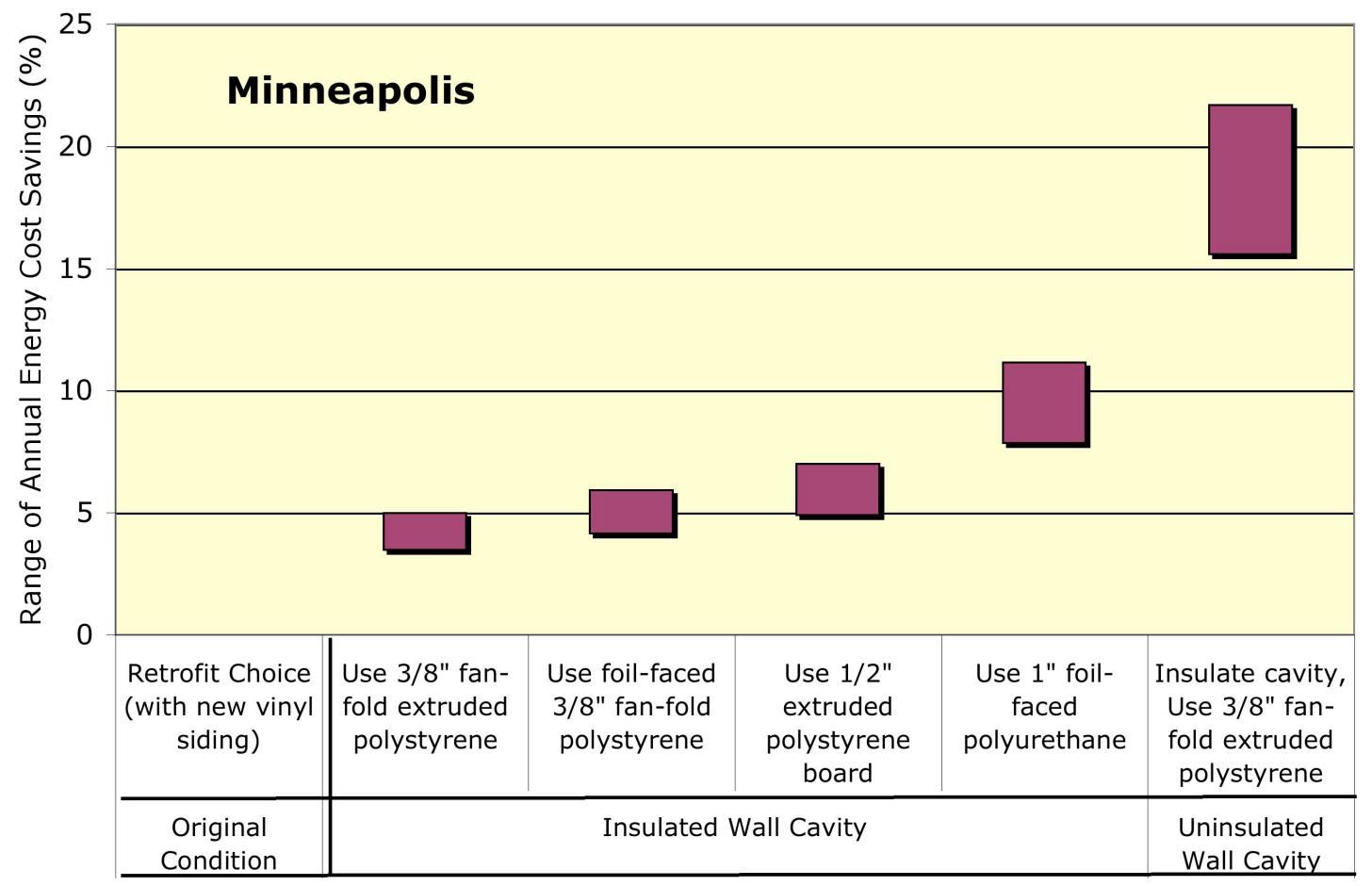

Figure 8. Potential Annual Heating and Cooling Energy Savings for Different Wall Retrofit Options 


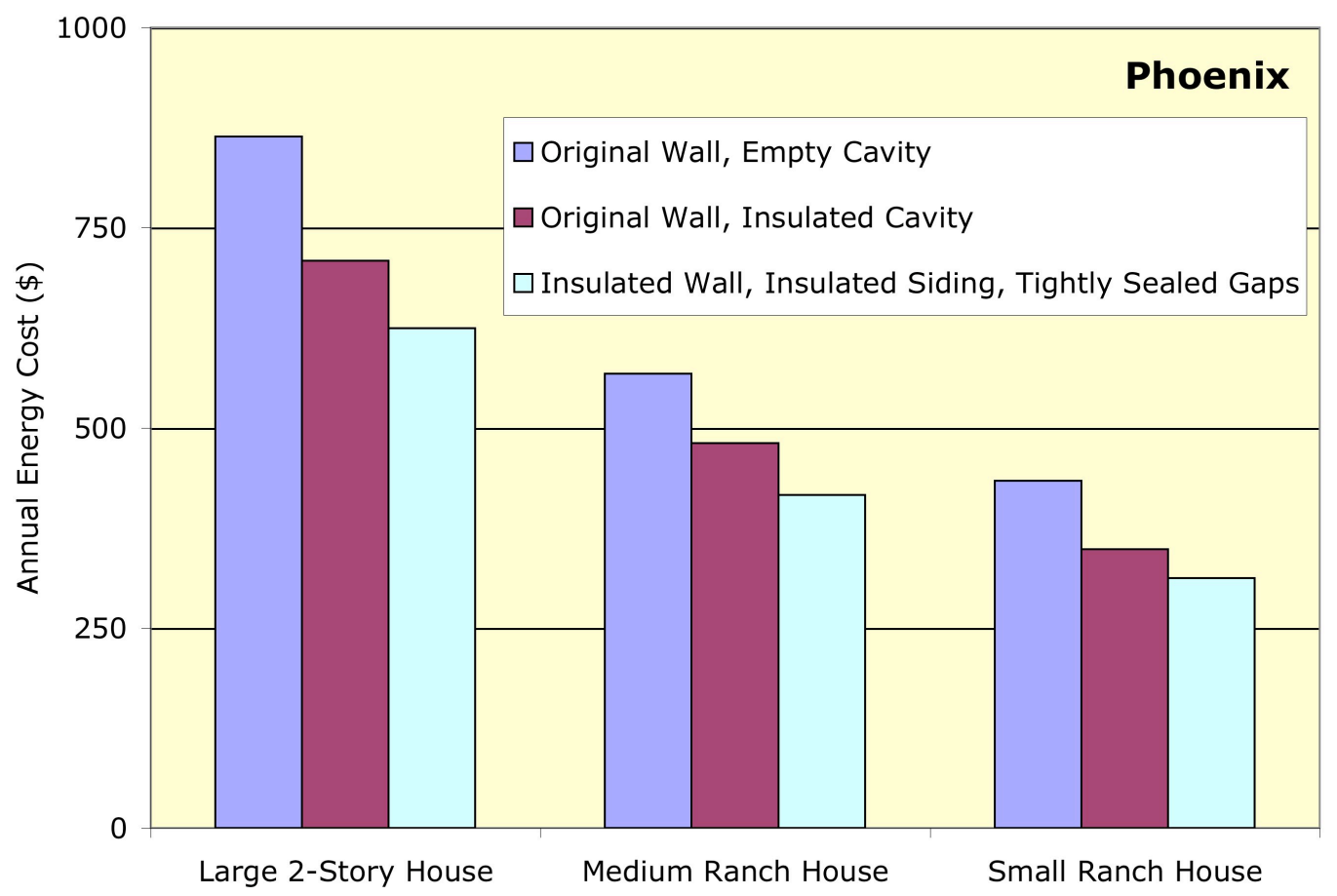

Figure 7. Annual Energy Costs

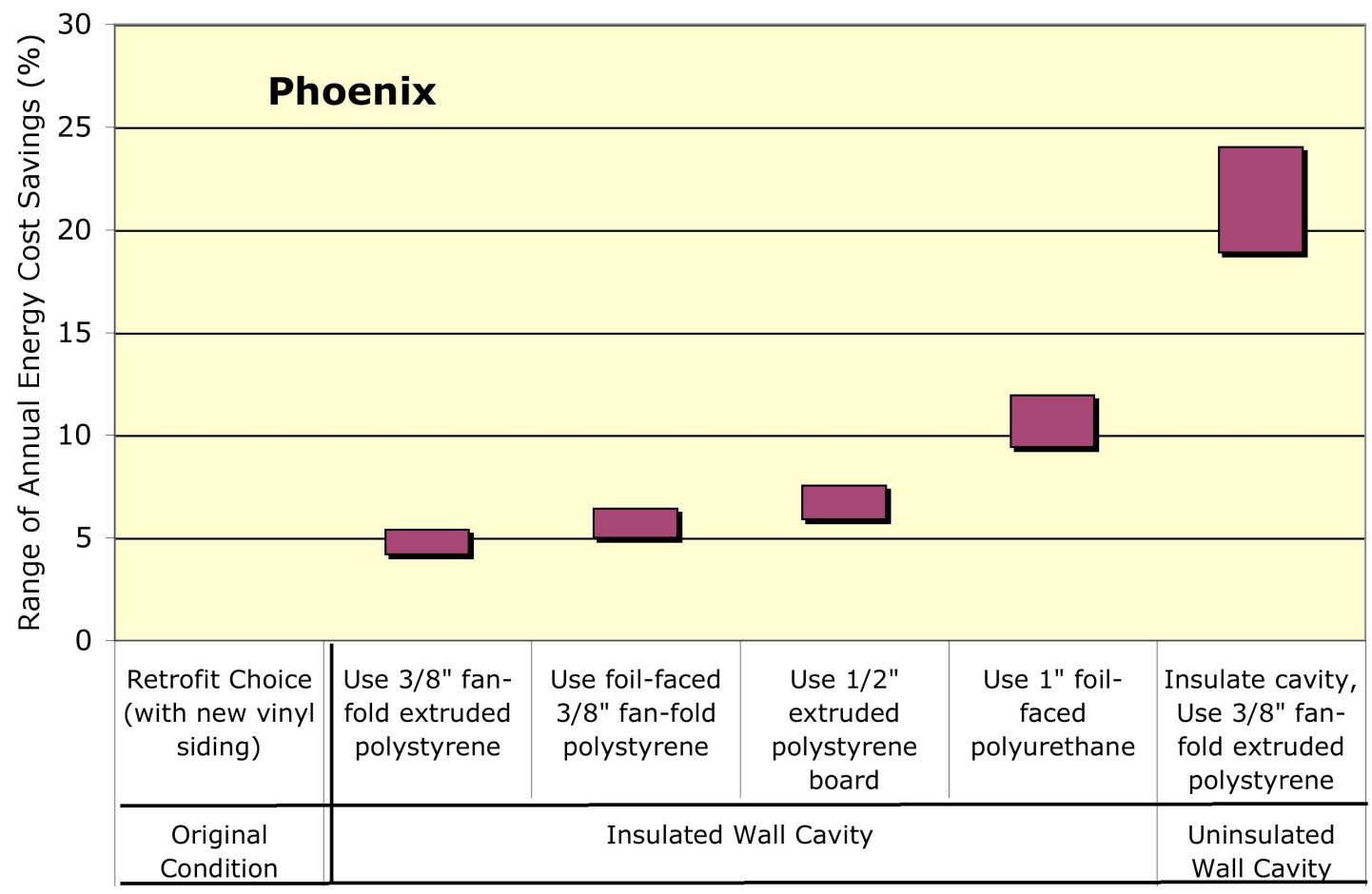

Figure 8. Potential Annual Heating and Cooling Energy Savings for Different Wall Retrofit Options 


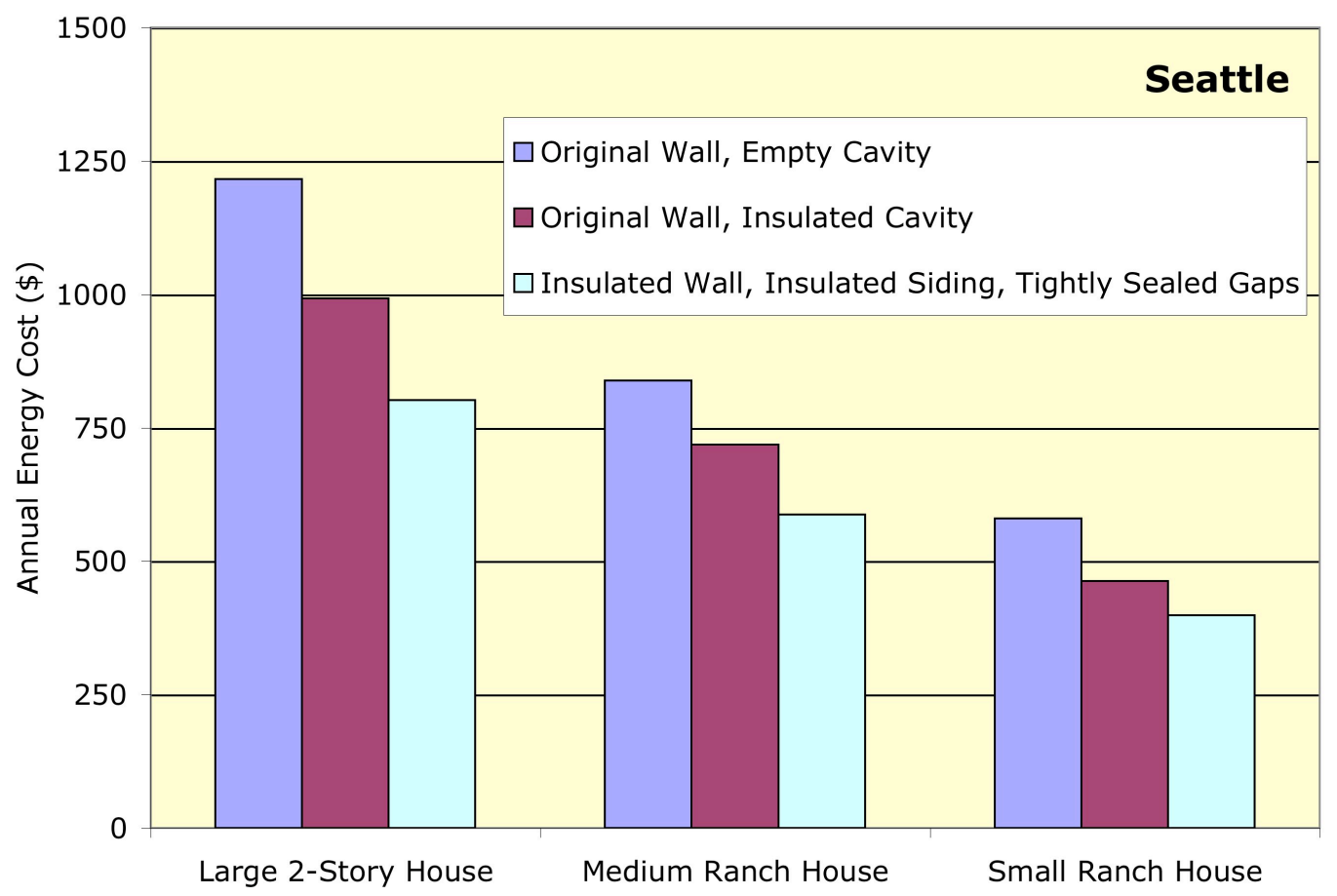

Figure 7. Annual Energy Costs

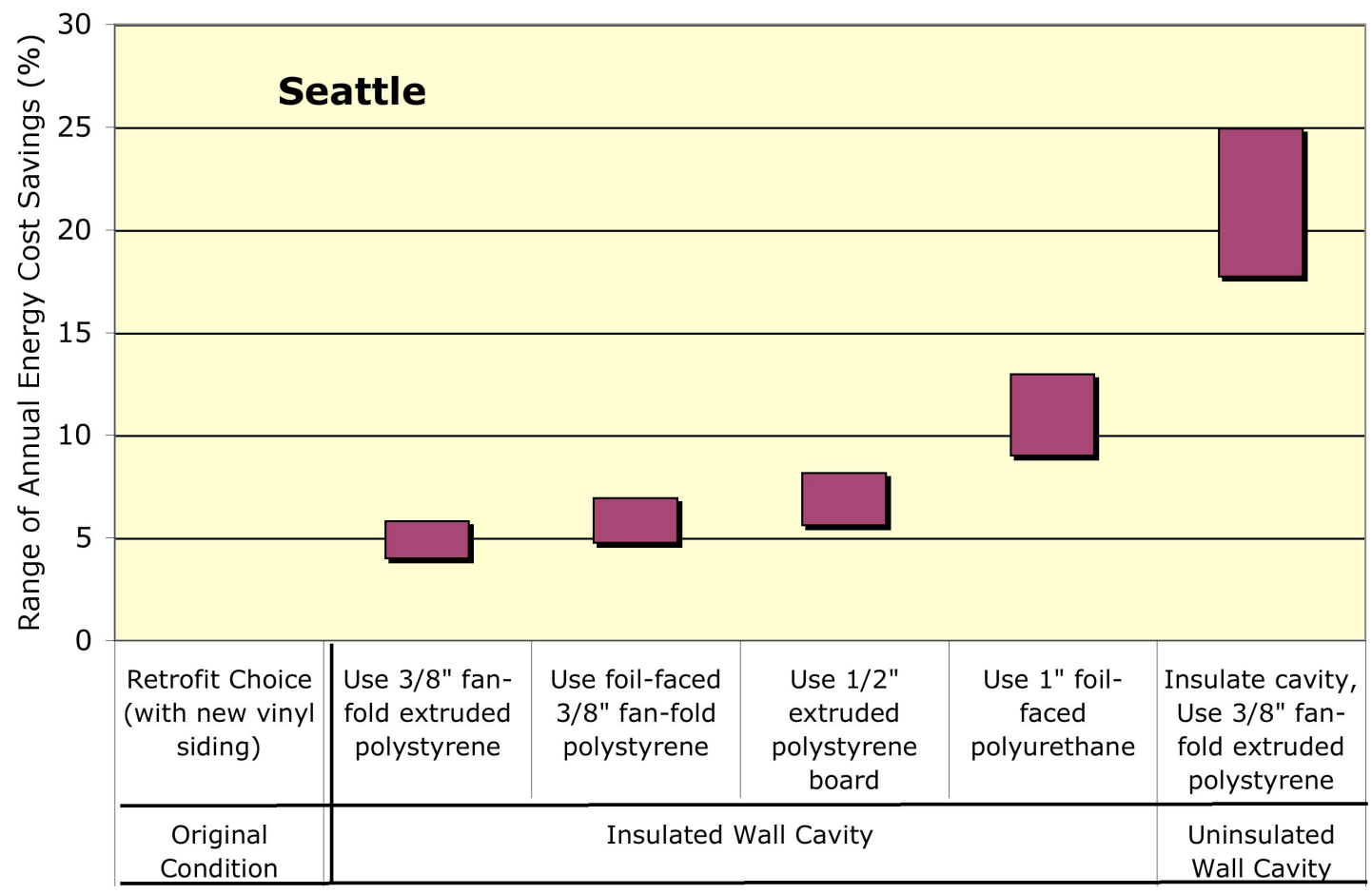

Figure 8. Potential Annual Heating and Cooling Energy Savings for Different Wall Retrofit Options 